\title{
The making of calibration sausage exemplified by recalibrating the transcriptomic timetree of jawed vertebrates
}

David Marjanović

Department of Evolutionary Morphology, Science Programme "Evolution and Geoprocesses", Museum für Naturkunde - Leibniz Institute for Evolutionary and Biodiversity Research, Berlin, Germany

ORCID: 0000-0001-9720-7726

6 Correspondence:

7 David Marjanović

8 david.marjanovic@gmx.at

9 Keywords: timetree, calibration, divergence date, Gnathostomata, Vertebrata

Abstract

Molecular divergence dating has the potential to overcome the incompleteness of the fossil record in inferring when cladogenetic events (splits, divergences) happened, but needs to be calibrated by the fossil record. Ideally but unrealistically, this would require practitioners to be specialists in molecular evolution, in the phylogeny and the fossil record of all sampled taxa, and in the chronostratigraphy of the sites the fossils were found in. Paleontologists have therefore tried to help by publishing compendia of recommended calibrations, and molecular biologists unfamiliar with the fossil record have made heavy use of such works (in addition to using scattered primary sources and copying from each other). Using a recent example of a large node-dated timetree inferred from molecular data, I reevaluate all thirty calibrations in detail, present the current state of knowledge on them with its various uncertainties, rerun the dating analysis, and conclude that calibration dates cannot be taken from published compendia or other secondary or tertiary sources without risking strong distortions to the results, because all such sources become outdated faster than they are published: 50 of the sources I cite to constrain calibrations were published in 2019, half of the total after mid-2016, and $90 \%$ after mid-2005. It follows that the present work cannot serve as such a compendium either; in the slightly longer term, it can only highlight known and overlooked problems. Future authors will need to solve each of these problems anew through a thorough search of the primary paleobiological and chronostratigraphic literature on each calibration date every time they infer a new timetree; and that literature is not optimized for that task, but largely has other objectives.

\section{Introduction}

This work is not intended as a review of the theory or practice of node (or tip) dating with calibration dates (or tip dates) inferred from the fossil record; as the most recent reviews of methods and sources of error I recommend those by Barido-Sottani et al. (2019, 2020), Matschiner (2019), Marshall (2019), Guindon (2020), Powell et al. (2020), Pardo et al. (2020), and, with caveats of which I will address two (Materials and methods: Calibrations: Node 152 - Placentalia), Springer et al. (2019). Neither is it intended as a review of the history of the dates assigned to certain calibrations; as an example of a recent detailed review of three commonly used calibrations, I recommend Pardo et al. (2020). Although I discuss wider implications, the scope of this work is narrow: to evaluate each of 
the 30 calibrations used in the largest vertebrate timetree yet published, that by Irisarri et al. (2017), and the total impact of the errors therein on the results (using the same node-dating method they used, which I do not evaluate beyond mentioning potential general points of criticism).

Irisarri et al. (2017) inferred a set of timetrees from the transcriptomes of 100 species of gnathostomes (jawed vertebrates) and combinations of up to 30 calibrations from the fossil record. On the unnumbered ninth page of their supplementary information, they described their calibration dates as "five well-accepted fossil calibrations plus a prior on the root" and "24 additional wellestablished calibration points with solid paleontological evidence". For many of the calibrations, these optimistic assessments are not tenable. I have tried to present, and use, the current state of knowledge on each of these calibrations.

In doing so, the present work naturally resembles the compendia of suggested calibrations that paleontologists have occasionally compiled with the intent to provide a handy reference for molecular biologists who wish to date divergences (e.g. Müller and Reisz, 2007; Benton et al., 2015, and six other articles in Palaeontologia Electronica 18(1); Wolfe et al., 2016; Morris et al., 2018); Irisarri et al. (2017) took seven of their 30 calibrations from the compendium in Benton and Donoghue (2007: table 1) alone - without citing the enlarged update by Benton et al. (2015) -, compared to six taken from the primary literature. However, I will show that all such compendia are doomed to be (partially) outdated almost as fast as they are published in the best case, and faster than they are published in the average case. Soon, therefore, the present work will no longer be reliable as such a compendium either; rather, it is intended to show readers where the known uncertainties and disagreements lie, and thus what anybody who wants to use a particular calibration should probably search the most recent literature for. This is why I do not generally begin my discussion of a calibration by presenting my conclusions on what the best, or least bad, minimum and maximum ages of the calibration may be. (They are, however, presented without further ornament in Table 1.) Instead, I walk the reader through a sometimes meandering discovery process, demonstrating how this knowledge was arrived at and how it may soon change - how the sausage was made and how it may spoil.

Some works used as compendia in this sense are not even compiled by paleontologists: molecular biologists often copy from each other. Irisarri et al. (2017) took four of their calibrations from table 1 of Noonan and Chippindale (2006), a work that contains a phylogenetic and divergence-date analysis of molecular data and cites severely outdated paleontological primary and secondary literature (from 1981 to 2003) as its sources.

A continually updated online compendium could largely avoid the problem that knowledge has a half-life. There has been one attempt to create one, the Fossil Calibration Database (Ksepka et al., 2015 - https://fossilcalibrations.org; not counting separately its predecessor, called Date a Clade, which is no longer online and apparently merely presented table 1 of Benton and Donoghue, 2007). It appears to have run out of funding long ago and has not been updated since 2 February 2018, the day on which three of the numerous calibrations proposed in Wolfe et al. (2016) were added; other calibrations from the same source were added on 30 and 31 January 2018 (one each) and 22 December 2017 (three), and no other updates were made on those days. I cannot resist pointing out that this is one of many cases where funding menial labor in the sciences - reading and interpreting papers, evaluating the contradictions between them, and entering the interpretations in a database, a task that cannot be automated - would go a long way toward improving the quality of a large number of publications, but is unlikely to be granted because it is not likely to result in a single flashy publication or in an immediately marketable application directly, even though precise and accurate timetrees are an essential component of our understanding of the model organisms used in biomedical research. 
85

86

87

88

89

90

91

92

93

94

95

96

97

98

99

100

101

102

103

104

105

106

107

108

109

110

111

112

113

114

115

116

117

118

119

120

121

122

123

124

125

126

127

128

129

A continually updated online database aiming to represent the entire fossil record exists, and is currently being funded: the Paleobiology Database, accessible through two different interfaces at http://www.pbdb.org and https://paleobiodb.org. Among many other things, it aims to contain the oldest currently known record of every taxon and would thus be useful as a source for calibrations. However, the warnings by Parham et al. (2011) still apply: the quality of the Paleobiology Database is quite heterogeneous. While some entries are written by the current top experts in the respective fields, others copy decades-old primary descriptive literature uncritically, often leading to severely outdated taxonomic, let alone phylogenetic placements (in all but the most recent literature that is not the same), not to mention misunderstandings based on the convoluted history of taxonomic nomenclature. It is not uncommon for two entries to contradict each other. Finally, despite the hundreds of contributors, our current knowledge of the fossil record is so vast that the database remains incomplete (again, of course, differently so for different taxa). Like Irisarri et al. (2017), I have not used the Paleobiology Database or the Fossil Calibration Database; I have relied on the primary literature.

\subsection{Nomenclature}

After the publication of the International Code of Phylogenetic Nomenclature (PhyloCode) (Cantino and de Queiroz, 2020) and its companion volume Phylonyms (de Queiroz et al., 2020), the registration database for phylogenetic nomenclature - RegNum (Cellinese and Dell, 2020) - went online on 8 June 2020; regulated phylogenetic nomenclature is therefore operational. In an effort to promote uniformity and stability in nomenclature, I have used the names and definitions from Phylonyms here; wherever applicable, all of them are followed by "[PN]" at least at the first mention (this includes vernacularized forms like "gnathostome") to avoid confusion with earlier uses of the same names for different clades. I have not, however, followed the ICPN's Recommendation 6.1A to set all taxonomic names in italics.

The definitions of these names, their registration numbers (which establish priority among the combinations of name and definition) and the exact chapter citations can be found in RegNum, which is freely accessible (https://www.phyloregnum.org/).

$I C P N$-regulated names have not been created or converted according to a single overarching scheme. As a result, for example, the name Osteichthyes has been defined as applying to a crown group, and the corresponding total group has been named Pan-Osteichthyes; but the name Chondrichthyes has not been defined and could end up as the name for a crown group, a total group, or neither (indeed, current common usage by paleontologists is neither). This has required some awkward circumlocutions. Following Recommendation 9B of the ICPN, I have not coined any new names or definitions in the present work.

The shapes and definitions of most other taxonomic names used here do not currently compete for homonymy or synonymy under any code of nomenclature. (The ICPN is not retroactive, and the rank-based International Code of Zoological Nomenclature [ICZN, 1999] does not regulate the priority of names at ranks above the family group.) In such cases, I have followed current usage where that is trivial; I occasionally mention synonyms where that seems necessary.

The usage of "stem" and "crown" requires a comment. The crown group of a clade consists of the last common ancestor of all extant members of that clade, plus all its descendants. The rest of the clade in question is its stem group. For example, Gallus is a crown-group dinosaur, and Triceratops is a stem-group dinosaur. In a development that seems not to have been foreseen by the first two or so generations of phylogeneticists that established the terminology - for example, the zoology textbook by Ax (1987) exclusively named total groups, i.e. halves of crown groups! -, many clades 
with defined names are now identical to their crown groups (in other words, they are crown clades); they do not contain any part of their stem. Aves [PN] is an example; although Triceratops is a stemdinosaur [PN] and a stem-ornithodiran among other things, it is not a stem-bird or stem-avian because by definition there is no such thing. In such cases, if no name is available for a suitable larger group, I have resorted to the circumlocution that Triceratops, for instance, is "on the bird stem" or "in the avian total group" (expressing that it is closer to Aves than to any mutually exclusive crown group).

\section{Materials and methods}

138 Although I have followed the spirit of the guidelines developed by Parham et al. (2011) for how best 139 to justify or evaluate a proposed calibration, I have not consistently followed their letter. Most notably, the specimen numbers of the fossils that I largely refer to by genus names can all be found in the directly cited primary literature, so they are not repeated here.

\section{$142 \quad 2.1 \quad$ Hard and soft minima and maxima}

143 Without discussing the matter, Irisarri et al. (2017) stated that they had treated all calibration ages as soft bounds, which, in the software they used, means that "a proportion of 0.05 of the total probability mass is allocated outside the specified bound(s) (which means, $5 \%$ on one side, in the cases of the pure lower and pure upper bounds, and $2.5 \%$ on each side in the case of a combination of lower and upper bound)" (Lartillot, 2015: manual). This is particularly odd for minimum ages; after all, the probability that a clade is younger than its oldest fossil is not $5 \%$ or $2.5 \%$, it is $0 \%$. A few other works have used soft minima as an attempt to account for phylogenetic or chronostratigraphic uncertainty of the specimens chosen as calibrations. I have not used the former approach here (despite two clumsy attempts in the first preprint of this paper - Marjanović, 2019 - that were rightly pointed out as incoherent by a reviewer): in the cases of phylogenetic uncertainty discussed below, different fossils that could calibrate the age of a cladogenetic event are commonly tens of millions of years apart, a situation that cannot be smoothed over by using the oldest one as a soft minimum. Soft minima that can be justified by uncertainty over the exact age of a calibrating fossil are very rare nowadays (as already pointed out by Parham et al., 2011); within the scope of this paper there is only one such case, the minimum age of Neognathae (node 113), which is determined by a specimen that is roughly $70 \pm 1 \mathrm{Ma}$ old according to a fairly long chain of inference. I have treated all other minima as hard, and I have not spelled this out below.

As recommended by Parham et al. (2011), minimum ages have generally been chosen in the literature as the youngest possible age of the calibrating specimen(s). This is practically guaranteed to result in ages that are too young for various reasons (Marshall, 2019). To account, if crudely, for non-zero branch lengths and especially for the nested phylogenetic positions of some calibrating specimens, and to counteract "the illusion of precision" (Graur and Martin, 2004: title) spread by calibration ages with five significant digits like $421.75 \mathrm{Ma}$ (the minimum age chosen by Irisarri et al. [2017] for the root node, see below), I have rounded up (stratigraphically down) to the nearest million years, with a few exceptions suggested by mass extinction events.

168 Maximum ages are by default much more difficult to assign than minimum ages. Absence of proof is not proof of absence; absence of evidence is evidence of absence, but in most cases it is quite weak evidence. Yet, omitting maximum ages altogether and assigning only minimum ages to all calibrations automatically results in much too old divergence dates as nothing stops the $99.9 \%$ or 99.99\% confidence intervals for all node ages from avoiding all overlap with the calibrated minimum ages. I have therefore followed Irisarri et al. (2017) and their sources in assigning as many maximum 
ages as I dare. For this purpose I have basically followed the recommendations of Parham et al. (2011) and Pardo et al. (2020: 11), which amount to assigning a maximum age whenever we can reasonably expect (after preservation biases, collection biases, collection intensity, paleobiogeography etc.) to have found evidence of the clade in question if it had been present at the time in question, but have not found any. This has widely been followed in the literature, but various compendia like Benton et al. (2015) have gone beyond this in many cases: in short, the oldest certain fossil provides the minimum age under that approach, while the oldest uncertain fossil of the same clade provides the maximum age. This practice is not defensible; therefore I assign, in the aggregate, fewer and more distant maximum ages than Irisarri et al. (2017).

Given the limits of our current knowledge of the fossil record, all maximum ages might be expected to be soft bounds. In a few cases discussed below, however, I find that the absence of evidence is so hard to explain away that a hard maximum is justified. This generally concerns unrealistically old maxima that I have chosen because no younger maximum suggests itself. Ultimately, of course, this 187 is subjective.

188 The choices of hard vs. soft bounds do not seem to make a great difference to the big picture. Due to practical constraints, a set of calibration ages mostly identical to the present ones was analyzed twice, with all bounds treated as soft or as hard, in the first preprint of this work (Marjanović, 2019); the results were quite similar to each other (Marjanović, 2019: fig. 1, table 2). Even so, however, in the run where all bounds were soft, most divergence dates were younger than in the run where all bounds were hard (usually negligibly so, but by $20 \mathrm{Ma}$ in the extreme cases); the mean ages of some calibrated nodes even ended up younger than their minimum ages.

\subsection{Calibrations}

In the 29 subsections below I discuss the minimum and maximum ages of all 30 nodes used as calibrations by Irisarri et al. (2017), referring to each by clade names and by the node number assigned by Irisarri et al. (2017: especially supp. table 8 and supp. fig. 19), also shown in Fig. 1. The abbreviation Fm stands for Formation; ICS refers to the International Chronostratigraphic Chart v2020/3 (Cohen et al., 2020); Ma is the quasi-SI symbol for megayear (million years).

\subsubsection{Root node (100): Gnathostomata [PN] (total group including Chondrichthyes - Pan- Osteichthyes [PN])}

The cladogenesis that created the total groups of Chondrichthyes and Osteichthyes [PN] was assigned a minimum age of $421.75 \mathrm{Ma}$, a remarkably precise date close to the Silurian-Devonian boundary, and a maximum age of $462.5 \mathrm{Ma}$, which is currently (ICS) thought to lie in the Darriwilian stage of the Middle Ordovician.

The Darriwilian should rather be regarded as the minimum age of this calibration date. While articulated bones and teeth of gnathostomes - both total-group chondrichthyans (Burrow and Young, 1999) and pan-osteichthyans (Choo et al., 2017, and references therein) - are only known from the Ludfordian (Ludlow, late Silurian) upward, a large diversity of scales that are increasingly confidently assigned to stem-chondrichthyans extends all the way down into the early Darriwilian (Sansom et al., 2012; Andreev et al., 2015, 2016a, b; Žigaitè-Moro et al., 2018; Sansom and Andreev, 2018; and references therein). The Darriwilian is currently thought to have begun $467.3 \pm$ 1.1 Ma ago and to have ended $458.4 \pm 0.9 \mathrm{Ma}$ ago (ICS); for the purposes of reducing "the middle part of the Stairway Sandstone" (Sansom et al., 2012: 243) to a single number, the age of $465 \mathrm{Ma}$ should be adequate as the minimum age of Gnathostomata. 
217 As a maximum age I cautiously propose the mid-Floian (Early Ordovician) upper fossiliferous level

218 of the Burgess-like Fezouata Shale; at both levels, gnathostomes are absent among the "over 200

219 taxa, about half of which are soft-bodied" (Lefebvre et al., 2017: 296). Note that the oldest known

220 hard tissues of vertebrates are Floian in age as well (reviewed by Sansom and Andreev, 2018). The

221 Floian began 477.7 \pm 1.4 Ma ago and ended 470.0 \pm 1.4 Ma ago (ICS), so I suggest a soft maximum

222 age of $475 \mathrm{Ma}$ for this calibration date.

223 The minimum and the maximum age proposed here are unexpectedly close together. This may be a

224 sign that one or both is an unduly optimistic assessment of our knowledge of the fossil record - or

225

226

\section{7} that the origin of Gnathostomata formed part of the Great Ordovician Biodiversification Event (Sansom et al., 2012; Sansom and Andreev, 2018), which does not seem implausible.

\subsubsection{Node 102: Osteichthyes [PN] (Pan-Actinopterygii [PN] - Sarcopterygii)}

228

229

Irisarri et al. (2017) assigned a minimum age of $416 \mathrm{Ma}$ and a maximum age of $439 \mathrm{Ma}$, spanning the Silurian-Devonian boundary, to the cladogenesis that created the osteichthyan crown-group by

230 separating the sister-groups Pan-Actinopterygii and Sarcopterygii.

232

233

234

235

236

237

238

239

240

The minimum age of this cladogenesis event depends on the phylogenetic position of the "psarolepids" (Choo et al., 2017) Guiyu and Sparalepis from the Kuanti [Guandi] Fm of Yunnan, China, which represents an early part of the abovementioned Ludfordian stage (425.6 \pm 0.9 to 423.0 \pm 2.3 Ma ago: ICS). The "psarolepids" lie either just outside Osteichthyes or just inside, on the sarcopterygian side of the basal dichotomy (Clement et al., 2018, and references therein). To some extent the result depends on the analysis method: Clement et al. (2018) found the "psarolepids" outside Osteichthyes by parsimony (bootstrap support throughout the tree artificially low due to missing data), but inside by Bayesian inference ( $94 \%$ posterior probability). Following the discussions of this issue in Choo et al. (2017), Lu et al. (2017) and Clement et al. (2018), and in particular the work of King (2019), I favor a stem-pan-osteichthyan position for this assemblage over a large number of unexpected reversals to a "placoderm" state.

242

243

The oldest known uncontroversial osteichthyan is the oldest known dipnomorph, Youngolepis, as discussed below; following the assignment of Andreolepis and Lophosteus to the osteichthyan stem (e.g. Botella et al., 2007; Chen et al., 2016), all certain or uncertain actinopterygians are Devonian or younger. Thus, the minimum age for this calibration is the same as that for the next, Node 104.

Likewise, for the same reasons as discussed under Node 104, I cannot assign a maximum age to this divergence other than that for the root node. I have, in other words, not calibrated this node, and recommend against using this cladogenetic event as a calibration date if Nodes 100 and 104 are available.

\subsubsection{Node 104: Dipnomorpha - Tetrapodomorpha}

The divergence of the sister-groups Dipnomorpha (the lungfish total group) and Tetrapodomorpha

252 (the tetrapod total group) was assigned a minimum age of 408 and a maximum age of $419 \mathrm{Ma}$. $407.6 \pm 2.6 \mathrm{Ma}$ (ICS). However, the minimum age is clearly younger than the oldest known dipnomorphs. The oldest known specimens have been referred to Youngolepis and come from the lower part of the Xishancun Fm (Zhu and Fan, 1995). This formation is generally (e.g. Choo et al., 2017; Liu et al., 2017; and references therein) considered to represent the lower third or less of the Lochkovian stage, its bottom coinciding with the Silurian-Devonian boundary, which is currently 
dated to 419.2 $\pm 3.2 \mathrm{Ma}$ (ICS). However, Zhang et al. (2014) placed it in the middle of the immediately preceding Přídolí stage, which began 423.0 \pm 2.3 Ma ago (ICS). Needing a single number to summarize this uncertainty, I suggest a minimum age of $420 \mathrm{Ma}$ for Node 104, the divergence of Dipnomorpha and Tetrapodomorpha. (This is a revision stratigraphically downward from the 410 Ma recommended by Marjanović and Laurin, 2007.)

A maximum age is difficult to assign. The abovementioned Kuanti Fm, which is universally (Zhang et al., 2014) regarded as representing an early part of the Ludfordian stage which preceded the Přídolí, has yielded several gnathostomes, but the sample seems too small to tell whether the absence of dipno- and tetrapodomorphs is real. Only one even partial articulated gnathostome is known from any other Ludfordian site in the world (Yealepis, which lies on the chondrichthyan stem: Burrow and Young, 1999). Comparably rich sites older than the Ludfordian have not been discovered. I cannot recommend any particular maximum age for this calibration point, other than by implication the maximum age of the root node (475 Ma, see above).

\subsubsection{Node 105: Tetrapoda [PN] (Amphibia [PN] - Pan-Amniota [PN])}

The divergence between the ancestors of lissamphibians and those of amniotes was assigned a minimum age of 330.4 and a maximum of 350.1 Ma following Benton and Donoghue (2007). Although Pardo et al. (2020) have reviewed the breadth of issues it raises far beyond the scope of this work, and I broadly agree with their conclusions, a few points still remain to address or summarize.

For a long time, the oldest tetrapod was thought to be Lethiscus, variably supposed to be a stemamphibian or a stem-pan-amniote (see below), which is mid-Viséan in age (Smithson et al., 2012, and references therein; the Viséan lasted from $346.7 \pm 0.4$ to 330.9 $\pm 0.2 \mathrm{Ma}$ ago: ICS). More likely, Lethiscus and the other aïstopods are rather early-branching stem-stegocephalians [PN] (Pardo et al., 2017, 2018; Clack et al., 2019; further discussion in Marjanović and Laurin, 2019). Whether Casineria from a geographically (southeastern Scotland) and stratigraphically close site (mid-late Viséan: Paton et al., 1999; Smithson et al., 2012) can replace it in that function depends on two unresolved issues: its own phylogenetic position, for which estimates range from very close to Amniota (within Tetrapoda) into Temnospondyli (Marjanović and Laurin, 2019, and references therein; Clack et al., 2019; Daza et al., 2020: fig. S15); and the controversial phylogenetic position of Lissamphibia [PN] in the stegocephalian tree (Marjanović and Laurin, 2013a, 2019; Danto et al., 2019; Laurin et al., 2019; Pardo et al., 2020; Daza et al., 2020; and references in all five), which determines whether the temnospondyls are tetrapods or quite rootward stem-stegocephalians by determining which node of the otherwise largely stable tree of early stegocephalians bears the name Tetrapoda.

Anderson et al. (2015) reported a number of isolated anthracosaur [PN] (embolomere or eoherpetid) bones from a mid-Tournaisian site (the Tournaisian preceded the Viséan and began at the Devonian/Carboniferous boundary $358.9 \pm 0.4$ Ma ago: ICS). Whether these are tetrapods depends on the relative positions of temnospondyls, anthracosaurs and other clades in that region of the tree (Pardo et al., 2018, 2020; Marjanović and Laurin, 2019; Ruta et al., 2020; and references in all four) in addition to the position of Lissamphibia: even if the lissamphibians are temnospondyls, the anthracosaurs may still be stem-stegocephalians.

The same site has also yielded the oldest colosteid remains (Anderson et al., 2015). Colosteidae ("Colosteida" of Pardo et al., 2020) was referred to Temnospondyli throughout the $20^{\text {th }}$ century and found in that position by Marjanović and Laurin (2019) to our great surprise (also in some of the trees by Daza et al., 2020: fig. S15); as pointed out by Pardo et al. (2020), this means it could belong to Tetrapoda. However, ongoing work on enlarging and improving the matrix of Marjanović and Laurin (2019) and Daza et al. (2020) shows this result was most likely an artefact of the taxon and 
306

307

308

309

310

311

312

313

314

315

316

317

318

319

320

321

322

323

324

325

326

327

328

329

330

331

332

333

334

335

336

337

338

339

340

341

342

343

344

345

346

347

348

349

350

character sample; similarly, Ruta et al. (2020) found the colosteid they included to be a temnospondyl with weak support in their Bayesian analysis, but to lie rootward of Temnospondyli in their parsimony analyses (unweighted, reweighted or with implied weighting).

The same site has further yielded tetrapod trackways, some of which are tetradactyl (Smithson et al., 2012, and references therein). Among Paleozoic tetrapods, tetradactyly is only known among "microsaurs" (including lysorophians), scincosaurids, some urocordylids, temnospondyls and Colosteus (but not its close pentadactyl relative Greererpeton). (Reports of tetradactyl limbs in diplocaulids have been erroneous: Milner, 2019; Marjanović and Laurin, 2019, and references therein.) Colosteus and probably (Clack et al., 2019) the urocordylids are stem-stegocephalians, but both were fully aquatic, thus unlikely to leave trackways; "microsaurs" and probably scincosaurids were tetrapods, and most were amphibious to terrestrial; temnospondyls spanned the full range of lifestyles, but see above for their phylogenetic position. In short, whether tetradactyl trackways are evidence of tetrapods in the mid-late Tournaisian remains unclear.

The oldest uncontroversial tetrapod is thus Westlothiana from close to the end of the Viséan (Marjanović and Laurin, 2019, and references therein, especially Smithson et al., 1994, 2012). Other stegocephalians from the same site and age may or may not be tetrapods: whether the temnospondyl Balanerpeton (Milner and Sequeira, 1994; Schoch and Milner, 2014) is one depends on the resolution of the abovementioned controversy about Lissamphibia; likewise, see above on the "anthracosaur-grade" (Marjanović and Laurin, 2019; Ruta et al., 2020) animals Silvanerpeton and Eldeceeon; Ophiderpeton kirktonense is an aïstopod, on which see above; Kirktonecta (Clack, 2011) is likely a tetrapod, but needs to be fully prepared or $\mu \mathrm{CT}$-scanned before a confident assessment can be made.

Thus, the minimum age may be as young as roughly $335 \mathrm{Ma}$ (mid-late Viséan) or as old as roughly $350 \mathrm{Ma}$ (early-middle Tournaisian) depending on two phylogenetic problems.

The few Tournaisian tetrapod sites discovered so far (Smithson et al., 2012; Anderson et al., 2015; Clack et al., 2016) have not yielded any uncontroversial tetrapods, temnospondyl bones or temnospondyl footprints; thus, if the temnospondyls are stem-tetrapodomorphs, the ages of these sites (up to roughly $350 \mathrm{Ma}$ ) may be useful as a maximum age. However, as stressed by Pardo et al. (2020), they represent a very small region of the Carboniferous globe, so I continue (Marjanović and Laurin, 2019) to caution against this regardless of the phylogenetic issues. Rather, the richer and better studied Famennian (end-Devonian) record, which has not so far yielded close relatives of Tetrapoda but has yielded more rootward stegocephalians and other tetrapodomorphs (Marjanović and Laurin, 2019; Ahlberg and Clack, 2020; and references therein), should be used to place a soft maximum age around very roughly $365 \mathrm{Ma}$.

\subsubsection{Node 106: Amniota [PN] (Pan-Mammalia [PN] - Sauropsida)}

The cladogenesis that separated the total group of mammals (also called Synapsida [PN] or Theropsida: Goodrich, 1916) from the total group of diapsids including turtles (Sauropsida: Goodrich, 1916) was assigned a minimum age of $288 \mathrm{Ma}$ (Artinskian, Early Permian) and a maximum age of $338 \mathrm{Ma}$ (Viséan, Early Carboniferous).

This minimum age is rather puzzling. I am not aware of any doubts on the membership of Hylonomus in Sauropsida since its redescription by Carroll (1964), except the very vague ones presented by Graur and Martin (2004) and taken from even more outdated literature; none are mentioned in the review by Pardo et al. (2020) either. Because of its late Bashkirian age, this calibration has often been dated to $310 \mathrm{Ma}$ (as discussed by Graur and Martin, 2004). Currently (ICS), the Bashkirian is thought to have ended 315.2 \pm 0.2 and begun $323.2 \pm 0.4 \mathrm{Ma}$ ago, and the site (Joggins, Nova Scotia) that has

This is a provisional file, not the final typeset article 
351

352

353

354

355

356

357

358

359

360

361

362

363

364

365

366

367

368

369

370

371

372

373

374

375

376

377

378

379

380

381

382

383

384

385

386

387

388

389

390

391

392

393

394

395

396

yielded Hylonomus has been dated to 317-319 Ma (Carpenter et al., 2015); thus, given the phylogenetic position of Hylonomus (Ford and Benson, 2019, and references therein), I suggest a minimum age of $318 \mathrm{Ma}$ for this calibration.

There appears to be pan-mammalian material from the same site (Carroll, 1964; Mann et al., 2020), which has also yielded various "microsaurs" that Pardo et al. (2017) included in Sauropsida (see also Marjanović and Laurin, 2019, and Pardo et al., 2020). I should also emphasize that the next younger sauropsids and pan-mammals (and "microsaurs") older than 288 Ma come from several sites in each following geological stage (Moscovian through Artinskian) and represent a considerable diversity; from the Moscovian alone, four sites of successive ages are known that present more or less complete skeletons of uncontroversial amniotes, namely sauropsids closely related to Diapsida and Hylonomus (Anthracodromeus, Brouffia, Cephalerpeton, Paleothyris), the oldest "parareptile" (Carbonodraco) as well as what appears to be the sister-group to most other sauropsids (Coelostegus), and, on the pan-mammalian side, ophiacodontids (Echinerpeton; Archaeothyris from two sites). A fifth site preserves the oldest varanopid, a group of amniotes of unclear phylogenetic position (Ford and Benson, 2018, 2019). As reviewed in detail by Pardo et al. (2020), this implies ghost lineages for several other amniote clades that might not have lived in coal swamps; several of these show up in the fossil record of the next and last two stages of the Carboniferous, which ended $298.9 \pm 0.15 \mathrm{Ma}$ ago (ICS). For more information on the Carboniferous amniote record see Reisz and Modesto (1996: fig. 3), Müller and Reisz (2006), Mann and Paterson (2019), Mann et al. (2019), Maddin et al. (2019) and Pardo et al. (2020), the second and the third with phylogenetic analyses, as well as references in all six. Additionally, the oldest known diadectomorphs ("diadectamorphs" of Pardo et al., 2020) date from the Kasimovian ("Missourian" in Kissel, 2010) which follows the Moscovian; they may represent the sister-group of Amniota, or they may be what should have been called non-synapsid theropsids (Marjanović and Laurin, 2019; Klembara et al., 2019; Pardo et al., 2020; and references in all three).

The absence of amniotes (and diadectomorphs) in the Serpukhovian record preceding the Bashkirian should not be given much weight for paleoecological reasons, as reviewed by Pardo et al. (2020); note that "lepospondyls" like the Viséan Kirktonecta and Westlothiana, probably closely related to but outside Amniota, are almost unknown from this age as well (candidates were described by Carroll et al., 1991; Carroll and Chorn, 1995; Lombard and Bolt, 1999). Their absence from the somewhat richer Viséan record (discussed above) suffers in part from the same problem, in part from geographic restrictions. Thus, I refrain from recommending a maximum age other than that of the preceding Node 105 , even though such an early age would imply very slow rates of morphological evolution in the earliest pan-mammals and sauropsids.

\subsubsection{Node 107: Reptilia [PN] (Pan-Lepidosauria - total group of Archelosauria); node 108: Archelosauria (Pan-Testudines [PN] - Pan-Archosauria [PN])}

The origin of the sauropsid crown group by a split into Pan-Lepidosauria and the total group of Archelosauria was assigned a minimum age of $252 \mathrm{Ma}$ and a maximum age of $257 \mathrm{Ma}$, both in the Late Permian. Ezcurra et al. (2014; correction: The PLOS ONE Staff, 2014) agreed that the oldest unambiguous reptile that can be clearly dated is the supposed pan-archosaur Protorosaurus, which is, however, $257.3 \pm 1.6 \mathrm{Ma}$ old as they also discussed. Therefore, they revised the minimum age to 255.7 Ma, the younger end of this confidence interval.

However, like all other recent phylogenetic analyses of molecular data, Irisarri et al. (2017) found the turtles to be closer to Archosauria [PN] than Lepidosauria [PN]. Thus, the question whether Eunotosaurus is a member of the turtle stem (Schoch and Sues, 2017, and references therein) becomes relevant, because the earliest occurrence of Eunotosaurus is roughly middle Capitanian in 
397

398

399

400

401

402

403

404

405

406

407

408

409

410

411

412

413

414

415

416

417

418

419

420

421

422

423

424

425

426

427

428

429

430

431

432

433

434

435

436

437

438

439

440

441

442

age (the Capitanian, the last stage of the Middle Permian, ended 259.1 $\pm 0.5 \mathrm{Ma}$ ago and began 265.1 \pm 0.4 Ma ago: ICS), and further because Protorosaurus would presumably belong to PanArchosauria and thus calibrate Node 108, not 107.

For present purposes I set the minimum age of Archelosauria (Node 108) as $263 \mathrm{Ma}$, the approximate midpoint of the Capitanian, and do not assign a minimum age to Reptilia (Node 107). But in general I have to, at our current level of understanding, recommend against using either of these nodes as a calibration. The reason are two major uncertainties about the topology of the phylogenetic tree.

First, if Eunotosaurus has moved from the "parareptiles" well outside Diapsida [PN] - or well inside Diapsida, though presumably still in its stem-group (Ford and Benson, 2019) - to the turtle stem within the crown group of Diapsida (i.e. Reptilia [PN]), do any other "parareptiles" follow it? The oldest known member of that assemblage, Carbonodraco, comes from the site of Linton in Ohio (Mann et al., 2019), which is about 307-308 Ma old (compare Reisz and Modesto, 1996, and Carpenter et al., 2015), so that should be the minimum age of Archelosauria if all "parareptiles" are archelosaurs; the currently available phylogenetic analyses of "parareptiles" (Laurin and Piñeiro, 2018; MacDougall et al., 2019) have not adequately tested this question. While Schoch and Sues (2017) did test the mutual relationships of "parareptiles", Eunotosaurus and diapsids and found Eunotosaurus nested in the latter, several nodes away from the former, these nodes were very poorly supported. The character and taxon samples of all existing matrices for analyses of amniote phylogeny need to be substantially improved (Ford and Benson, 2018, 2019; Laurin and Piñeiro, 2018; MacDougall et al., 2019; Mann et al., 2019); Ford and Benson (2019) made a large step in that direction, but deliberately excluded Eunotosaurus and the turtles from their analysis so as not to have to deal with all problems at the same time.

Second, the position of Protorosaurus as a pan-archosaur, accepted for decades, was thrown into doubt by Simões et al. (2018), who found it as such in their Bayesian analyses of morphological or combined data (Simões et al., 2018: ext. data fig. 5, 6; also, after a few changes to the dataset, Garberoglio et al., 2019: fig. S2; Sobral et al., 2020: fig. S9, S10), but not in their parsimony analyses of morphological data without or with implied weights (ext. data fig. 3, 4; likewise Garberoglio et al,. 2019: fig. S3, and Sobral et al., 2020: fig. S7, S8), where it came out as a stem-sauropsid; the question was unresolved in their Bayesian tip-dating or tip-and-node dating analyses of combined data (ext. data fig. 7, 8). After a different set of changes to the dataset, Simões et al. (2020) found Protorosaurus as a pan-archosaur when they used MrBayes (supp. fig. 2-5) or when they used BEAST for dating with a correction (supp. fig. 7), but not when they used BEAST for dating without a correction (supp. fig. 6). Support was moderate throughout. However, these trees are hard to compare to that of Irisarri et al. (2017) because they all find the turtles outside the diapsid crown (with limited support); no extant archosaurs or turtles, and therefore no molecular data for them, are included in these datasets. Using a smaller dataset with much denser sampling of Triassic reptiles, Pritchard et al. (2018) found Protorosaurus closer to Archosauria than to Lepidosauria with very strong support (parsimony bootstrap value: 100\%, Bayesian posterior probability: 99.06\%), but whether that is on the archosaur or the archelosaur stem could not be determined because there were no turtles in that dataset.

The maximum age of either node is likewise difficult to narrow down. Uncontroversial diapsids have a notoriously patchy Paleozoic record (Ford and Benson, 2018, and references therein); the same holds for "parareptiles", which have only two known Carboniferous records so far (Modesto et al., 2015; Mann et al., 2019). I cannot express confidence in a maximum age other than that of Node 106, which I cannot distinguish from the maximum age of Node 105 as explained above. This leaves Node 107 without independent calibrations in the current taxon sample. 


\subsubsection{Node 109: Archosauria [PN] (Crocodylotarsi - Avemetatarsalia)}

444 The origin of Archosauria by cladogenesis into the total groups of crocodiles and birds was given a minimum age of $243 \mathrm{Ma}$ (Middle Triassic) and a maximum age of $251 \mathrm{Ma}$ (Early Triassic).

The earliest securely dated known archosaur, belonging to the crocodile stem, is Ctenosauriscus from just before the end of the Olenëkian; several close relatives may be coeval or a little younger (Butler et al., 2011). The age of the Olenëkian/Anisian (Early/Middle Triassic) boundary is given in the ICS as 247.2 Ma without a confidence interval; any such confidence interval cannot be long, however, because an Olenëkian sample has been dated to $247.32 \pm 0.08 \mathrm{Ma}$, while an Anisian sample has been dated to $247.08 \pm 0.11 \mathrm{Ma}$ (Maron et al., 2018). Given the highly nested phylogenetic position of Ctenosauriscus in Archosauria (Butler et al., 2011), I propose $248 \mathrm{Ma}$ as the minimum age of this calibration. maximum age on the grounds that a major radiation of pan-archosaurs at the beginning of the Triassic seems likely for ecological reasons: the Permian record, up to its very end, is full of panmammals that seem ecologically comparable to Triassic archosaurs, and given the Pangea situation of the time it seems reasonably unlikely that archosaurs existed in unsampled localities. I must caution, however, that the fossil record of pan-archosaurs and possible pan-archosaurs in the four million years of the Triassic preceding the minimum age, and in the Permian, is very patchy, with a poor fit between stratigraphy and phylogeny; indeed, the Permian record of archosauriforms [PN] is currently entirely limited to the poorly known non-archosaur Archosaurus and possibly the even more poorly known non-archosaur Eorasaurus (Ezcurra et al., 2014).

\subsubsection{Node 111: Alligatoridae (Alligatorinae - Caimaninae)}

The origin of Alligatoridae (the crown group of Globidonta) by split into Alligatorinae and Caimaninae was given a minimum age of $66 \mathrm{Ma}$ (the Cretaceous/Paleogene boundary) and a maximum age of $75 \mathrm{Ma}$ (Campanian, Late Cretaceous). The minimum age would fit well with the finding by Cossette and Brochu (2018) that Bottosaurus from the very end of the Cretaceous is a caimanine. Given, however, the limited material and the stratigraphic gap between Bottosaurus and the next younger known caimanines, Cossette and Brochu (2018) expressed doubt about the result of their phylogenetic analysis which placed Bottosaurus not only within the caimanine crown-group but next to the extant Paleosuchus. from within the first million years of the Paleocene (Puercan NALMA [North American Land Mammal Age]), translating to a minimum age of $65 \mathrm{Ma}$ (Wang et al., 2016, and references therein). The oldest known caimanines (Protocaiman, Eocaiman paleocenicus and Necrosuchus: Bona et al., 2018) follow shortly thereafter (Peligran SALMA [South American Land Mammal Age], 64-63 Ma ago: Woodburne et al., 2014).

Halliday et al. (2013), however, found the Campanian to Maastrichtian Brachychampsa to be an alligatorine, as did Arribas et al. (2019) in a less densely sampled analysis of Crocodyliformes; Bona et al. (2018) found it and the newly added Campanian Albertochampsa to be caimanines. In either of these cases, the earliest record of an alligatorid is Brachychampsa sealeyi from early in the Campanian, which began 83.6 0.2 Ma ago (ICS). These results were not replicated by Lee and Yates (2018) or by Groh et al. (2019), who both found Brachychampsa on the brevirostrine stem, not as an alligatorid, and who both did not include Albertochampsa in their datasets. I must caution, however, that Groh et al. (2019) found Alligatorinae, and even Alligator itself, as a Hennigian comb 
in which Caimaninae was nested; this result strongly suggests that the character sample was insufficient to resolve Brevirostres.

489 Given this uncertainty, I have used a minimum age of $65 \mathrm{Ma}$ for present purposes, but generally recommend against using this cladogenesis as a calibration for timetrees.

Up to (and including) the Campanian, the record of neosuchians is a surprisingly spotty affair (e.g.

492

493

494 than 100.5 Ma: ICS) is likely, I cannot, therefore, assign a maximum age younger than the Triassic/Jurassic boundary, i.e. twice as old (201.3 $\pm 0.2 \mathrm{Ma}$ : ICS; rounded to 200). Only in the Triassic is the record of ecologically comparable phytosaurs dense enough to really rule out the presence of amphibious crocodylomorphs such as alligatorids. However, I have treated this maximum as hard because the likelihood that the true age approaches it is very low.

\subsubsection{Node 113: Neognathae (Galloanserae [PN] - Neoaves)}

499

The last common ancestor of Anas, Gallus and Meleagris on one side and Taeniopygia on the other was assigned a minimum age of $66 \mathrm{Ma}$ (the Cretaceous/Paleogene boundary) and a maximum age of 86.5 Ma (Coniacian/Santonian boundary. Late Cretaceous) following Benton and Donoghue (2007). The oldest known neognath appears to be the presbyornithid stem-anserimorph (Elżanowski, 2014; Tambussi et al., 2019; within two steps of the most parsimonious trees of Field et al., 2020) Teviornis from somewhere low in the Late Cretaceous Nemegt Fm of Mongolia; it is known only from a carpometacarpus, two phalanges and the distal end of a humerus that all seem to belong to the same right wing (Kurochkin et al., 2002). The most recent work on the specimen has bolstered its presbyornithid identity (De Pietri et al., 2016), even though the next younger presbyornithids are middle or late Paleocene (i.e. younger than 61.6 Ma: ICS).

The age of the Nemegt Fm is difficult to pin down; radiometric dating of this or adjacent formations has not been possible, and the only fossils available for biostratigraphy are vertebrates that have to be compared to those of North America where marine correlations and radiometric dates are known. These comparisons favor a vaguely early Maastrichtian age, without ruling out a Campanian component. Magnetostratigraphic evidence was reported in a conference abstract by Hicks et al. (2001); I have not been able to find a follow-up publication. Hicks et al. (2001) stated that the sampled sections from the Nemegt and the conformably underlying Baruungoyot Fm "can be quite reliably correlated to the Geomagnetic Reversal Time Scale [...] and clearly lie in the Campanian/Maastrichtian interval that extends from the uppermost part of subchron C33n, through chron 32 into the lower half of chron 31." Where the Baruungoyot/Nemegt boundary lies on this scale was not mentioned. The upper boundary of the Nemegt Fm is an unconformity with a Paleocene formation.

Hicks et al. (2001) also studied the Late Cretaceous Djadokhta Fm, finding that "a distinct reversal sequence is emerging that allows us to correlate the sections in a preliminary way to the late Campanian through Maastrichtian interval that ranges from C32 to C31." While I have not been able to find a publication by an overlapping set of authors on this finding, it agrees at least broadly with Dashzeveg et al. (2005: 18, 26, 27), whose own magnetostratigraphic work on the Djadokhta Fm indicated "that the sediments were deposited during the rapid sequence of polarity changes in the late part of the Campanian incorporating the end of Chron 33 and Chron 32 between about 75 and $71 \mathrm{Ma}$ [...]. However, this tentative correlation to the Geomagnetic Polarity Timescale cannot yet be certainly established." Hasegawa et al. (2008) disagreed with the stratigraphy by Dashzeveg et al. (2005), but not with their dating. 
531

532

533

534

535

536

537

538

539

540

541

542

543

544

545

546

547

548

549

550

551

552

553

554

555

556

557

558

559

560

561

562

563

564

565

566

567

568

569

570

571

572

573

574

575

Most often, the Djadokhta Fm has been thought to underlie the Baruungoyot Fm, but a contact between the two has not so far been identified (Dingus et al., 2008; cited without comment e.g. by Chinzorig et al., 2017); they could be partly coeval (references in Hasegawa et al., 2008). Still, it seems safe to say that most of the Nemegt Fm is younger than most of the Djadokhta Fm.

According to Milanese et al. (2018: fig. 12), the Campanian-Maastrichtian boundary (72.1 $\pm 0.2 \mathrm{Ma}$ ago: ICS) lies near the end of chron 32. The Djadokhta Fm thus corresponds to the end of the Campanian, the Baruungoyot Fm should have at most the same age, and the youngest magnetostratigraphic sample from the Nemegt Fm, in the earlier half of chron 31, should be about 70 Ma old. Given the stratigraphic position of Teviornis low within the formation and its nested phylogenetic position within Neognathae, I propose $71 \mathrm{Ma}$ (within the same subchron as $70 \mathrm{Ma}$ : Milanese et al., 2018: fig. 12) as the soft minimum age of the present calibration.

Field et al. (2020: 400) stated that the likely stem-pangallanseran "Asteriornis provides a firm calibration point for the minimum age of divergence of the major bird clades Galloanserae and Neoaves. We recommend that a minimum age of 66.7 million years is assigned to this pivotal neornithine node in future divergence time studies, reflecting the youngest possible age of the Asteriornis holotype including geochronological uncertainty." In their supplementary information (p. 13), however, they revealed being aware of Teviornis, citing De Pietri et al. (2016) for its position as a presbyornithid (and thus, by their own phylogenetic analyses, an anserimorph) without discussing it any further.

Should the fragmentary Teviornis fall out elsewhere, the minimum age might nonetheless not have to rest on Asteriornis, because Vegaviidae, a clade containing the late Maastrichtian (Clarke et al., 2005; Salazar et al., 2010) Vegavis, Polarornis and Neogaeornis and probably the end-Campanian (McLachlan et al., 2017) Maaqwi, has been found on the anserimorph stem in some of the latest analyses (Agnolín et al., 2017; Tambussi et al., 2019). However, Mayr et al. (2018) discussed reasons for skepticism, and the analyses of McLachlan et al. (2017), Bailleul et al. (2019: supp. trees 7-11, 16, 17), Field et al. (2020) and O'Connor et al. (2020) found the vegaviids they included close to but outside Aves (or at least Galloanserae in the case of Bailleul et al., 2019, and O'Connor et al., 2020, who did not sample Neoaves or Palaeognathae in the analyses in question).

As the soft maximum age I tentatively suggest $115 \mathrm{Ma}$, an estimate of the mid-Aptian age of the terrestrial Xiagou Fm of northwestern China, which has yielded a diversity of stem-birds but no particularly close relatives of the crown (Wang et al., 2013; Bailleul et al., 2019; O'Connor et al., 2020; and references therein).

\subsubsection{Node 117: Testudines [PN] (Pan-Pleurodira [PN] - Pan-Cryptodira [PN])}

The origin of the turtle crown group by split into the pleurodiran [PN] and cryptodiran [PN] total groups was assigned a minimum age of $210 \mathrm{Ma}$ and no maximum age; this was taken from Noonan and Chippindale (2006) who cited a work from 1990 as their source.

The calibration dates treated above are almost all too young (some substantially so, others by just a few million years). This one, in contrast, is far too old. It rests on the outdated interpretation of the Norian (Late Triassic) Proterochersis as a stem-group pan-pleurodire. With one short series of exceptions (Gaffney et al., 2006, 2007; Gaffney and Jenkins, 2010), all $21^{\text {st }}$-century treatments of Mesozoic turtle phylogeny have found Proterochersis and all other turtles older than those mentioned below to lie well outside the crown group (Shao et al., 2018: fig. S8, S9; Sterli et al., 2019, 2020; and references therein, in Gaffney and Jenkins, 2010, and in Romano et al., 2014a).

The three oldest known xinjiangchelyids, of which one was referred to Protoxinjiangchelys, seem to be between $170 \mathrm{Ma}$ and $180 \mathrm{Ma}$ old (Aalenian/Bajocian boundary, Middle Jurassic, to Toarcian, late 
576

577

578

579

580

581

582

583

584

585

586

587

588

589

590

591

592

593

594

595

596

597

598

599

600

601

\section{2}

603

604

605

606

607

608

609

610

611

612

613

614

615

616

617

618

619

Early Jurassic; Hu et al., 2020, and reference therein). In the last three years, the xinjiangchelyids have been found as stem-testudinates or as stem-pan-cryptodires (Shao et al., 2018; Evers et al., 2019; González Ruiz et al., 2019: fig. 6, supp. fig. 4; Gentry et al., 2019; Anquetin and André, 2020; Sterli et al., 2020: supp. fig. "X" = 19), even in both positions when the same matrix was analyzed with different methods (Sterli et al., 2019: supp. file SterlietalSupplementary_material_3.pdf).

The oldest known securely dated and securely identified crown-group turtle is thus the mid-late Oxfordian stem-pan-pleurodire Caribemys (de la Fuente and Iturralde-Vinent, 2001; Shao et al., 2018; mostly referred to Notoemys as N. oxfordiensis in more recent literature, e.g. Sterli et al., 2019). Given that the Oxfordian ended $157.3 \pm 1.0 \mathrm{Ma}$ ago (ICS), I suggest a minimum age of 158 Ma.

The stem-trionychian cryptodire Sinaspideretes (Tong et al., 2013), which would provide a minimum age for Cryptodira (node 118) rather than only Testudines, was long thought to have the same age or to be somewhat older. Of the three known specimens, at least one (the exact localities where the type and the other specimen were found are unknown) comes from the Upper (Shang-) Shaximiao Fm (Tong et al., 2013), which conformably overlies a sequence of two supposedly Middle Jurassic formations and is overlain by two Upper Jurassic formations (Tong et al., 2011; Xing et al., 2013), so it should be about Oxfordian to Callovian in age. The biostratigraphic evidence for the age of the Upper Shaximiao Fm is conflicting; there was no consensus on whether it is Middle or Late Jurassic (Xing et al., 2013) before Wang et al. (2018) showed that the immediately underlying Lower (Xia-) Shaximiao Fm is at most $159 \pm 2$ Ma old, a confidence interval that lies entirely in the Late Jurassic (which began, with the Oxfordian, 163.5 $\pm 1.0 \mathrm{Ma}$ ago: ICS). Most likely, then, the same holds for all Sinaspideretes specimens, and none of them is older than Caribemys.

The unambiguously Early Jurassic and Triassic record of turtles throughout Pangea lies entirely on the stem and has a rather good stratigraphic fit (see Sterli et al., 2019, 2020). I therefore suggest a soft maximum age of $185 \mathrm{Ma}$ (in the Pliensbachian: ICS) that probably postdates all of these taxa but predates the oldest possible age of the oldest known xinjiangchelyids.

\subsubsection{Node 124: Pleurodira [PN] (Pan-Chelidae - Pan-Pelomedusoides)}

The origin of Pleurodira by the cladogenesis that generated Pan-Chelidae (represented by Phrynops) and Pan-Pelomedusoides (represented by Pelusios) was given a minimum age of $25 \mathrm{Ma}$ (Oligocene) and no maximum age. This was miscopied from Noonan and Chippindale (2006: table 1), who assigned that age to Pelomedusidae (their calibration 18, represented here by Pelusios alone), not to Pleurodira; to Pleurodira they assigned (their calibration 17) a minimum age of $100 \mathrm{Ma}$ (Early/Late Cretaceous boundary) and a maximum age of $150 \mathrm{Ma}$ (Tithonian, Late Jurassic).

Pleurodira has long been known to extend into the Early Cretaceous (reviewed by Pérez-García, 2019); pan-podocnemidids within Pelomedusoides have a particularly rich fossil record. At present, the oldest known pleurodire is the late Barremian pan-podocnemidid Atolchelys (Romano et al., 2014a; Pérez-García, 2019; Hermanson et al., 2020), suggesting a minimum age of $125 \mathrm{Ma}$ for this calibration (Romano et al., 2014a; ICS).

Due to the fairly highly nested position of Atolchelys within Pleurodira (whether or not it is a bothremydid - Romano et al., 2014a; Cadena, 2015; Hermanson et al., 2020), and due to the somewhat sparse record of stem-pleurodires (from the Late Jurassic onwards: Romano et al., 2014a; Cadena, 2015; Pérez-García 2019), I accidentally agree with Irisarri et al. (2017) in not assigning a maximum age other than that of Node 117. The maximum age assigned by Noonan and Chippindale (2006: table 1) "assumes the Late Jurassic Platychelys actually predates the origin of modern

This is a provisional file, not the final typeset article 
pleurodiria [sic]", which does not logically follow from the fact that it is close to but outside

621 Pleurodira.

\section{2.2.12 Node 125: Lepidosauria [PN] (Rhynchocephalia - Pan-Squamata [PN])}

623 The minimum age of this calibration, given as $238 \mathrm{Ma}$, has to be slightly revised to $244 \mathrm{Ma}$ (both in 624 the Middle Triassic) based on Megachirella, the oldest known unambiguous stem-pan-squamate 625 (Renesto and Bernardi, 2013; Simões et al., 2018: table S2, 2020; Garberoglio et al., 2019; Sobral et 626 al., 2020), which is older than the oldest known rhynchocephalian (238-240 Ma: Jones et al., 2013).

627 The Early Triassic Sophineta, a large collection of isolated bones, may be a stem-pan-squamate or a 628 stem-pan-lepidosaur (Evans and Borsuk-Białynicka, 2009a; Simões et al., 2018, 2020; Garberoglio et al., 2019; Sobral et al., 2020). The text of Sobral et al. (2020) makes clear that Vellbergia, another such animal, is younger than Megachirella, despite being shown as older in Sobral et al. (2020: fig. 4).

An Early Triassic or perhaps Late Permian maximum age seems reasonable, but, given the rarity of stem-pan-lepidosaurs and of Permian diapsids in general (Carroll's Gap - Marjanović and Laurin, 2013a), I rather propose to use the ecologically similar small amniotes (e.g. Haridy et al., 2017; MacDougall et al., 2019) of Richards Spur (289 \pm 0.68 Ma; Woodhead et al., 2010), immediately before Carroll's Gap, to support a soft maximum age of 290 Ma.

\subsubsection{Node 129: Toxicofera (Pan-Serpentes [PN] - Anguimorpha + Pan-Iguania [PN])}

This calibration was given a minimum age of $148 \mathrm{Ma}$ (Tithonian, Late Jurassic) and no maximum age. Note that the minimum age was not operational because Node 131, Iguania, was given an older minimum age of $165 \mathrm{Ma}$; in other words, Node 129 was really not calibrated at all.

642 And indeed I should first mention that the pan-squamate fossil record suffers from three problems that make it difficult to calibrate this node. First, it exhibits Carroll's Gap (Marjanović and Laurin, 2013a) very strongly. After the Middle Triassic stem-pan-squamate Megachirella and at least one Early Triassic pan-lepidosaur that may or may not be a pan-squamate (Sophineta in particular compare the different phylogenetic analyses in Simões et al., 2018, 2020), the pan-squamate record as known today goes completely silent (see below under Node 131 for the one or two supposed exceptions) until the dam suddenly breaks in the Bathonian (Middle Jurassic) and representatives of the stem as well as, by current understanding, several parts of the crown appear in several sites in the northern continents and northernmost Gondwana. Second, these early representatives are all isolated and generally incomplete bones that preserve few diagnostic characters; the oldest complete skeletons come from one Tithonian (latest Jurassic) cluster of sites (Conrad, 2017), followed by a few Early Cretaceous ones as well as the oldest partially articulated material other than Megachirella. Third, the morphological datasets so far assembled for analysis of pan-squamate phylogeny are all so plagued by correlated characters and other problems that all of them support either Pan-Iguania as the sister-group to all other squamates, or the amphisbaenians (alone or even together with the dibamids) as the sister-group to Pan-Serpentes (e.g. Simões et al., 2020: supp. fig. 2), or both (e.g. Conrad, 2017: fig. 27, 28), while both are strongly contradicted by the molecular consensus (e.g. Irisarri et al., 2017; Garberoglio et al., 2019; Sobral et al., 2020: fig. S10; Simões et al., 2020: supp. fig. 1, 3, 5, 8). (As I try to redate the exact tree topology of Irisarri et al. [2017], it is not relevant to the present work data, most recently and thoroughly by Mongiardino Koch and Gauthier [2018], who also reviewed that issue.) 
The oldest known toxicoferans appear to be represented by four isolated vertebral centra from the

664 Anoual Fm of Morocco, which is early Bathonian in age (Haddoumi et al., 2015). These bones were assigned to "cf. Parviraptor" by Haddoumi et al. (2015). Other material - vertebrae and jaw fragments from Europe and North America discussed in Panciroli et al. (2020) - was originally assigned to "cf." or "aff. Parviraptor", including but not limited to the late Bathonian or earliest Callovian Eophis, the Kimmeridgian Diablophis and Portugalophis, and Parviraptor itself from around the Jurassic/Cretaceous (Tithonian/Berriasian) boundary. Traditionally regarded as representing the oldest anguimorphs, these fossils would calibrate Node 130, the split between PanIguania [PN] and Anguimorpha; however, phylogenetic analyses following a redescription of much

673 of the material have found it to constitute the oldest known pan-serpents, thus calibrating Node 129 (Caldwell et al., 2015; Martill et al., 2015; by implication Conrad, 2017; accepted without analysis by Garberoglio et al., 2019, and Simões et al., 2020). As the Bathonian began 168.3 $\pm 1.3 \mathrm{Ma}$ ago and ended $166.1 \pm 1.2 \mathrm{Ma}$ ago, i.e. with uncertainty ranges that overlap in the middle (ICS), the suggestion of $167 \mathrm{Ma}$ by Caldwell et al. (2015) would then be a reasonable minimum age for this calibration.

Alifanov's (2019) casual referral of Parviraptor to an unusually large version of Mosasauria should not be construed to contradict this: the Cretaceous aquatic squamates, mosasaurs included, are probably all pan-serpents (see below), unless they lie on the common stem of Anguimorpha and Iguania (Simões et al., 2020: supp. fig. 8, with very low support).

682 As mentioned, all these remains are very fragmentary, and all are disarticulated; according to a reviewer, new, apparently unpublished material shows the "parviraptorids" are not snakes, and indeed Panciroli et al. (2020) were careful not to state in the text whether they agreed with the referral to the snake stem, designating "cf. Parviraptor sp." as "Squamata indet." in their faunal list 686 (table 1).

The next younger record of a possible toxicoferan is the just as fragmentary Callovian Changetisaurus, a supposed anguimorph, though Alifanov (2019) provided reasons to doubt that it is a toxicoferan. It is followed by the several species of Dorsetisaurus, another assemblage of skull fragments with osteoderms from the Kimmeridgian through Berriasian of Europe and North America, that was explicitly accepted as an anguimorph by Caldwell et al. (2015) and, on different grounds, Alifanov (2019), but has not, to the best of my knowledge, been included in any phylogenetic analysis. (Older and secondary literature has often claimed that the oldest Dorsetisaurus specimens are 148 Ma old, but the Kimmeridgian ended 152.1 \pm 0.9 Ma ago: ICS.)

Most of the rich record of Cretaceous aquatic squamates has traditionally been referred to Anguimorpha, but more likely belongs to Pan-Serpentes (e.g. Garberoglio et al., 2019; Palci et al., 2019; Sobral et al., 2020: fig. S10; Simões et al., 2020: supp. fig. 3, 4, 6, 9; and references therein). It sets in in what seems to be the Hauterivian with Kaganaias (Evans et al., 2006; Campbell Mekarski et al., 2019); the Hauterivian ended 129.4 Ma ago (ICS, uncertainty not quantified). If neither the "parviraptorids" nor Changetisaurus nor Dorsetisaurus are accepted as toxicoferans, the minimum age of Node 129 should thus be $130 \mathrm{Ma}$. To err on the side of caution, that is the age I have used here.

703 Due to Carroll's Gap (Marjanović and Laurin, 2013a) I agree with Irisarri et al. (2017) in not 


\subsubsection{Node 131: Iguania [PN] (Pan-Acrodonta [PN] - Pan-Iguanidae [PN])}

706

707

708

709

710

711

712

713

714

715

716

717

718

719

720

721

722

723

724

725

726

727

728

729

730

731

732

733

734

735

736

737

738

739

740

741

742

743

744

745

746

747

748

749

750
The origin of Iguania by cladogenesis into Pan-Acrodonta and Pan-Iguanidae was assigned a minimum age of $165 \mathrm{Ma}$ (late Middle Jurassic) and a maximum age of $230 \mathrm{Ma}$ (Carnian, Late Triassic) following Noonan and Chippindale (2006).

Tikiguania was described as a Late Triassic acrodontan [PN]. Not only is it an acrodontan, it is a draconine agamid (Hutchinson et al., 2012); most likely, therefore, the very well preserved isolated lower jaw is not a fossil, but belongs to one of the draconine species that live on the site, and fell into the screenwashing sample (Hutchinson et al., 2012).

Bharatagama, cited by Noonan and Chippindale (2006), is known (Evans et al., 2002) from at least 85 maxilla and dentary fragments (with supposed genuine absence of the splenial and supposed fusion of the angular to the dentary) that undoubtedly come from the Upper Member of the Kota Fm in Andhra Pradesh (India), for which, on the balance of conflicting biostratigraphic evidence (Prasad and Manhas, 2007; Prasad et al., 2014), a late Middle Jurassic age seems most likely (notwithstanding the fact that the Lower Member conformably overlies the Dharmaram Fm, which extends down into the Triassic as shown by its phytosaurs and aëtosaurs: Goswami et al., 2016). Even so, this age (i.e. 163.5 $\pm 1.0 \mathrm{Ma}$ or older: ICS) is old enough by comparison to the pan-iguanian fossil record and the position of Iguania in all molecular phylogenies (including Irisarri et al., 2017) that Jones et al. (2013: 15), whose molecular dating found Toxicofera as a whole to be younger than Bharatagama, stated: "It is possible that Bharatagama represents an early stem crown-group [sic] squamate with a jaw morphology convergent with modern acrodont [ = acrodontan] iguanians, or that it belongs to another clade." Simões et al. (2017) cited these doubts without further comment. Evans et al. (2002: 306) listed a number of features shared by acrodontans and sphenodontians; three of these do not occur in the Cretaceous priscagamid stem-pan-acrodontans, but all are found in Bharatagama. Although no known sphenodontian is a good match (Evans et al., 2002), I very tentatively suggest that Bharatagama could represent a morphologically innovative clade of Diphydontosaurus-grade sphenodontians. It would not lie outside the large (Reynoso, 2005, and references therein) sphenodontian morphospace: the shape, size, implantation and attachment of the distal teeth recalls Clevosaurus (depicted in Evans et al., 2002), while the shape and size of the mesial teeth is reminiscent of Sphenovipera (Reynoso, 2005). Indeed, the one phylogenetic analysis that has ever included Bharatagama found it as a rhynchocephalian rather than a squamate, although close to the pleurosaurs (despite the more Diphydontosaurus-like plesiomorphic gradient of tooth implantation) and, not surprisingly given the limited material, with weak support (Conrad, 2017). In sum, the optimism of Scarpetta (2019) is unwarranted, and the status of Bharatagama as a panacrodontan is too doubtful for use in calibration.

Xianglong from the Yixian Fm of Liaoning (China), which dates to around the Barremian-Aptian boundary ( 125.0 Ma: ICS), was described as a pan-acrodontan, possibly an acrodontan (Li et al., 2007). Unfortunately, this rests on very limited evidence: the one known individual is clearly juvenile, and much of the skeleton remains unknown because is covered by exquisitely preserved soft tissue and has not been $\mu$ CT-scanned (Li et al., 2007; Simões et al., 2017; Scarpetta, 2019, and reference therein).

Daza et al. (2016) briefly described three isolated hindlimbs from Burmese amber (99 Ma old: Daza et al., 2016, 2020) as agamids, and a largely complete articulated individual as a chamaeleonid. The supposed chamaeleonid later turned out to be an albanerpetid amphibian with a ballistic tongue (Matsumoto and Evans, 2018: 52-53; Daza et al., 2020), and the supposed agamids are so incomplete that they probably provide more ecological than phylogenetic information; indeed, the only supposed pan-acrodontan Daza et al. (2016) included in their phylogenetic analysis was the albanerpetid. 
751

752

753

754

755

756

757

758

759

760

761

762

763

764

765

766

767

768

769

770

771

772

773

774

775

776

777

778

779

780

781

782

783

784

785

786

787

788

789

790

791

792

793

794

795

Therefore, again unlike Scarpetta (2019), I do not think any of these four specimens can be used to calibrate divergence dates.

Priscagamidae is a Campanian clade (from the Djadokhta, Baruungoyot and more or less coeval formations; see node 113 above and Borsuk-Białynicka, 1996) of squamates that have usually been considered stem-pan-acrodontans (most recently found as such by Simões et al., 2018, and the three matrices independently derived from theirs: Garberoglio et al., 2019; Sobral et al., 2020; Simões et al., 2020; also by DeMar et al., 2017), but have also been found as stem-pan-iguanians (Conrad, 2015: fig. 6, with much denser sampling of pan-iguanians than in DeMar et al., 2017, or Simões et al., 2018, and their successors).

A consensus now appears to exist that Gobiguania (Conrad and Norell, 2007) is a clade or grade of Campanian and Maastrichtian stem-pan-iguanians (Simões et al., 2015; Conrad, 2015), though DeMar et al. (2017: supp. inf.) could not determine if their two gobiguanian clades were stem-paniguanians or stem-pan-iguanids [PN].

"Ctenomastax" Gao and Norell, 2000, a junior homonym of the staphylinid beetle Ctenomastax Kraatz in von Heyden, 1870, is likewise known from the Djadokhta and Baruungoyot formations (see node 113); probably due to the poor preservation of the specimens (Gao and Norell, 2000), it has variously been found as the sister-group of all other pan-acrodontans (Simões et al., 2015; Reeder et al., 2015; DeMar et al., 2017) or as a gobiguanian stem-pan-iguanian (Conrad, 2015). In the latter case it cannot date the origin of Iguania.

Isodontosaurus, from the Djadokhta Fm and more or less coeval sites, is known from fairly large amounts of material representing much of the skeleton, but its phylogenetic position has been hard to determine (Gao and Norell, 2000); Conrad (2015) found it as a stem-pan-acrodontan, Reeder et al. (2015) as a gobiguanian, DeMar et al. (2017) in the "gobiguanian" grade.

DeMar et al. (2017: supp. inf.: 26-28) briefly reviewed the various Cretaceous specimens from North and South America that had been attributed to Pan-Iguanidae [PN], in some cases even Iguanidae [PN] (see node 132), and found all these attributions doubtful at best.

Alifanov (2013) described Desertiguana as a phrynosomatid iguanid [PN] based on an almost complete left lower jaw from the Baruungoyot Fm. Curiously, it has been summarily ignored ever since by everyone other than its author (in single-authored publications that do not provide further information and never contain phylogenetic analyses), except for a citation as a pan-iguanian without any comment by Head (2015). Given that Alifanov (2013) also classified three other Djadokhta/Baruungoyot genera otherwise considered gobiguanians as phrynosomatids, I cannot be certain that Desertiguana is not a gobiguanian stem-pan-iguanian as well.

Equally Campanian or older (summarized in Langer et al., 2019) is the stem-pan-acrodontan Gueragama (Simões et al., 2015, 2017). Known from an isolated but largely complete lower jaw, it appears to suffice for setting up a minimum age for Iguania at the Campanian/Maastrichtian boundary $(72.1 \pm 0.2 \mathrm{Ma}$ : ICS), which I round to $72 \mathrm{Ma}$. I should mention, however, that a reviewer doubts the phylogenetic position of Gueragama for unstated reasons, and that Romo de Vivar et al. (2020) found that most or all of the similarities between Gueragama and Acrodonta are shared with the Triassic pan-lepidosaur Cargninia, likely indicating that these features are evolutionarily correlated with each other and prone to convergence. Meanwhile, Alifanov (2020) called Gueragama an isodontosaurid (see above) without stating a reason.

Apesteguía et al. (2016) described Jeddaherdan from a Cenomanian jaw fragment. Using a dataset entirely restricted to iguanians, their parsimony analysis recovered it as a pan-acrodontan rather than a pan-iguanid (the only other option) and did not resolve it further until implied weighting was

This is a provisional file, not the final typeset article 
796

797

798

799

800

801

802

803

804

805

806

807

808

809

810

811

812

813

814

815

816

817

818

819

820

821

822

823

824

825

826

827

828

829

830

831

832

833

834

835

836

837

838

839

840

applied, which placed Jeddaherdan in a clade with Gueragama and the extant agamid Uromastyx. Bayesian inference found the same result, although with rather low support (posterior probability of 0.8 ). As the authors pointed out, this topology implies that the occurrence of tooth replacement in Gueragama is a reversal. Given the very limited material, the taxon sample which presupposes that Jeddaherdan is an iguanian, the constraints on the applicability of implied weighting and the poorly understood performance of Bayesian inference with missing data distributed by body part (Marjanović and Laurin, 2019, and references therein; King, 2019), as well as the implications for Gueragama, I prefer not to use Jeddaherdan to date the origin of Iguania as long as further material has not been discovered.

If none of the taxa listed above are iguanians, the fossil record of Iguania is entirely restricted to the Cenozoic, possibly beginning in the Thanetian, the last stage of the Paleocene (reviewed in Alifanov, 2020 - a work that is, however, perfectly happy to name paraphyletic taxa that are not intended as clades). I cannot assign a maximum age other than that for Node 125.

\subsubsection{Node 132: Iguanidae [PN] (Iguaninae + Corytophanidae - Dactyloidae + Phrynosomatidae)}

The origin of Iguanidae was given a minimum age of $125 \mathrm{Ma}$ (Barremian/Aptian boundary, Early Cretaceous) and a maximum age of $180 \mathrm{Ma}$ (Toarcian, Early Jurassic). This was miscopied from Noonan and Chippindale (2006), who did assign a maximum age of $180 \mathrm{Ma}$, but a minimum age of only $25 \mathrm{Ma}$ (late Oligocene), citing an early Miocene specimen and its description from 1991.

Other than the abovementioned Cretaceous and Paleocene questionable iguanids like Desertiguana (see node 131), it is unexpectedly hard to determine from the literature what the oldest possible iguanid could be (though even the questionable ones are all much younger than $125 \mathrm{Ma}$ ). Smith (2009) described two assemblages of isolated skull bones from the Paleocene-Eocene boundary (56.0 Ma ago: ICS) as the new taxa Suzanniwana, which he considered a likely stem-corytophanid, and Anolbanolis, which he thought close to Polychrus and Dactyloidae. He did not perform a phylogenetic analysis. Unfortunately, nobody has ever included Anolbanolis in a phylogenetic analysis to the best of my knowledge. DeMar et al. (2017) mentioned it in the text as one of the two oldest definitive iguanids (the other being the younger Afairiguana), but it does not occur in their tree figure or their entire supplementary information; Suzanniwana occurs nowhere in that publication at all. Conrad (2015), nowhere mentioning Anolbanolis, stated that Suzanniwana was one of the two "taxa with the most volatile positions within this analysis", but only published the Adams consensus of that analysis, which shows Suzanniwana as part of a polytomy that also encompasses Corytophanidae and a clade containing all other extant iguanids - whether Suzanniwana remains inside Iguanidae in all of the 98 most parsimonious trees or is placed as the sister-group of Iguanidae in some could only be determined by repeating the analysis. Scarpetta (2020: supp. inf.) did include Suzanniwana in one of the two datasets he analyzed, and found it in the corytophanid total group or at least in a clade with Corytophanidae, Polychrus and Dactyloidae, but the sample of extinct species is extremely small in that matrix, and Anolbanolis is nowhere mentioned.

The oldest certain iguanid, then, is the oldest one known from articulated remains: the fairly highly nested Kopidosaurus, even though it is not clear where it is nested exactly (Scarpetta, 2020). Being slightly older than a $52.59 \pm 0.12$ Ma old tuff that overlies it (Scarpetta, 2020), and being followed by Afairiguana (which forms an exclusive clade with the extant Polychrus and Dactyloidae in the analysis of Conrad, 2015), the highly nested corytophanid Babibasiliscus and the less highly nested corytophanid Geiseltaliellus (Conrad, 2015) within the next five million years, it establishes a rather tight minimum age of $53 \mathrm{Ma}$ for this calibration point, very close to the abovementioned $56 \mathrm{Ma}$. 
841

842

843

844

845

846

847

848

849

850

851

852

853

If Desertiguana is not an iguanid, the absence of iguanids might suggest a late Campanian maximum age for Iguanidae. But as this possibility cannot be excluded at present, even apart from unknown geographic or ecological factors that could have kept iguanids out of the environments that deposited the Campanian and Maastrichtian formations of Asia and North America, I find myself unable to assign a maximum age other than, again, that for Node 125 . The argument by Noonan and Chippindale (2006: table 1) was "based on observations of Evans et al. (2002) and the assumption that the origin of this group does not predate the earliest known Iguaninan [sic] in the Jurassic" and is therefore doubly untenable.

Burbrink et al. (2020) found extremely short internal branch lengths for the basal radiation of Iguanidae; similarly, Scarpetta (2020) found the phylogeny of Iguanidae difficult to resolve, which likewise suggests a fast radiation (but might also be a consequence of the sparse taxon sampling in both matrices). Paleoecologically, the recovery phase immediately after the Cretaceous-Paleogene boundary suggests itself as the time of such a radiation. But this remains to be tested.

\subsubsection{Node 150: Mammalia [PN] (Pan-Monotremata [PN] - Theriimorpha)}

The origin of the crown-group Mammalia by the divergence of Pan-Monotremata represented by Ornithorhynchus, on one side, and Theriimorpha, which comprises Theria (to which all extant mammals except the monotremes belong), Spalacotheroidea, Meridiolestida, Dryolestidae, Multituberculata, $(\mathrm{Eu})$ triconodonta and many others, on the other side, was assigned a minimum age of 162.5 Ma (Oxfordian, Late Jurassic) and a maximum age of 191.4 Ma (Early Jurassic) following Benton and Donoghue (2007).

The phylogenetic position of Haramiyida, a clade that reaches beyond these ages into the Late Triassic, has been controversial; Celik and Phillips (2020) have presented a strong argument that it lies well outside Mammalia, which is one of the two positions found in previous analyses.

The oldest uncontroversial mammals are the pan-monotremes Asfaltomylos and Henosferus and the volaticotherian (eu)triconodont Argentoconodon, which all come from a level that was originally thought to be high in the Cañadón Asfalto Fm and to be Callovian or even Oxfordian (late Middle or early Late Jurassic) in age, but has more recently been correlated to its very bottom, the transition with the underlying Lonco Trapial Fm (Cúneo et al., 2013). From this bottom of the Cañadón Asfalto Fm, three successive (from lowest to highest) $\mathrm{U}-\mathrm{Pb}$ zircon dates were determined by Cúneo et al. (2013): $178.766 \pm 0.23 \mathrm{Ma}, 177.37 \pm 0.12 \mathrm{Ma}$ and $176.15 \pm 0.24 \mathrm{Ma}$. These are maximum ages in that reworked zircon crystals occur in these lacustrine tuff beds, so that the youngest crystals, from which the cited ages were derived, could still be older than the deposition of the tuff beds themselves; however, given the correlation of the recovered ages with stratigraphic height, and the rarity of older zircons in the oldest and the youngest sample (Cúneo et al., 2013), a large discrepancy is unlikely. Therefore, I recommend a minimum age of $179 \mathrm{Ma}$ for this calibration.

The maximum age assigned by Irisarri et al. (2017) may be intended to represent the Sinemurian/Pliensbachian boundary (190.8 $\pm 1.0 \mathrm{Ma}$ : ICS). Indeed, the Sinemurian record of mammalomorphs (tritylodontids, tritheledontids, Sinoconodon, morganucodontans, Hadrocodium) from North America, southern Africa and China is fairly rich and diverse, but has not yielded mammals so far. However, ghost lineages encompassing almost the entire Early Jurassic to the middle of the Middle Jurassic occur for haramiyidans and docodonts, both of which have been found in the Rhaetian and the Bathonian, but not so far in between; and while the Rhaetian and/or possibly Norian Thomasia and Haramiyavia lie outside the smallest clade of all other haramiyidans, the Rhaetian Tikitherium is the sister-group of all Jurassic docodonts except the probably Middle Jurassic Gondtherium (Zhou et al., 2019: supp. inf. M), requiring two such ghost lineages within Docodonta. Two more such ghost lineages for Pan-Monotremata and Theriimorpha would not be very surprising.

This is a provisional file, not the final typeset article 
887

888

889

890

891

892

893

894

895

\section{6}

897

898

899

900

901

902

903

904

905

906

907

908

909

910

911

912

913

914

915

916

917

918

919

920

921

922

923

924

925

926

927

928

929

930
This may be especially relevant if Haramiyida, rather than the Sinemurian Hadrocodium, is the sister-group of Mammalia. Currently, the former is recovered by parsimony, the latter by Bayesian analysis of the same matrix (Huttenlocker et al., 2018: extended data fig. 9; Zhou et al., 2019: supp. inf. M), neither option having strong support by its own criteria; judging from the dashes in their fig. 2 and S1, Celik and Phillips (2020) may have found the same result using an improved version of the same matrix, but they did not publish their most parsimonious trees. For comparisons between the methods as applied to paleontological datasets, see the references cited under node 102 (above). Preferring to err on the side of caution, I place the hard maximum age in the Carnian Pluvial Episode $233 \mathrm{Ma}$ ago (Maron et al., 2018), which is also substantially older than all possible haramiyidans.

\subsubsection{Node 151: Theria (Metatheria - Eutheria)}

The origin of Theria by the split into the total groups Metatheria (crown group: Marsupialia) and Eutheria (crown group: Placentalia) was given a minimum age of 124.6 Ma (Barremian/Aptian boundary, Early Cretaceous) and a maximum age of 138.4 Ma (Valanginian, Early Cretaceous) following Benton and Donoghue (2007).

The oldest securely dated therian is currently the stem-eutherian Ambolestes at $126 \mathrm{Ma}$ (Bi et al., 2018).

Juramaia (Luo et al., 2011) has often been cited as a much older stem-eutherian. However, both its age and its phylogenetic position are in doubt; if either of these doubts is corroborated, Juramaia becomes irrelevant to dating this node. Originally, the only known specimen was thought to come from the Lanqi Fm, specifically a site variably called Daxigou or Daxishan (Yuan et al., 2013: supp. inf.: 4), which has meanwhile been dated to between $160.889 \pm 0.069 \mathrm{Ma}$ and $160.254 \pm 0.045 \mathrm{Ma}$ (Jia and Gao, 2019). Meng (2014: 526, 529-530), however, doubted this, called the specimen "floating", and pointed out its great similarity to Eomaia in particular (found as its sister-group in the very different matrices of Bi et al., 2018, and Zhou et al., 2019: supp. inf. M; Mao et al., 2019: fig. S9, did find Juramaia outside the clade of all other included eutherians, but did not sample Ambolestes despite building on the matrix of Bi et al., 2018) and to Barremian-Albian eutherians in general, as well as the long ghost lineages a mid-Oxfordian age for Juramaia would create within Eutheria, for Metatheria and for several of the closest relatives of Theria. Bi et al. $(2018,2019)$ referred to Meng (2014) for this issue but did not try to resolve it. As long as it is not resolved, I much prefer to consider the single Juramaia specimen to have been discovered in the Yixian Fm (like Ambolestes, Eomaia and Acristatherium), as suggested by Bi et al. (2019).

Celik and Phillips (2020) called Juramaia "purportedly Jurassic" without comment and found middling support for a sister-group relationship to Theria as a whole, noting that this agreed with earlier doubts (e.g. by Sweetman et al., 2017). However, like Mao et al. (2019), they did not sample Ambolestes, and the sensitivity of this result to whether parsimony or a model-based method is used was not published.

Sweetman et al. (2017) described two teeth from the very beginning of the Cretaceous ( $145 \mathrm{Ma}$ old) as two genera of Late-Cretaceous-grade eutherians, Durlstotherium and Durlstodon. In view of this limited material, I remain skeptical (see also Bi et al., 2018) and recommend $126 \mathrm{Ma}$ as the minimum age for this calibration.

While the oldest uncontested metatherians are only some 110 Ma old (Bi et al., 2018), Mao et al. (2019: fig. S9) and Celik and Phillips (2020) have returned Sinodelphys (of the same age as Eomaia and Acristatherium, slightly younger than Ambolestes) to its status as the oldest known metatherian. If this holds and if Juramaia has the same age instead of being Jurassic or is not a therian, and if 
further Durlstotherium and Durlstodon can be disregarded, virtually no ghost lineage is required at the base of Metatheria.

933 Accepting that Juramaia is not from the Lanqi Fm or not a therian, I propose $160 \mathrm{Ma}$ as the soft maximum age of this calibration, on the grounds that therians or their closest relatives - other than, perhaps, Juramaia - are absent in the Lanqi Fm and the laterally equivalent Tiaojishan Fm, likewise absent in the Kimmeridgian and Tithonian of Portugal and the US (where the Morrison Fm, intensely sampled since the 1860s, extends across several states), and further absent in the end-Tithonian and Berriasian of England - other than, perhaps, Durlstotherium and Durlstodon - despite the diversity of ecologically comparable mammals found there. Given the strong evidence of a Laurasian origin of Theria (e.g. Huttenlocker et al., 2018; Bi et al., 2018), the earliest possible time and place for the origin of Theria that could stay out of the fossil record is therefore Asia after the deposition of the Tiaojishan and Lanqi formations ended in the Oxfordian.

\subsubsection{Node 152: Placentalia (Atlantogenata - Boreo(eu)theria); Node 153: Boreo(eu)theria (Laurasiatheria - Euarchontoglires/Supraprimates)}

The origin of Placentalia, the crown group of Eutheria, was given a minimum age of 95.3 Ma

946

947 (Cenomanian, Late Cretaceous) and a maximum age of $113 \mathrm{Ma}$ (Aptian/Albian boundary, Early Cretaceous) following Benton and Donoghue (2007). Its immediate descendant nodes were not constrained.

949 The minimum age rests on the assumption, commonly but not universally held in 2007, that the 950 zhelestids are "ungulates", i.e. belong to Placentalia, or perhaps even that the zalambdalestids are related to Glires and therefore belong to Placentalia. For a long time now, as already pointed out by Parham et al. (2011), every reinvestigation of the anatomy of these Cretaceous animals, and every phylogenetic analysis that sampled Cretaceous eutherians densely (i.e. not including Zhou et al., 2019: supp. inf. M), has found them on the eutherian stem, often not even particularly close to Placentalia (e.g. Novacek et al., 1997; Asher et al., 2005, 2019; Wible et al., 2009; Goswami et al., 2011; Halliday et al., 2015; Manz et al., 2015; Bi et al., 2018: fig. 2, SI-1; Wang et al., 2019: ext. data fig. 5; and references in Parham et al., 2011 "2012"; see also Fostowicz-Frelik and KielanJaworowska, 2002).

A few terminal Cretaceous (late Maastrichtian) eutherians have been attributed to Placentalia in the past. This is at best dubious for all of them. Protungulatum (Wible et al., 2009; Halliday et al., 2015, 2019: fig. 1 contrary to the text; Manz et al., 2015: fig. 2a; Wang et al., 2019: ext. data fig. 5; Mao et al., 2019: fig. S9) and Gypsonictops (Halliday et al., 2015, 2019; Bi et al., 2018; Manz et al., 2015: fig. 2; Wang et al., 2019: ext. data fig. 5; Mao et al., 2019: fig. S9) are now placed close to but consistently outside Placentalia. Deccanolestes - at least if the teeth and the tarsal bones belong together - is placed far away (Goswami et al., 2011 [see there also for Sahnitherium]; Manz et al., 2015: fig. 2, SI-1; Penkrot and Zack, 2016; Halliday et al., 2019). The single worn tooth named Kharmerungulatum, which had been assigned to Placentalia mostly through comparison to Protungulatum in the first place (Prasad et al., 2007), has more recently been found outside Placentalia as well ("Although none of the strict consensus trees supported the placement of Kharmerungulatum within the placental crown group, the limited dental material for this taxon proved insufficient for resolving its phylogenetic relationships, and so it was removed a posteriori from the MPTs to produce the reduced strict consensus trees." - Goswami et al., 2011: 16334), specifically as an adapisoriculid like Deccanolestes when full molecular constraints were applied by Manz et al. (2015: fig. 2b). The stylinodontid taeniodont Schowalteria (Fox, 2016, and references therein) belongs to a clade that survived into the Eocene; the conference abstract by Funston et al. (2020) reported that a very large phylogenetic analysis has found the group outside Placentalia. 
977

978

979

980

981

982

983

984

985

986

987

988

989

990

991

992

993

994

995

996

997

998

999

1000

1001

1002

1003

1004

1005

1006

1007

1008

1009

1010

1011

1012

1013

1014

1015

1016

1017

1018

1019

1020

1021

1022

1023

The same reasons make it difficult to decide which of the earliest Paleocene eutherians should be accepted as securely enough identified placentals. But in any case, Williamson et al. (2019: 220) reported that the herbivorous periptychid Ectoconus, estimated to have reached about $100 \mathrm{~kg}$, was "present within 0.4 Ma of the K-Pg boundary"; phylogenetic analyses have found it to be not only a placental, but a laurasiatherian - Halliday et al. (2015; regardless of constraints) found it and the other periptychids on the pholidotan stem; Halliday et al. (2019), using combined data and maximum likelihood, found a comparable result with much less resolution; Püschel et al. (2019), using a somewhat smaller matrix with, however, a focus on periptychids and new data on them, recovered them as stem-artiodactylomorphs. I therefore suggest $66 \mathrm{Ma}$, the Cretaceous/Paleogene boundary (66.021 $\pm 0.081 \mathrm{Ma}$ : Clyde et al., 2016), as the minimum age for Node 153, the basal node of Boreoeutheria (a name apparently coined by accident by Murphy et al., 2001) or simply Boreotheria (explicitly coined by Waddell et al., 2001). For Node 152 I cannot recommend a separate minimum age.

Given the continuing worldwide absence of unambiguous placentals in the rich Maastrichtian record (see above as well as Halliday et al., 2016, and Davies et al., 2017) and the absence of even ambiguous ones in the even richer Campanian record (although there are three isolated Turonian teeth indistinguishable from both species of Gypsonictops: Cohen and Cifelli, 2015; Cohen, 2017), despite the presence of stem-eutherians (all northern continents, Madagascar and India), stemmetatherians (Asia and North America), and ecologically comparable spalacotheroids (Asia and North America), meridiolestidans (South America) and gondwanatheres (South America, Madagascar, India, and some point between the late Turonian and latest Campanian of Africa O'Connor et al., 2019), only Antarctica, Australia and New Zealand are left as paleocontinents where Campanian or Maastrichtian placentals could have escaped the fossil record, and they are all unlikely for biogeographical reasons (e.g. Huttenlocker et al., 2018). Therefore, I suggest the Campanian/Maastrichtian boundary, rounded to $72 \mathrm{Ma}$, as the hard maximum age for Node 152. (I cannot make a separate recommendation for Node 153.) This is more generous than the result of Halliday et al. (2016), 95\% of whose reconstructions of the age of Placentalia were $69.53 \mathrm{Ma}$ old or younger. The discrepancy to the published molecular ages (references in Halliday et al., 2016) is most likely due to the effects of body size (Berv and Field, 2017; Phillips and Fruciano, 2018), or perhaps other factors like generation length, on rates of molecular evolution.

At this point, readers may be wondering why I have mentioned neither the extremely large phylogenetic analysis by O'Leary et al. (2013) nor the objections by Springer et al. (2019), who wrote in their abstract that "morphological cladistics has a poor track record of reconstructing higherlevel relationships among the orders of placental mammals". It would be more accurate to say that phylogenetic analysis of morphological data has no track record of reconstructing the phylogeny of Placentalia, good or bad. To avoid long-branch attraction and long-branch repulsion, any such analysis of morphological data will have to sample the enormous and poorly understood diversity of Paleo- and Eocene eutherians very densely, which will have to entail sampling enough of the characters that unite and distinguish them without falling into the trap of accumulating redundant or otherwise correlated characters that inevitably distort the tree (Marjanović and Laurin, 2019; Sookias, 2019; Celik and Phillips, 2020; and references in all three). This is so much work, and so hard to get funded, that at the most generous count only three attempts at such a matrix have ever been made; I should also point out that matrices of such sizes were not computationally tractable until a few years ago, at least not in less than a few months of calculation time. The first attempt is the "phenomic" matrix by O'Leary et al. (2013); as Springer et al. (2019) pointed out repeatedly, it contains no less than 4,541 characters - but several hundred of these are parsimony-uninformative (O'Leary et al., 2013), and many others are redundant, which means they represent a smaller number of independent 
characters of which many are weighted twice or more often. At 86 terminal taxa, almost all of which are extant, the taxon sample is hopelessly inadequate for eutherian phylogeny. It is no surprise that parts of the topology are highly implausible (e.g. the undisputed stem-whale Rodhocetus landing on the common ungulate [PN] stem, as pointed out by Springer et al., 2019) and that even such undisputed clades as Afrosoricida, Lipotyphla and Artiodactyla are no longer recovered when the hundreds of soft-tissue characters, which cannot be scored for the extinct terminal taxa, are removed (Springer et al., 2019), which casts doubt on the ability of that matrix to place extinct taxa accurately. The second attempt began in the doctoral thesis of Zack (2009) and was further modified and merged with other datasets in Halliday's doctoral thesis that culminated in the publication of Halliday et al. (2015). The taxon sample contains an appreciable number of Cretaceous and Paleocene eutherians; the character sample is of course more modest and contains, as usual for mammals, a large proportion of tooth characters, some of which might be redundant (e.g. Kangas et al., 2004; Harjunmaa et al., 2014). The further improved version (Halliday et al., 2019) suffers from the drawback that all characters were reduced to two states to make the matrix tractable by maximum-likelihood software; this throws away a lot of information (probably for no gain: Sansom et al., 2018; King, 2019). The third is that of the PalM group; funded by an enormous grant, it involves a lot of people each revising a group of Paleo- or Eocene eutherians as their doctoral thesis and contributing the gained knowledge (e.g. Napoli et al., 2017) to a growing matrix (ultimately based on that of Wible et al., 2009) that will then be evaluated for character redundancy and other issues. The only phylogenetic publications that have yet resulted are conference abstracts, of which I have cited Püschel et al. (2019) and Funston et al. (2020) above.

1045 Springer et al. (2019) went on to claim that "Sansom and Wills (2013) showed that fossils are more likely to move stemward than crownward when they are only known for biomineralized characters". Indeed Sansom and Wills (2013) made that claim. They had taken 78 neontological matrices of extant animals with biomineralized tissues, deleted the data for soft-tissue characters from random taxa and found that those taxa changed their phylogenetic position significantly more often than random, and further underwent "stemward slippage" as opposed to "crownward slippage" significantly more often than random. Deleting data from hard-tissue characters instead had no such effect. Sansom and Wills (2013) concluded that some mysterious factor causes hard-tissue characters to contain a systematically misleading signal much more often than soft-tissue characters do, and that therefore the phylogenetic positions of all taxa known only from hard tissues - in other words most animal fossils - are highly suspect of falsely appearing more rootward than they really are. Therefore, fossils assigned to various stem groups could really belong to the crown groups, and the minimum ages of divergence-date calibrations could be systematically too young (Sansom and Wills, 2013), just as Springer et al. (2019) believed. A much simpler explanation is available: hard-tissue characters are unreliable specifically among extant species because the hard-tissue anatomy of extant species is usually very poorly known. For example (Marjanović and Witzmann, 2015), the vertebrae of some of western and central Europe's most common newt species are simply unknown to science, even after 200 years or more of research, because neontologists have focused on soft-tissue anatomy, behavior and more recently the genome while treating the skeleton as an afterthought. And the vertebrae of salamandrids are at least known to contain a phylogenetic signal - whether the appendicular skeleton also does is anybody's guess at this point! As our knowledge of the skeletons of extant taxa would improve, so would, I predict, the ability of hard-tissue characters to accurately resolve the phylogenetic positions of extant taxa. 


\subsubsection{Node 154: Carnivora [PN] (Pan-Feliformia [PN] - Pan-Caniformia [PN])}

1069 The origin of Carnivora by the divergence of the sister-groups Pan-Feliformia (represented in this

1070 matrix by Felis) and Pan-Caniformia (represented by Canis) was assigned a minimum age of 42.8 Ma (Lutetian, Eocene) and a maximum age of 63.8 Ma (Danian, Paleocene). Irisarri et al. (2017) justified this by citing the identification of the middle Eocene Tapocyon as a pan-caniform by Wesley and Flynn (2003); this should be regarded as rendered obsolete by Spaulding and Flynn (2012) and Solé et al. (2016), who found Tapocyon as a stem-carnivoriform in phylogenetic analyses of two successively larger versions of a much larger dataset. The analysis by Tomiya and Tseng (2016) found Tapocyon as a pan-feliform, but used a much smaller sample of stem-carnivoriforms and of characters in a misguided (e.g. Kearney and Clark, 2003; Wiens, 2003a, b, 2005a, b; Prevosti and Chemisquy, 2009; Marjanović and Laurin, 2019; King, 2019; Mongiardino Koch et al., 2020) attempt to avoid missing data by throwing out known data.

1080 With "Miacis" sylvestris being recovered even more rootward on the carnivoriform stem than Tapocyon by Spaulding and Flynn (2012) and Solé et al. (2016), the oldest securely dated and identified carnivoran specimens belong to the amphicyonid stem-pan-caniform Daphoenus and the stem-canid Hesperocyon and are about 38 Ma old (Tomiya, 2011, and references therein). Lycophocyon could have the same age or be somewhat older (Tomiya, 2011), but unfortunately its phylogenetic position remains uncertain: it was published too late to be included by Spaulding and Flynn (2012), it was not added by Solé et al. (2016), and the much smaller phylogenetic analysis by Tomiya (2011) only resolved its position (as a stem-pan-caniform closer to Caniformia than Daphoenus) after all post-Paleogene taxa were excluded. Given the uncertainties in both age and phylogenetic position, I provisionally ignore Lycophocyon and suggest $38 \mathrm{Ma}$ as the minimum age of this calibration.

1091 As a hard maximum age I suggest the Paleocene/Eocene boundary 56.0 Ma ago (ICS), around which there is a very rich record of a range of carnivorous mammals of various sizes and ecologies, including stem-carnivoriforms and many others but not including carnivorans.

\section{2.2.20 Node 155: Euarchontoglires/Supraprimates (Gliriformes - Primatomorpha)}

1095 The last common ancestor of mice and men, the first crown-group member of a clade called 1096 Euarchontoglires (a name apparently coined by accident by Murphy et al., 2001) or, perhaps less clunkily, Supraprimates (explicitly coined by Waddell et al., 2001), was placed between 61.5 Ma ago (Selandian, Paleocene) and 100.5 Ma ago (Early/Late Cretaceous boundary) following Benton and Donoghue (2007).

1100 The oldest purported total-group primatomorph - not necessarily a pan-primate [PN] (Ni et al., 2016) - is Purgatorius coracis, found in an outcrop of the Ravenscrag Formation that is at most $0.4 \mathrm{Ma}$ younger than the 66.0-Ma-old Cretaceous/Paleogene boundary (Fox and Scott, 2011; Scott et al., 2016). However, Halliday et al. $(2015,2019)$ found Purgatorius outside of Placentalia despite the presence of stem-pan-primates in their analyses. When Manz et al. (2015) applied molecular constraints (fig. 2), they did find Purgatorius as a pan-primate, though in a strangely nested position when the monophyly of Laurasiatheria was enforced (fig. 2b). Without constraints, the included primatomorphs formed a grade outside most other placentals (and the included laurasiatherians formed a grade outside all other placentals: fig. SI3-1). Note that Halliday et al. $(2015,2019)$ scored Purgatorius for the tarsal bones that Chester et al. (2015) referred to this taxon (somewhat younger than $P$. coracis); Purgatorius is otherwise known exclusively from teeth and lower jaws (Chester et al., 2015; Scott et al., 2016), and Chester et al. (2015) referred the tarsals simply because their size fits and because they show arboreal adaptations which agree with the assumed pan-primate status of Purgatorius. Scott et al. (2016: 343) preferred to call these bones "several isolated, possible 
1114 plesiadapiform tarsals", Plesiadapiformes being a clade or grade of stem-pan-primates or stem-

1115 primatomorphs to which Purgatorius is generally thought to belong.

1116 Excluding the purgatoriids, the diverse oldest known total-group primatomorphs are, in terms of

1117 North American Land Mammal Ages, slightly younger than the Puercan/Torrejonian boundary

1118 (Silcox et al., 2017), which dates to about 64.8 Ma ago (Wang et al., 2016).

1119 On the presumably gliriform side, the oldest known members are anagalidans from the Lower

1120 Member of the Wanghudun Fm: the anagalids Anaptogale, Wanogale and Chianshania, the

1121

1122 pseudictopid Cartictops and the astigalid Astigale (Missiaen et al., 2012; Wang et al., 2016; López-

1123

Torres and Fostowicz-Frelik, 2018). Their ages are poorly constrained between $66 \mathrm{Ma}$ and about 62.5

1124 Ma, though probably closer to the older end of that range (Wang et al., 2016); López-Torres and

1125

1126

1127 Fostowicz-Frelik (2018: fig. 4) illustrated Anaptogale as considerably older than Wanogale and Chianshania, but did not explain why. However, Asher et al. (2019: fig. 4, S5B, supplementary file S4-optimalTrees.nex) found Anagalida in a "primatomorph grade" when using equally weighted parsimony or implied weights with $\mathrm{K}=24$, as afrotherians with $\mathrm{K}=2$, and on the eutherian stem by Bayesian inference; at least in the latter two cases, anagalidans cannot calibrate this node.

1130

1131

1132

1133

Thus, I propose $65 \mathrm{Ma}$ as the minimum age of this calibration. As the maximum age, if $66 \mathrm{Ma}$ is deemed too close to the minimum (although there are presently no proposed crown- or even totalgroup supraprimates from the Cretaceous, despite the abundance of ecologically Glires-like and early-primatomorph-like multituberculates, gondwanatheres and the presence - in India - of ecologically pan-primate-like adapisoriculids) or to the age of the oldest Purgatorius, I can only offer the maximum of Node 152 (Placentalia, see above).

\subsubsection{Node 157: Marsupialia (Didelphimorphia - Paucituberculata + Australidelphia)}

1136 The origin of the metatherian crown group Marsupialia was given a minimum age of 61.5 Ma (Selandian, Paleocene) and a maximum age of 71.2 Ma (Maastrichtian, Late Cretaceous) following

1138 Benton and Donoghue (2007).

Eldridge et al. (2019) reviewed this question, and found that the oldest definitive marsupials are only 54.6 Ma old as far as understood today, dating from shortly after the beginning of the Eocene (56.0 Ma ago: ICS). Their phylogenetic and geographic position (total-group australidelphians from Australia) suggests a longer history for Marsupialia, but of the many metatherians known from the Paleocene of South America and from the Late Cretaceous through Miocene of the northern continents, none can currently be shown to belong to the crown group (Eldridge et al., 2019). I therefore propose $55 \mathrm{Ma}$ as a probably overly strict minimum age for this calibration.

1146 Carneiro (2017; not cited by Eldridge et al., 2019, whose paper was accepted for publication on 15 1147 January 2018) found the terminal Maastrichtian tooth taxon Glasbius from North America as a 1148 didelphimorphian marsupial in a phylogenetic analysis (greatly expanded from that of Carneiro and Oliveira, 2017, with the same result, likewise not cited by Eldridge et al., 2019). That analysis, however, implied an extraordinary number of transoceanic dispersals around the Paleocene and - as the Gondwanan metatherians are all Cenozoic, but most Laurasian ones are Mesozoic - a surprisingly high rate of survival of metatherians across the Cretaceous/Paleogene boundary. I must suspect that correlation, if not downright redundancy, among mammalian tooth characters has been underestimated once again (e.g. Kangas et al., 2004; Harjunmaa et al., 2014; Celik and Phillips, 2020). In earlier analyses, Glasbius was found on the metatherian stem, e.g. by Wilson et al. (2016), whose analysis failed, however, to find the two included australidelphian taxa as sister-groups despite the morphological and molecular consensus (see Eldridge et al., 2019). 
1158

1159

1160

1161

1162

1163

1164

1165

1166

1167

1168

1169

1170

1171

1172

1173

1174

1175

1176

1177

1178

1179

1180

1181

1182

1183

1184

1185

1186

1187

1188

1189

1190

1191

1192

1193

1194

1195

1196

1197

1198

1199

1200

1201

1202

Marsupials, other metatherians and indeed other therians are wholly absent from the Late Cretaceous mammaliform record of South America, which consists instead of gondwanatherian haramiyidans, a few multituberculates and a very wide variety of meridiolestidan stem-theriiforms. The ages of the latest Cretaceous terrestrial sites of South America have been difficult to pinpoint, but there is evidence that they cover the entire Campanian and Maastrichtian (Rougier et al., 2008; Lawver et al., 2011; and references therein). The early Paleocene (Danian) sites of South America do contain stemmetatherians (and eutherians; references in Eldridge et al., 2019). If Glasbius is not a marsupial, it can be stated with great confidence that Marsupialia originated in South America (Eldridge et al., 2019, and references therein); if Glasbius is a marsupial, North America becomes the obvious candidate, and at least two clades of marsupials most likely survived the Cretaceous and immigrated into South America separately. In that case, it is noteworthy that Glasbius is the only possible marsupial out of the remarkable diversity of Maastrichtian, Campanian and in some cases yet earlier metatherians known from North America and to a lesser degree central Asia. Rather than the beginning of the Maastrichtian, I propose the beginning of deposition of the Lance and Hell Creek formations, where Glasbius has been found, as the hard maximum age for this calibration, which I estimate as $68 \mathrm{Ma}$.

\subsubsection{Node 160: Batrachia (Urodela - Salientia)}

The origin of Batrachia by the divergence of the sister-groups Urodela (the salamander total group now that Caudata $[\mathrm{PN}]$ is the crown group) and Salientia (the frog total group) was assigned a minimum age of $249 \mathrm{Ma}$ and no maximum age. This was, as usual, done on the basis of Triadobatrachus, one of the two oldest known salientians (the other is Czatkobatrachus, which is probably early Olenëkian in age: Evans and Borsuk-Białynicka, 2009); all known definitive urodeles are considerably younger (Schoch et al., 2020). Irisarri et al. (2017) only cited the classic redescription of Triadobatrachus from 1989 for this age; more recent stratigraphic work has been reviewed by Ascarrunz et al. (2016: 206-207) and places Triadobatrachus either in the late Induan or the very beginning of the Olenëkian. Unfortunately, the precise age of the Induan-Olenëkian boundary remains unclear; the ICS, indirectly citing a source from 2007, places it at 251.2 Ma without explicit error margins, while Maron et al. (2018) placed it at " 249.7 Ma" based on cyclostratigraphic counting away from the Permian-Triassic boundary, which is exceptionally precisely dated radiometrically. I conclude that $249 \mathrm{Ma}$ is a perfectly adequate minimum age for this calibration point.

For a maximum age, I reiterate the suggestion of Marjanović and Laurin (2013b) to use the beginning of Carroll's Gap (see Marjanović and Laurin, 2013a), i.e. the Early Permian record, which has yielded many tetrapods ecologically comparable to batrachians, but no batrachians, gymnophionomorphs or albanerpetids so far (e.g. Schoch and Milner, 2014; Glienke, 2015). The abovementioned particularly rich site of Richards Spur, where small terrestrial and possibly amphibious temnospondyls particularly similar to batrachians are very common, is $289 \pm 0.68 \mathrm{Ma}$ old (Woodhead et al., 2010), so that 290 Ma may be a defensible soft maximum value. (The value of 275 Ma suggested by Marjanović and Laurin, 2007 and 2013b, is outdated.)

\subsubsection{Node 169: crown group of Cryptobranchoidea (Hynobiidae - Pancryptobrancha)}

The divergence between the salamander clades Pancryptobrancha (the smallest total group containing the crown group Cryptobranchidae: Vasilyan et al., 2013) and Hynobiidae was assigned a minimum age of 145.5 Ma and no maximum age.

The minimum age, intended to correspond to the Jurassic/Cretaceous boundary ( 145.0 Ma ago: ICS), constitutes a snapshot in the convoluted history of dating the Jurassic and Cretaceous 
1203 Konservat-Lagerstätten of northeastern China. (Another such snapshot, likewise outdated, is the 1204 Valanginian age of 139.4 Ma suggested for this node by Marjanović and Laurin, 2007.) None of these sites are now considered Kimmeridgian through Valanginian in age. The oldest ones that have yielded purported caudates [PN] (references in Skutschas, 2015, beginning with Gao and Shubin, 2003, the reference cited for this calibration by Irisarri et al., 2017) belong to the Daohugou Beds, which correlate with the Haifanggou Fm and are Callovian (late Middle Jurassic) or earliest Oxfordian (Late Jurassic) in age (Gao and Shubin, 2012; Jiang et al., 2015; Liang et al., 2019; and references therein), not Bathonian as often claimed in older literature. These lithostratigraphic units immediately underlie the abovementioned (see node 151) Lanqi and Tiaojishan formations, which have - including in the abovementioned Daxishan or Daxigou site - likewise yielded purported caudates (Gao and Shubin, 2012; Jia and Gao, 2016, 2019), and the phylogenetic analysis by Jia and Gao (2019) found the former on the hynobiid stem and the latter as a stem-pancryptobranchan.

1215 Two Bathonian sites with supposed crown-group salamanders do exist. One (Kirtlington, UK; Forest 1216 Marble Fm) has yielded at least one undescribed vertebra called "Kirtlington salamander B". The 1217 other (Berezovsk, Russia; Itat Fm) has yielded Kiyatriton krasnolutskii Skutschas, 2015; while the association of the isolated bones from different body parts with each other is rather daring, the holotype of this species (like the holotype of the much younger type species, another isolated atlantal centrum) does preserve a clear synapomorphy with Caudata and three similarities to Cryptobranchoidea (Skutschas, 2014, 2015). Both sites have also yielded isolated femora that show one potential synapomorphy with Hynobiidae (Skutschas, 2014, 2015). Potentially, then, $K$. krasnolutskii could be the oldest known crown-cryptobranchoid and necessitate a minimum age of about $169 \mathrm{Ma}$ (ICS) for this node. Unfortunately, no bone referred to Kiyatriton has yet been included in a phylogenetic analysis, and that is not likely to happen soon: the two existing morphological datasets for analysis of salamander phylogeny (latest published versions: Wiens et al., 2005; Jia and Gao, 2019) are very light on atlas characters, which moreover are mostly not accessible in the Chinese Mesozoic specimens (complete, articulated, flattened skeletons with soft-tissue outlines and melanosomes) and not well understood in extant salamanders - like the rest of the skeleton in general and the postcranial skeleton in particular, which neontologists have by and large ignored in favor of molecular, behavioral and soft-tissue characters (see Marjanović and Witzmann,

1232 2015, for some drastic examples).

1233 The latest published phylogenetic analysis of Mesozoic salamanders is that by Jia and Gao (2019). Like the morphological subset of Wiens et al. (2005), it produces a clear example of what Wiens et al. (2005: title) called "[o]ntogeny discombobulates phylogeny": a clade composed of the extant neotenic non-cryptobranchoid salamander clades, i.e. (Amphiumidae (Sirenidae, Proteidae)), as the sister-group of the metamorphic ones. Indeed, its character sample is full of characters that translate straightforwardly to presence vs. absence of a complete metamorphosis (or of a strictly aquatic lifestyle). Instead, molecular data (e.g. Wiens et al., 2005; Irisarri et al., 2017; Vijayakumar et al., 2019: supplementary file Amphibia_New_India_SHL_Dryad.tre; Hime et al., 2020; and references therein) have consistently shown that Sirenidae lies outside the smallest clade formed by all other extant non-cryptobranchoid salamanders (Salamandroidea), as had long been presumed based on other considerations like the retention of external fertilization in sirenids (Reinhard et al., 2013). Likewise, Amphiumidae and Plethodontidae are consistently sister-groups in phylogenetic analyses of molecular data, rather than Amphiumidae being close to Proteidae or Sirenidae, or Plethodontidae being close to Salamandridae (e.g. Rong, 2018) or Ambystoma (e.g. Jia and Gao, 2019). This may be particularly relevant because all of the Chinese Mesozoic salamanders are either only known from larval or neotenic individuals (e.g. Chunerpeton: Gao and Shubin, 2003), or are metamorphic but aquatic (Pangerpeton: Wang and Evans, 2006), or combine features expected of different ontogenetic stages (perhaps indicating a less condensed metamorphosis than in extant metamorphic salamanders: 
Linglongtriton [Jia and Gao, 2019]; also, though found outside Cryptobranchoidea, Beiyanerpeton: Gao and Shubin, 2012), or are metamorphic and apparently terrestrial but have not been sufficiently described to be included in a phylogenetic analysis (Laccotriton). All known possible pancryptobranchans except the terminal Paleocene stem-pancryptobranchan Aviturus (Vasilyan and Böhme, 2012; Vasilyan et al., 2013) have been neotenic or undergone only partial metamorphosis (the extant Andrias loses the gills, the gill slits and the coronoid bone, but does not rebuild the palate or grow eyelids); this may attract stem-cryptobranchoids or even some of the more crownward stemurodeles toward them, even if some (Rong, 2018) or most (Jia and Gao, 2019) end up in the hynobiid total group rather than in Pancryptobrancha. Unfortunately, no published phylogenetic analysis has ever included extinct Cenozoic pancryptobranchans together with any Mesozoic salamanders; the overlap between the taxon samples of Vasilyan et al. (2013) and Pearson (2016) or Jia and Gao (2019), as well as all references in all three, is restricted to extant species.

I should point out that plesiomorphies unexpected in caudates have been found in some of the Chinese Mesozoic taxa. For example, as pointed out by Marjanović and Laurin (2019: appendix S1: 76), free palatines occur in Chunerpeton (Wang et al., 2015; illustrated in Gao and Shubin, 2003, though not indicated or mentioned in the text), Beiyanerpeton (Gao and Shubin, 2012) and Qinglongtriton (Jia and Gao, 2016).

1268 It does not help that the known fossil record of possible hynobiids outside of the mentioned Lagerstätten only begins in the late Miocene and consists entirely of isolated bones (reviewed by Jia and Gao, 2016: 44-45). One possible exception is the metamorphic Iridotriton, known from a partial but well preserved skeleton from the early Tithonian (Galli et al., 2018; Maidment and Muxworthy, 2019) Brushy Basin Member of the Morrison Fm (Rainbow Park Microsite, Utah), originally argued to be a non-cryptobranchoid caudate (Evans et al., 2005), more recently found on the hynobiid stem (Jia and Gao, 2019: fig. S6) or in an incompletely resolved position outside the cryptobranchoid crown-group (Pearson, 2016: fig. 4.11), and equipped with a confusing combination of characters (Evans et al., 2005).

Mesozoic pancryptobranchans seem to be represented by a large number of isolated bones from the early Cenomanian through early Campanian of Kazakhstan, Uzbekistan and Tajikistan (Skutschas, 2013) usually grouped as Eoscapherpeton and Horezmia (but considered two species of Eoscapherpeton by Skutschas, 2013). Unfortunately, they have never been included in a phylogenetic analysis outside of Pearson's (2016) doctoral thesis, but the arguments by Skutschas (2013) for referring at least some of the nonoverlapping material to Pancryptobrancha are not easily dismissed. In a Bayesian analysis of a matrix of morphological data containing extant lissamphibians, the Permian temnospondyls Doleserpeton and Gerobatrachus, the stem-salientian Triadobatrachus, Eoscapherpeton and number of Cretaceous and Cenozoic scapherpetids but no other caudates, Pearson (2016: fig. 4.2) recovered Eoscapherpeton as a stem-pancryptobranchan, though with a posterior probability of only 52\%; adding further Mesozoic salamanders led to the breakdown of this resolution (Pearson, 2016: fig. 4.12).

The oldest wholly undoubted pancryptobranchan is "Cryptobranchus" saskatchewanensis, which has been included in the phylogenetic analysis of Vasilyan et al. (2013). It comes from an exposure of the same Ravenscrag Fm that is mentioned under Node 155, but widely separated in space and age from the one mentioned there: in terms of North American Land Mammal Ages, the site with the oldest " $C$." saskatchewanensis specimens - including the holotype - is Tiffanian-4 in age, thus between 59 and $60 \mathrm{Ma}$ (Krause, 1978; Naylor, 1981; Wang et al., 2016: fig. 2). The material consists of isolated dentary fragments (like the holotype), maxilla fragments and an exoccipital referred by size alone; they all seem to be within the morphological range of known (Cenozoic) pancryptobranchans, but not more convincing than the similarly fragmentary Eoscapherpeton. 
I therefore use the beginning of the Cenomanian (100.5 Ma ago, given without uncertainty in the ICS), rounded to $101 \mathrm{Ma}$ ago, as the minimum age of this calibration for present purposes. Given the great uncertainty, I generally recommend against using this divergence as a calibration.

1301 (My previous suggestion - Marjanović, 2019 - to use this age as a soft minimum was incoherent, as a 1302 reviewer pointed out. A soft minimum would imply that a tail of the probability distribution of the age of this node would extend to younger ages than $101 \mathrm{Ma}$, so that an age of $100 \mathrm{Ma}$ would be treated as much more probable than an age of, say, $61 \mathrm{Ma}$. The opposite is the case: both 101 and 60 are much more probable than 100, which is younger than one potential minimum age but far older than the other. If Eoscapherpeton is a crown-group cryptobranchoid, so that $101 \mathrm{Ma}$ is "the correct" minimum age, 100 is impossible; if it is not a crown-group cryptobranchoid, so that 60 is "correct", 100 is so much older as to be much less probable than, say, 65.)

It is interesting in this respect that calibrating this node with an age around 139.4 Ma (Marjanović and Laurin, 2007) leads to far too high ages for cladogeneses within Hynobiidae and within Cryptobranchidae, even within Andrias japonicus judging by paleogeographic criteria (Matsui et al., 2008).

1313 Like Irisarri et al. (2017), I cannot assign a maximum age other than that of Node 160. The oldest known stem-salamanders, except for the Middle or Late Triassic Triassurus (Schoch et al., 2020), are exemplifies Carroll's Gap (Marjanović and Laurin, 2013a).

\subsubsection{Node 170: Lalagobatrachia/Bombinanura (total group of Bombinatoroidea/Costata - total group of Pipanura); Node 171: Pipanura (total group of Pipoidea/Xenoanura - total group of Acosmanura)}

The last common ancestor of Bombinatoroidea or Costata, represented by Bombina and

Discoglossus, and Pipanura, to which all other sampled frogs belong, was assigned a minimum age of

161.2 Ma (Oxfordian, Late Jurassic) and no maximum age. Pipanura itself was assigned a minimum age of $145.5 \mathrm{Ma}$ (end-Jurassic) and no maximum age.

Following the finding that Eodiscoglossus, to which a Bathonian (Middle Jurassic) species has been referred that forms the basis for the original minimum age, is probably not a costatan (Báez, 2013; Báez and Gómez, 2016, 2019), the oldest purported lalagobatrachian/bombinanuran is the poorly known Enneabatrachus from a site dated to $152.51 \pm 0.47 \mathrm{Ma}$ (Trujillo et al., 2015), which has never been included in a phylogenetic analysis. Given, however, the presence of the pipanuran (rhinophrynid or stem-xenoanuran: Henrici, 1998; Gómez, 2016; Aranciaga Rolando et al., 2019) Rhadinosteus at the same site as Iridotriton (the Rainbow Park Microsite, see node 169) and as further specimens of Enneabatrachus, a minimum age of 153 Ma for Pipanura (and Bombinanura by implication), coinciding with the maximum age of the Kimmeridgian/Tithonian boundary (152.1 \pm $0.9 \mathrm{Ma}$ : ICS) and constituting a minimal revision of the age proposed by Marjanović and Laurin (2013b), appears safe.

1335 Enneabatrachus, if not Rhadinosteus, is at present the oldest securely identified anuran (crown-group salientian). Remarkably, no salientians at all have so far been reported from the Yanliao Biota (Haifanggou, Lanqi, Tiaojishan and maybe other formations of Callovian to Oxfordian age in northeastern China), despite its wealth of salamanders (see node 169). The stem-salientian record is sparse (Marjanović and Laurin, 2013b; Stocker et al., 2019); the suggestion of a maximum age for Bombinanura of 170 to 185 Ma by Marjanović and Laurin (2013b) is based on the fairly good stratigraphic fit of stem-salientian phylogeny (Marjanović and Laurin, 2007, 2013a: fig. 5, 2013b; Stocker et al., 2019; and references therein), but given its poor geographic coverage, I prefer to 
1343 follow Irisarri et al. (2017) in not assigning a maximum age other than that of node 160 for present 1344 purposes.

1345 Thus, node 170 cannot currently be calibrated on its own: its minimum age is that of node 171 , its 1346 maximum age is that of node 160.

\section{2.2.25 Node 178: Pipidae (Pipinomorpha - Xenopodinomorpha)}

1348 The origin of Pipidae (the crown group of Pipimorpha) by the divergence of Pipinomorpha (crown group: Pipinae) and Xenopodinomorpha (crown group: Xenopodinae = Xenopus sensu lato) was given a minimum age of $86 \mathrm{Ma}$ (Coniacian/Santonian boundary, Late Cretaceous) and no maximum age.

1352 This cladogenesis is particularly difficult to date from the fossil record because molecular data support Hymenochirini as a member of Xenopodinomorpha, though less strongly than most other parts of the tree (Cannatella, 2015: fig. 1, with a bootstrap support of $71 \%$ while other branches have $74 \%, 93 \%$ or $100 \%$, and with a Bayesian posterior probability of $99 \%$ while three others have $100 \%$; Irisarri et al., 2017, with a jackknife support of 98\% instead of the usual 100\%; Vijayakumar et al., 2019: supplementary file Amphibia_New_India_SHL_Dryad.tre, with a Shimodaira/Hasegawa-like approximate likelihood ratio of $91 \%$ instead of the usual 100\%; Hime et al., 2020: supp. fig. 4, with a bootstrap support of $100 \%$ but a local posterior measure of branch support of only $50.77 \%$ instead of the usual $80 \%-100 \%$ ), while morphological data have so far only supported Hymenochirini as a member of Pipinomorpha (with a Bayesian posterior probability of 100\% in Cannatella, 2015). The only phylogenetic analysis of combined data from pipimorphs yet undertaken (Cannatella, 2015: analysis E1) found almost equal support for both possibilities (bootstrap support of $46 \%$ vs. $44 \%$; Bayesian posterior probabilities below 50\%), and the winning-sites test could not distinguish between them ( $\mathrm{p}=1.0$ : Cannatella, 2015: table 3), although tip-dating with three node calibrations strongly supported the hymenochirins as pipinomorphs at the cost of losing a terminal taxon (Pachycentrata, see below; Cannatella, 2015: analysis E6). Using considerably updated and expanded versions of the morphological dataset Cannatella (2015) had used, Gómez (2016), de Souza Carvalho et al. (2019) and Aranciaga Rolando et al. (2019) all found the Cenomanian Oumtkoutia (not included by Cannatella, 2015) to be the oldest known pipid; the Cenomanian ended 93.9 Ma ago (ICS, no error margin given). However, while the first of these three phylogenetic analyses found it as a stem-xenopodinomorph, the other two - whose matrices are almost identical to each other, and derived from that of the first with rather few changes - found it as a stem-pipinomorph, and the third cautioned that it may well be a stem-pipimorph because, although Rage and Dutheil (2008) described the material in great detail, it consists entirely of isolated braincases, vertebrae and pelves, and there is some character conflict as Oumtkoutia combines a pipinomorph autapomorphy with stem-pipimorph plesiomorphies. The next younger pipid remains Pachycentrata of end-Coniacian or Santonian age, found as a stem-hymenochirinomorph by Gómez (2016) but as a stem-pipinomorph by de Souza Carvalho et al. (2019) and Aranciaga Rolando et al. (2019); while the Coniacian ended 86.3 $\pm 0.5 \mathrm{Ma}$ ago, the Santonian ended only 83.6 $\pm 0.2 \mathrm{Ma}$ ago (ICS). further the facts that all known pipomorphs are strictly aquatic and that lissamphibians in general tend to tolerate saltwater poorly, it is tempting to assume that this distribution is due to vicariance and the cladogenesis that separated Pipa and the hymenochirins should be dated to the loss of contact between Outer Gondwana (including South America) and Afro-Arabia around the Cenomanian - in other words, a geological event should be used to calibrate this divergence date. If Pachycentrata is a stem-hymenochirinomorph, as found by Gómez (2016), this scenario fits the phylogeny beautifully, 
and neither any overseas dispersal nor any long ghost lineages need to be assumed, as Gómez (2016) pointed out. Contrariwise, if Pachycentrata is a stem-pipinomorph, as found by de Souza Carvalho et al. (2019) and Aranciaga Rolando et al. (2019), the fossil record offers no reason to date the origin of Pipinae to the Mesozoic, and the most parsimonious hypothesis becomes that Pipa dispersed from Africa to South America together with the platyrrhine monkeys and the caviomorph rodents, perhaps on the same natural raft; de Souza Carvalho et al. (2019: 228) have discussed the possibility of a Paleogene island chain or even landbridge on the Walvis Ridge and the Rio Grande Rise at some length.

1397 On the phylogenies by de Souza Carvalho et al. (2019) and Aranciaga Rolando et al. (2019), the 1398 xenopodinomorph fossil record begins only in the late Oligocene (briefly reviewed in Blackburn et al., 2019; see also Gardner and Rage, 2016: 184) rather than the Cenomanian (Gómez, 2016).

As mentioned, the only combined dataset yet brought to bear on this question (Cannatella, 2015: dataset $\mathrm{E}$ ), which is also the only dataset containing extinct taxa that supports the hymenochirins as pipinomorphs, is based on a superseded morphological dataset that lacked Oumtkoutia and Pachycentrata, not to mention any taxa described since 2007. Given this and the discussion in the preceding paragraphs, it remains unclear whether Oumtkoutia is a pipid, and so I can only suggest 84 $\mathrm{Ma}$ as a safe minimum age for Pipidae.

1406 Any maximum age will have to accommodate the undescribed possible pipid from the Aptian or Barremian of Cameroon (Gardner and Rage, 2016: 177, 179). However, the only maximum age I feel able to propose is much older: the end of deposition of the lake sediments of the Newark Supergroup (Tanner and Lucas, 2015) sometime around the Hettangian/Sinemurian boundary (199.3 $\pm 0.3 \mathrm{Ma}$ ago: ICS). All known pipimorphs, extant or extinct, have been fully aquatic (reviewed in Cannatella, 2015). The upper formations of the Newark Supergroup, which represent the rift lakes that preceded the opening of the Central Atlantic Ocean between Africa and North America, have yielded whole species flocks of semionotid actinopterygians among other parts of a lake fauna and flora (Olsen, 1988, 2010), and they cover so much space and time that if any aquatic salientians existed in northwestern Pangea during that time, we should expect to have found them - yet, salientians are consistently absent from these sediments (Olsen, 1988). The absence of salamanders (Olsen, 1988) may be explained by geography in that that group may have originated in Asia or at least northeastern Pangea (where indeed the Middle or Late Triassic Triassurus was found: Schoch et al., 2020). All other Barremian or earlier xenoanurans, however, have so far been found on the Iberian microcontinent or in North America, and the stratigraphic fit of their phylogeny (Gómez, 2016; Aranciaga Rolando et al., 2019) is good enough that if pipids older than Oumtkoutia existed, northwestern Pangea is where we should look for them. I therefore propose $199 \mathrm{Ma}$ as the hard

1423 maximum age for this calibration.

1424 It may be significant that anurans have not so far been found in the lacustrine Bathonian sediments ( $\sim 167 \mathrm{Ma}$ old) of the Anoual Fm in Morocco (Haddoumi et al., 2015).

\subsubsection{Node 187: crown group of Chondrichthyes (Holocephali - Elasmobranchii)}

The origin of the chondrichthyan crown group was given a minimum age of $410 \mathrm{Ma}$ Cambrian). Note that the maximum age was not operational because the root node was given a younger maximum age of $462.5 \mathrm{Ma}$.

1431 By current understanding (Frey et al., 2019), the oldest known crown-chondrichthyan is the stem1432 elasmobranch Phoebodus fastigatus from the middle Givetian. The Givetian, part of the Middle 
1433 Devonian, began 387.7 \pm 0.8 Ma ago and ended 382.7 \pm 1.6 Ma ago (ICS), so I propose $385 \mathrm{Ma}$ as

1434 the minimum age of the chondrichthyan crown-group.

1435 Although I cannot assign a maximum age separate from that of the root node (node 100) to this 1436 calibration, no less than ninety million years before the minimum age, I note that this is still twenty 1437 million years after the 495 Ma assigned, futilely, by Irisarri et al. (2017).

\section{$1438 \quad$ 2.2.27 Node 188: crown group of Elasmobranchii (Selachimorpha - Batomorpha)}

1439 The origin of the elasmobranch crown group by split into Selachimorpha (sharks) and Batomorpha 1440 (rays and skates) was given a minimum age of $190 \mathrm{Ma}$ (Sinemurian/Pliensbachian boundary, Early Jurassic) and no maximum age. (Note that the name Neoselachii is consistently treated in the paleontological literature as if defined by one or more apomorphies, not by tree topology; it probably applies to a clade somewhat larger, and possibly much older, than its crown group.)

1444 Any attempt to date this cladogenesis suffers from the fact that the elasmobranch fossil record consists mostly of 'the tooth, the whole tooth and nothing but the tooth' (as has often been said about the Mesozoic mammalian fossil record); scales and the occasional fin spine do occur, but more substantial remains are very rare. The shape of tooth crowns is naturally prone to homoplasy, the number of phylogenetically informative characters it offers is easily overestimated due to correlations between them (e.g. Kangas et al., 2004; Harjunmaa et al., 2014; Celik and Phillips, 2020; see node 157), and histological studies, which are needed to determine the states of certain characters (e.g. Andreev and Cuny, 2012; Cuny et al., 2017), have not been carried out on all potentially interesting 1452 tooth taxa.

Consequently, there is not as much interest in phylogeny among specialists of early elasmobranchs than among specialists of early mammals or early dinosaurs. This goes so far as to affect the use of terminology: Andreev and Cuny (2012) mentioned "stem selachimorphs" in the title of their work, implying that they understood Selachimorpha as a clade name, but quietly revealed it to be the name of a paraphyletic assemblage on p. 263 by stating that bundled enameloid is "diagnostic for Neoselachii exclusive of batomorphs, i.e., Selachimorpha", and their consistent referral of Synechodontiformes (see below) to "Selachimorpha" is not necessarily a referral to the crown group - even though they called bato- and selachomorphs sister-groups in the next sentence.

A safe minimum age of $201 \mathrm{Ma}$, used here, is provided by the oldest unambiguous crown-group selachimorph, the total-group galeomorph Agaleus, dating from the Hettangian, apparently close to its beginning (Stumpf and Kriwet, 2019, especially fig. 5, and references therein), which was the beginning of the Jurassic and happened 201.3 \pm 0.2 Ma ago (ICS); I round this down (stratigraphically up) to avoid breaching the mass extinction event at the Triassic/Jurassic boundary. The oldest batoid batomorph is only sightly younger, see node 192 below. However, this may err very far on the side of caution. Indeed, for purposes beyond the present work, I must recommend against using the minimum age of this divergence to calibrate a timetree for at least as long as the histology of Paleozoic "shark" teeth has not been studied in much more detail in a phylogenetic context. As if by typographic error, the oldest widely accepted crown-group elasmobranch is not 190 but about 290 Ma old: the oldest fossils referred to the neoselachian Synechodus are four teeth of Sakmarian age (referred to $S$. antiquus, whose type tooth comes from the following Artinskian age: Ivanov, 2005; Stumpf and Kriwet, 2019), and the Sakmarian ended $290.1 \pm 0.26 \mathrm{Ma}$ ago (ICS). Teeth referred to other species of Synechodus range into the Paleocene; 
“[t]he first proven selachimorph". Rounding up, this would suggest suggest $291 \mathrm{Ma}$ as the minimum age of this calibration.

1479 (My previous suggestion - Marjanović, 2019 - to use that age as a soft minimum was incoherent, as a reviewer pointed out. A soft minimum would imply that a tail of the probability distribution of the age of this node would extend to younger ages than $291 \mathrm{Ma}$, so that an age of $290 \mathrm{Ma}$ would be treated as much more probable than an age of $201 \mathrm{Ma}$. The opposite is the case: both 291 and 202 are much more probable than 290, which is younger than one potential minimum age but far older than the other. If Synechodus antiquus is a crown-group elasmobranch, so that $291 \mathrm{Ma}$ is "the correct" minimum age, 290 is impossible; if it is not a crown-group elasmobranch, so that 201 is "correct", 290 is so much older as to be much less probable than, say, 205 or 210.)

1487 Potential crown-group elasmobranchs older than $291 \mathrm{Ma}$ are known: Andreev and Cuny (2012) and Cuny et al. (2017: 69) suggested that the tooth taxa Cooleyella and Ginteria could be stembatomorphs. The oldest known Cooleyella specimen dates from around the end of the Tournaisian (Richards et al., 2018), which occurred 346.7 $\pm 0.4 \mathrm{Ma}$ ago (ICS); Ginteria appeared in the following Viséan stage. Cuny et al. (2017: 21, 69) further pointed out that Mcmurdodus, a tooth taxon that first appeared around the Early/Middle Devonian (Emsian/Eifelian) boundary (Burrow et al., 2008), has occasionally been placed within Selachimorpha, even within Hexanchiformes in the selachimorph crown-group (Burrow et al., 2008, and references therein); they very tentatively suggested a stemselachimorph position. Boisvert et al. (2019) wondered instead if it is a stem-chondrichthyan.

The absence of any however tentative suggestions of crown-elasmobranchs before Mcmurdodus in the rather rich total-group chondrichthyan microfossil record despite the traditional optimism of paleodontologists may, somewhat ironically, serve as a hard maximum age for this calibration; the ICS places the Emsian/Eifelian boundary at 393.3 $\pm 1.2 \mathrm{Ma}$ ago, so I suggest $395 \mathrm{Ma}$.

\subsubsection{Node 192: Batoidea (skates - rays)}

The origin of the batomorph crown group, Batoidea, by split into skates (Rajiformes; represented by Raja and Leucoraja) and rays (taxonomically unnamed; represented by Neotrygon) was assigned a minimum age of $176 \mathrm{Ma}$ (Toarcian, Early Jurassic) and no maximum age.

1504 The oldest known batoid is a single rajiform tooth named Antiquaobatis from the late Pliensbachian, specifically the apyrenum subzone of the spinatum ammonite zone (Stumpf and Kriwet, 2019), which is close to the end of the Pliensbachian (Fraguas et al., 2018); that end occurred $182.7 \pm 0.7$ Ma ago (ICS), so I propose $184 \mathrm{Ma}$ as the minimum age for this calibration. (The name should of

1509 As a hard maximum age, the Triassic/Jurassic boundary (201.3 \pm 0.2 Ma ago: ICS; rounded to 201 $1510 \mathrm{Ma})$ suggests itself for ecological reasons: plesiomorphically, crown-group rays are fairly large 1511 marine durophages, a guild formed by the placodont amniotes in the well sampled Middle and Late 1512 Triassic.

\section{2.2.29 Node 195: Neopterygii [PN] (Holosteomorpha - Pan-Teleostei [PN])}

1514 The origin of Neopterygii by cladogenesis into the total groups of Holostei (bowfins - Amia - and gars, represented by Lepisosteus) and Teleostei [PN] (represented by the clupeocephalans Takifugu and Danio) was given a minimum age of $345 \mathrm{Ma}$ and a maximum age of $392 \mathrm{Ma}$.

1517 At present, there are only two candidates for Paleozoic neopterygians. One is Acentrophorus, "a

1518 'semionotid'-like taxon that desperately requires restudy and formal analysis" (Friedman, 2015: 222; 1519 cited as current by $\mathrm{Xu}, 2019$; also Sun et al., 2016) of Wujiapingian age (between 254.14 $\pm 0.07 \mathrm{Ma}$ 
and 259.1 $\pm 0.5 \mathrm{Ma}$ : ICS). The "semionotids" are stem-members of Ginglymodi, i.e. closer to Lepisosteus than to Amia (Giles et al., 2017: ext. data fig. 6-8; López-Arbarello and Sferco, 2018; $\mathrm{Xu}, 2019)$, but a generic "semionotid'-like taxon" could easily lie outside Neopterygii. In their indepth study of neopterygian phylogeny, López-Arbarello and Sferco (2018) did not include

1524 Acentrophorus or even mention it in the text.

Sun et al. (2016) cited Archaeolepidotus, supposedly closely related to Watsonulus (see below), together with undescribed specimens as a Changxingian neopterygian (which was originally thought to be Early Triassic, but probably is not according to references in Ronchi et al., 2018). The Changxingian is the stage between the Wujiapingian and the Permian/Triassic boundary (251.902 \pm 0.024 Ma ago: ICS). Archaeolepidotus does not appear to be well understood; Friedman (2015), Giles et al. (2017), López-Arbarello and Sferco (2018) and Xu (2019) did not mention it, let alone include it in a phylogenetic analysis, and Google Scholar only finds 17 occurrences in the entire literature.

The oldest certain member of Neopterygii is Watsonulus, a stem-halecomorph or stemholosteomorph (Friedman, 2015; Giles et al., 2017: ext. data fig. 6-8; López-Arbarello and Sferco, 2018; Xu, 2019) which comes from the Middle Sakamena Group of Madagascar (López-Arbarello and Sferco, 2018) just like Triadobatrachus (see node 160) and should therefore be around $249 \mathrm{Ma}$ old. I therefore propose $249 \mathrm{Ma}$ as the minimum age of Neopterygii.

Assuming from the almost phylogeny-free quantification of the Permo-Triassic fossil record of osteichthyans by Romano et al. (2014b) that at least the Asselian record of pan-actinopterygians [PN] is reasonably good, I suggest a soft maximum age for Neopterygii immediately before it, i.e. at the Carboniferous/Permian boundary (298.9 \pm 0.15 Ma: ICS), rounded to $299 \mathrm{Ma}$, which conveniently places it $50 \mathrm{Ma}$ before the minimum age.

\section{$1543 \quad 2.3 \quad$ Analysis methods}

1544 Johan Renaudie (Museum für Naturkunde, Berlin) kindly performed the divergence dating using the tree (topology and uncalibrated branch lengths), the model of evolution (CAT-GTR $+\Gamma$ ) and clock model (lognormal autocorrelated relaxed) inferred by Irisarri et al. (2017) and the data ("nuclear test data set": the variable sites of the 14,352 most complete amino acid positions of their "NoDP" dataset), but the calibrations presented above (all at once, not different subsets).

The intent was to also use the software Irisarri et al. (2017) had used (PhyloBayes, though the latest version, 4.1c: Lartillot, 2015). However, PhyloBayes is unable to treat some bounds as hard and others as soft in the same analysis; it can only treat all as soft, as Irisarri et al. (2017) had done, or all as hard. Consequently, we ran one analysis in PhyloBayes with all bounds treated as hard in order to account for the hard minima (discussed above: Materials and methods: Hard and soft minima and maxima), and a second analysis in another program.

Above I describe phylogenetic uncertainty leading to two different minimum ages for Tetrapoda (node 105), $335 \mathrm{Ma}$ and "roughly" $350 \mathrm{Ma}$. Even when all bounds were treated as soft in the first preprint of this work (Marjanović, 2019) and the younger age was used for this node, its inferred $95 \%$ confidence interval had a younger bound of $346 \mathrm{Ma}$ and an older bound of 366 Ma (Marjanović, 1560 minimum age of this node is set to $350 \mathrm{Ma}$.

1561 Having evaluated (in the preceding section) the inherent uncertainty of each calibration before the analyses unlike Irisarri et al. (2017), I did not cross-validate the calibrations. In the words of Pardo et al. (2020), "a priori assessment of the quality of a priori node calibrations must retain logical 
1564 primacy in assessing the quality of a molecular clock". Any 'inconsistencies' between the

1565 calibrations, 'reductio ad absurdum' cases aside (e.g. van Tuinen and Hedges, 2004: 46-47;

1566 Waggoner and Collins, 2004; Matsui et al., 2008; Phillips et al., 2009; Ruane et al., 2010), should be

1567 seen as indicating not that the calibrations are wrong, but that the rate of evolution varies

1568 substantially across the tree, as already expected from other considerations (e.g. Berv and Field,

1569 2017).

\section{Results and discussion}

\section{$1571 \quad 3.1 \quad$ Bibliometry}

1572 Irisarri et al. (2017: supp. table 8) cited 15 works as sources for their calibrations, six of them

1573 compilations made by paleontologists to help molecular biologists calibrate timetrees.

1574 Not counting Irisarri et al. (2017) and the ICS (which has been updated at least once a year since

1575 2008), I cite 231 references to discuss minimum ages (mostly for the age or phylogenetic position of

1576 a potentially calibrating specimen), 24 to discuss maximum ages (mostly to argue if observed

1577 absence of a clade is reliable), and 15 for both purposes. Of the total of 270, one each dates to 1964,

$15781978,1981,1988$ and 1991, 2 each to 1994,1995 and 1996, 1 each to 1997 and 1998, 3 to 1999,1 to 2000, 2 to 2001, 4 to 2002, 1 to 2003, 0 to 2004,7 to 2005, 4 to 2006, 6 each to 2007 and 2008, 4 to

15802009,5 to 2010,8 to 2011,9 to 2012,15 to 2013,12 to 2014,23 to 2015,25 to 2016,22 to 2017,28

1581 to 2018,50 to 2019 and 22 to 2020. (Whenever applicable, these are the years of actual publication,

1582 i.e. public availability of the layouted and proofread work, not the year of intended publication which can be a year earlier, and not the year of print which is very often one or even two years later.) Only three of these are among the 14 used by Irisarri et al. (2017), and none of them are among the six compilations they cited. publications cited here that were published in 2016 (rounded up to 13) came out too late to be used by Irisarri et al. (2017), the total proportion of the works cited here that would have been useful to them for calibrating their timetree but were not available amounts to 134 of 270 , or $49.6 \%$. Similarly, 243 of the works cited here, or $90 \%$, were published since mid-2005. I conclude from this extreme "pull of the recent" that knowledge in this area has an extremely short half-life; calibration dates, therefore, cannot be taken from published compilations (including the present work) or other secondary sources, but must be checked every time anew against the current primary literature. This is time-consuming even in the digital age, much more so than I expected, and requires reading more works for context than actually end up cited (for some nodes three times as many); but there is no shortcut.

\subsection{Changes in the calibration dates}

Of the 30 minimum ages assigned by Irisarri et al. (2017), I find only one to be accurate by the current state of knowledge, that of Batrachia (node 160) anchored by good old Triadobatrachus (see Ascarrunz et al., 2016, for the latest and most thorough redescription and stratigraphy, and Daza et al., 2020, for the latest and largest phylogenetic analysis).

The minimum age of Pleurodira (node 124), which has long been known to be 100 Ma older than Irisarri et al. (2017) set it, turns out to be copied from the calibration of a much smaller clade in Noonan and Chippindale (2006), a secondary source whose minimum age for Pleurodira was actually better by a factor of four. The minimum age of Iguanidae (node 132) turned out to be miscopied, most likely with a typographic error, from Noonan and Chippindale (2006), who had it as $25 \mathrm{Ma}$ 
1607 instead of the 125 Ma of Irisarri et al. (2017) - though $25 \mathrm{Ma}$ is not tenable either, but too young by

1608 at least $28 \mathrm{Ma}$.

1609 In four more cases (Osteichthyes: node 102; Reptilia: node 107; Placentalia: node 152;

1610 Lalagobatrachia/Bombinanura: node 170) I find myself unable to assign any minimum age specific to

1611 that node. In two of these cases (Reptilia and Placentalia) the specimens previously thought to

1612 constrain that node actually constrain a less inclusive clade (Archelosauria, node 108;

1613 Boreo(eu)theria, node 153) that was sampled but not constrained by Irisarri et al. (2017); I have used

1614 these minimum ages to constrain the latter two nodes.

1615 As might be expected, 15 of the minimum ages are too young, by margins ranging from 1.4 Ma to

$1616100 \mathrm{Ma}$ or, ignoring Pleurodira, 43.25 Ma (Table 1: last two columns). Unsurprisingly, this also

1617 holds for the two nodes that Irisarri et al. (2017) did not calibrate but I did. In eight cases, including

1618 Boreo(eu)theria (node 153), the reason is the expected one, the more or less recent discovery of

1619 previously unknown fossils (mostly before 2016); the magnitude of the resulting changes ranges

1620 from 1.4 Ma to $11 \mathrm{Ma}$. In four more cases, including the one used by Irisarri et al. (2017) to date

1621 Osteichthyes (node 102) but by me to date the subsequent split of Dipnomorpha and

1622 Tetrapodomorpha (node 104), the dating of the oldest known specimens has improved by 4 to 16.5

1623 Ma. The specimen used to constrain Tetrapoda (node 105) is probably not a tetrapod, but the oldest

1624 known certain tetrapods are now nonetheless dated as roughly $5 \mathrm{Ma}$ older than the minimum

1625 assigned by Irisarri et al. (2017); depending on the phylogenetic hypothesis, isolated bones or (!)

1626 footprints roughly $20 \mathrm{Ma}$ older that were published in 2015 could represent the oldest tetrapods

1627 instead. The remaining six cases, including Reptilia (node 107) and Archelosauria (node 108) by

1628 implication, are caused by phylogenetic reassignments of previously known specimens (mostly

1629 before 2016) and have effects ranging from 4 Ma to 43.25 Ma.

1630 The minimum ages of the remaining 13 nodes (including, accidentally, Iguanidae) are too old; the

1631 margins vary from $1 \mathrm{Ma}$ to $96 \mathrm{Ma}$. This includes the case of Toxicofera (node 129), whose minimum

1632 age of $148 \mathrm{Ma}$ assigned by Irisarri et al. (2017) was not operational as that node was in fact

1633 constrained by the minimum age of its constituent clade Iguania (node 131), $165 \mathrm{Ma}$; both of these

1634 ages are too old - I find minimum ages of $130 \mathrm{Ma}$ for Toxicofera and $72 \mathrm{Ma}$ for Iguania.

1635 Interestingly, none of the changes to minimum ages are due to more precise dating. There is one case

1636 of the opposite: I have changed the minimum age of Pipidae (node 178) from 86 to 84 Ma because

1637 the oldest known safely identified pipid, Pachycentrata, may be somewhat older than the

1638 Coniacian/Santonian boundary (86.3 $\pm 0.5 \mathrm{Ma}$ ago: ICS), but also somewhat younger, so the

1639 Santonian/Campanian boundary (83.6 $\pm 0.2 \mathrm{Ma}$ ago: ICS) is a safer approximation. All others are due

1640 to more or less recent findings that the oldest supposed members of the clades in question cannot, or

1641 at least cannot be confidently, assigned to these clades.

1642 I agree with the reasoning for one of the maximum ages used by Irisarri et al. (2017), that for 1643 Archosauria (node 109), though its numeric value had to be increased by 1 Ma due to improved 1644 dating of the Permian/Triassic boundary since the source Irisarri et al. (2017) used was published in 16452005.

1646 I find myself unable to assign a separate maximum age to seven of the 18 remaining nodes that 1647 Irisarri et al. (2017) used maximum ages for; these nodes are only constrained by the maximum ages of more inclusive clades in my reanalysis. This includes the case of Chondrichthyes (node 187), whose maximum age of $495 \mathrm{Ma}$ assigned by Irisarri et al. (2017) was not operational as that node was in fact constrained by the maximum age of the root node, $462.5 \mathrm{Ma}$; I can likewise constrain it only by the maximum age of the root, $475 \mathrm{Ma}$. In one of these cases the new implied maximum age 
is younger (by $28.5 \mathrm{Ma}$ ) than the previously explicit maximum; in the remainder it is older by $27 \mathrm{Ma}$ 1653 to $110 \mathrm{Ma}$.

1654 Of the remaining 11 maximum ages, six were too young by $12.5 \mathrm{Ma}$ to $125 \mathrm{Ma}$. In one case (the root: 1655 Gnathostomata, node 100), the old maximum is younger than the new minimum, and in two more 1656 cases (Mammalia and Theria), phylogenetic (or, in the case of Theria, possibly stratigraphic) uncertainty is the reason; the remaining three merely show greater caution on my part in interpreting absence of evidence as evidence of absence.

1659 The remaining five I consider too old by 3.2 Ma to $93 \mathrm{Ma}$; these show greater confidence on my part 1660 in interpreting absence of evidence as evidence of absence in well-sampled parts of the fossil record.

1661 The same holds, naturally, for the six nodes that lacked maximum ages in Irisarri et al. (2017) but 1662 that I propose maximum ages for; one of these new ages, however (for Lepidosauria, node 125), is 1663 older than the previously implied maximum age provided by the next more inclusive clade, and that 1664 by $33 \mathrm{Ma}$. The other five are 60.1 Ma to no less than 261.5 Ma younger than their previously implied 1665 equivalents.

\section{$1666 \quad 3.3$ Changes in the divergence dates}

1667 This is a placeholder description \& discussion based on the results in the previous submission. A few 1668 of the calibrations have changed, and the resulting reanalysis is currently running. The changes are 1669 small enough that I don't expect great changes.

1670 Reanalyzing the data of Irisarri et al. (2017) with their methods, but with the calibration ages proposed and discussed above, generally leads to implausibly old ages and large confidence intervals for the unconstrained nodes: e.g., the last common ancestor of chickens and turkeys (node 115) is placed around the Cretaceous/Paleogene boundary, with a 95\% confidence interval that spans half of each period, and the confidence interval of the bird crown-group (Aves, node 112) spans most of the Jurassic, with a younger bound barely younger than the age of the distant stem-avialan Archaeopteryx (just over $150 \mathrm{Ma}$ ), while the oldest known crown-birds are less than half as old, about $71 \mathrm{Ma}$ (see Materials and methods: Calibrations: Node 113). But there are exceptions. Most notably, the squamate radiation is constrained only between the origin of Lepidosauria (see above under node 125: 244-290 Ma ago) and the origin of Toxicofera (see above under node 129: minimum age 130 $\mathrm{Ma}$ ), yet it is bunched up around the latter date, unlike in Irisarri et al. (2017) where it was more spread out and generally older even though both calibrations were younger. For example, the unconstrained origin of Squamata (node 126) was found to have a mean age of 199 Ma by Irisarri et al. (2017), but 169 Ma here (Table 2). The crucial difference may be that Lepidosauria did not have a maximum age, but this does not explain the very short internodes from Squamata to Iguania in my results. We'll see if changing the minimum age of Toxicofera from $167 \mathrm{Ma}$ to $130 \mathrm{Ma}$ has spread them out again - though if so, most likely in the other direction, towards yet younger ages. I should point out that $169 \mathrm{Ma}$ is the approximate age of the oldest likely squamate remains (reviewed in Panciroli et al., 2020).

In part, this may be due to effects of body size (Berv and Field, 2017) or loosely related factors like generation length: most sampled squamates are small, while the two sampled palaeognath birds are much larger than all sampled neognaths. This may be supported by the body size increase in snakes: their oldest sampled node (Macrostomata or Afrophidia: node 136) as well as the origin of Endoglyptodonta (node 138) are placed in the Early Cretaceous, while even Late Cretaceous caenophidians (a clade containing Endoglyptodonta) remain unknown, all potential Cretaceous totalgroup macrostomates are beset with phylogenetic uncertainty, and considerably younger dates were found by Burbrink et al. (2020) despite the use of a mid-Cretaceous potential macrostomate as a 
minimum-age-only calibration. Similarly, the fact that the entire confidence interval for Supraprimates/Euarchontoglires (node 155) was younger than its calibrated minimum age when all bounds were treated as soft in Marjanović (2019) may be due to the fact that one of the two sampled supraprimates is Homo, the second-largest sampled mammal and the one with the second-longest

\section{1 generation span.}

Whelan and Halanych (2016) found that the CAT-GTR model (at least as implemented in PhyloBayes) is prone to inferring inaccurate branch lengths, especially in large datasets; this may turn out to be another cause of the results described above. The omission of the constant characters from the dataset, intended to speed up calculations (Irisarri et al., 2017), may have exacerbated this problem by leading to inaccurate model parameters (Whelan and Halanych, 2016).

1707

1708

Naturally, the changes to the calibration dates have changed the inferred ages of many calibrated nodes, and the sizes of their confidence intervals. For instance, Irisarri et al. (2017) inferred a mean age of $207 \mathrm{Ma}$ for Batoidea, with a 90-Ma-long 95\% confidence interval that stretched from $172 \mathrm{Ma}$ ago to $262 \mathrm{Ma}$ ago (node 192; Table 2); that node was calibrated with a soft minimum age set to 176 Ma, but not only was no maximum age set, no other node between there and the root node (Gnathostomata, node 100) had a maximum age either, so that effectively the soft maximum age for Batoidea was that of the root node, 462.5 Ma. Following the discovery of new fossils, I have increased the hard minimum age to $184 \mathrm{Ma}$; however, out of ecological considerations, I have also introduced a hard maximum age of $201 \mathrm{Ma}$, younger than the previously inferred mean age.

1717 time between the calibration dates (Table 2).

\section{$1718 \quad 3.4 \quad$ Pitfalls in interpreting the descriptive paleontological literature}

1719 It is widely thought that paleontologists are particularly eager to publish their specimens as the oldest known record of some taxon. Indeed it happens that five different species of different ages are published as the oldest record of the same taxon within ten years. In such cases, finding a specimen that can establish a minimum age for that taxon can be as simple as finding the latest publication that makes such a claim; and that can be as simple as a Google Scholar search restricted to the last few years. But there are harder cases; I will present two. Above (Materials and methods: Calibrations: Node 132 - Iguanidae) I argue for using the age of Kopidosaurus, about 53 million years, as the minimum age of Iguanidae. Kopidosaurus was named and described from a largely complete skull by Scarpetta (2020) in a publication where the words "oldest" and "older" do not occur at all, and "first" and "ancient" only occur in other contexts - even though Scarpetta (2019) had just published on calibration dates for molecular divergence date analyses. The reason may be that he did not think Kopidosaurus was the oldest iguanid; one of the two matrices he used for phylogenetic analyses contained the 56-Ma-old Suzanniwana, and his analyses found it as an iguanid (Scarpetta, 2020: supp. inf.). Moreover, he was most likely aware that the publication that named and described Suzanniwana (Smith, 2009) also named and described Anolbanolis from the same site and age and argued that both of them - known from large numbers of isolated skull bones - were iguanids. Yet, Anolbanolis has never, to the best of my knowledge, been included in any phylogenetic analysis; and Conrad (2015), not mentioning Anolbanolis and not cited by Scarpetta (2020), had found the phylogenetic position of Suzanniwana difficult to resolve in the analysis of a dataset that included a much larger sample of early pan-iguanians. 
1742 Swainiguanoides which had been described as "the oldest North American iguanid" (Sullivan, 1982).

1743

1744

1745

1746

1747

1748

1749

1750

1751

1752

1753

1754

1755

1756

1757

1758

1759

1760

1761

1762

1763

1764

1765

1766

1767

1768

1769

1770

1771

1772

1773

1774

1775

1776

1777

1778

1779

1780

1781

1782

1783

1784

1785

1786

All of that and more was considered too uncertain by DeMar et al. (2017: 4, file S1: 26-28), who pointed out not only how fragmentary that material was (and that some of the Cretaceous specimens more likely belong to certain other squamate clades), but also that the presence of exclusive synapomorphies with Iguanidae (if confirmed) does not mean the specimens are actually inside that crown clade - they could be on its stem. As the "oldest definitive" iguanids, DeMar et al. (2017: 4) accepted Anolbanolis, followed by the uncontroversial Afairiguana which is younger than Kopidosaurus; curiously, they did not mention Suzanniwana at all.

The conclusion that the status of Suzanniwana and Anolbanolis (let alone Swainiguanoides and the like) is too uncertain and that Kopidosaurus, nowhere advertised for that purpose, should be used to set the minimum age for node 132 was accessible to me as an outsider to the fossil record of iguanians (or indeed squamates in general), but it took me several days of searching and reading papers and their supplementary information.

It took me much less effort to find that, under some phylogenetic hypotheses, the oldest known tetrapod (Materials and methods: Calibrations: Node 105 - Tetrapoda) is Casineria, a specimen I have studied in person and published on (Marjanović and Laurin, 2019); yet, the idea had never occurred to me or apparently anyone else in the field, even though its possibility should have been evident since 2017 and even though the phylogenetic hypotheses in question are by no means outlandish - one of them is even majoritarian.

In short, the paleontological literature is not optimized for divergence dating; the questions of which is the oldest known member of a group or when exactly that group evolved often take a back seat to understanding the anatomy, biomechanics, ecology, extinction, phylogeny or generally speaking evolution of that group in the minds of paleontologists - paleobiologists -, and this is reflected in the literature. Mining it for bounds on divergence dates is still possible, as I hope to have shown, but also rather exhausting.

\section{Summary and conclusions}

Irisarri et al. (2017) published the largest vertebrate timetree to date, calibrated with 30 minimum and 19 maximum ages for selected nodes (although one of each was not operational because the calibrations of other nodes set tighter constraints). With just three years of hindsight, only one of these dates stands up to scrutiny. Of the remaining 29 minimum ages, two had to be removed altogether, two had to be moved to previously uncalibrated nodes (with modifications to their numeric values), 15 were $4 \mathrm{Ma}$ to $43 \mathrm{Ma}$ too young, and 13 were $1 \mathrm{Ma}$ to $96 \mathrm{Ma}$ too old. Of the 19 maximum ages, seven had to be canceled altogether, while six were too young by 13 to $125 \mathrm{Ma}$ and five too old by 3 to $93 \mathrm{Ma}$.

One of the minimum ages was taken from the wrong node in the cited secondary source, an earlier divergence-date analysis of molecular data (Noonan and Chippindale, 2006); another from the same source had a hundred million years added without explanation, most likely by typographic error. Only six of the 30 calibrated nodes were calibrated from primary literature. The calibration dates for seven nodes were taken from the compilation by Benton and Donoghue (2007), several from other compendia, four from Noonan and Chippindale (2006) who did not succeed in presenting the contemporary state of knowledge either.

Using software that was only able to treat all bounds as hard or all as soft (meaning that $2.5 \%$ or $5 \%$ of the confidence interval of each inferred node age must extend beyond the bound - younger than the minimum and older than the maximum age, where present), Irisarri et al. (2017) opted to treat all bounds as soft. For all minimum ages except one, this decision is not reproducible; it is even arguable

This is a provisional file, not the final typeset article 
1787 for some of the maxima. This is not a purely theoretical problem; even the inferred mean ages of

1788 some calibrated nodes were younger than their minima in Marjanović (2019).

1789 Redating of the tree of Irisarri et al. (2017) with the presumably improved calibrations results in 1790 many changes to the mean ages of nodes and to the sizes of their confidence intervals; not all of these 1791 changes are easily predictable.

1792 Of the 270 references I have used to improve the calibrations, 50 were published in 2019, half of the 1793 total were published after mid-2016 (when Irisarri et al. seem to have completed the work on their 1794 manuscript), and 90\% were published after mid-2005. Paleontology is a fast-moving field; secondary 1795 sources cannot keep up with the half-life of knowledge. A continually updated online compendium of 1796 calibration dates would be very useful, but the only attempt to create one (Ksepka et al., 2015) is no 1797 longer funded, has not been updated since early 2018, and had limited coverage. For the time being, 1798 each new attempt to calibrate node or tip ages will have to involve finding and studying the recent 1799 paleontological and chronostratigraphic literature on the taxa, strata and sites in question; although 1800 the Internet has made this orders of magnitude easier, it remains labor-intensive, in part because the 1801 the oldest record of a clade is often not published as such, but has to be inferred from comparing 1802 several sources on phylogeny, chronostratigraphy and sometimes taphonomy or even phylogenetics, 1803 as I illustrate here.

1804 I urge that such work will be undertaken and sufficiently funded. Accurate and precise timetrees 1805 remain an essential component of our understanding of, for example, the model organisms that are 1806 used in biomedical research: how much they can tell us about ourselves depends on how much 1807 evolution has happened along both branches since our last common ancestor, and that is in part a 1808 function of time.

\section{Conflict of Interest}

1810 The author declares that the research was conducted in the absence of any commercial or financial 1811 relationships that could be construed as a potential conflict of interest.

\section{Author Contributions}

1813 D. M. designed the experiments, gathered the data, interpreted the results, prepared the figure and the 1814 tables and wrote the paper.

\section{Funding}

1816 I received no funding for this work; indeed I had to interrupt it for a long time for this reason.

\section{Acknowledgments}

1818 Glory to our pirate queen, without whose work this paper would at best have taken a lot longer to 1819 write and at worst would have been severely outdated before submission.

1820 Thanks to Albert Chen and Matteo Belvedere for an electronic reprint that would likely have been 1821 impossible to acquire in a timely manner otherwise; to Johan Renaudie for making me aware of 1822 another; to Olga Karicheva and the editorial office for several deadline extensions; to Jason Silviria 1823 and Paige dePolo for discussion of early eutherians; to the editor, Denis Baurain, for finding five 1824 reviewers; to all five reviewers and the editor for helpful comments; and to the editor and the 1825 editorial office for several more deadline extensions. 
PhyloBayes only runs on Unix systems; Johan Renaudie (Museum für Naturkunde, Berlin) has access to such and kindly performed the time-consuming analyses after expertly overcoming the gaps in the documentation of PhyloBayes.

1829 The first submission of this manuscript was released as a preprint at bioR $\chi$ iv 2019.12.19.882829v1

1830 (Marjanović, 2019). I thank Adam Yates for finding a misused term in the preprint (here corrected), 1831 Ben King for alerting me to his important paper (King, 2019), and Tiago Simões for a partial but 1832 detailed review of the preprint.

\section{References}

1834 Agnolín, F. L., Brissón Egli, F., Chatterjee, S., Garcia Marsà, J. A., Novas, F. E. (2017). Vegaviidae, 1835 a new clade of southern diving birds that survived the K/T boundary. Sci. Nat. 104, 87. doi:

1836 10.1007/s00114-017-1508-y

Ahlberg, P. E., Clack, J. A. (2020). The smallest known Devonian tetrapod shows unexpectedly derived features. R. Soc. Open Sci. 7, 192117. doi: 10.1098/rsos.192117

Alifanov, V. R. (2013). Desertiguana gobiensis gen. et sp. nov., a new lizard (Phrynosomatidae, Iguanomorpha) from the Upper Cretaceous of Mongolia. Paleont. J. 47, 417-424. doi: 10.1134/S0031030113040023

Alifanov, V. R. (2019). Lizards of the families Dorsetisauridae and Xenosauridae (Anguimorpha) from the Aptian-Albian of Mongolia. Paleont. J. 53, 183-193. doi: 10.1134/S0031030119020023

Alifanov, V. R. (2020). A new lizard (Agamidae, Iguania) from the late Paleocene of south Mongolia. Paleont. J. 54, 410-413. doi: 10.1134/S0031030120040036 tetrapod fauna at the base of 'Romer's Gap'. PLOS ONE 10, e0125446. doi: 10.1371/journal.pone.0125446

Andreev, P. S., Cuny, G. (2012). New Triassic stem selachimorphs (Chondrichthyes, Elasmobranchii) and their bearing on the evolution of dental enameloid in Neoselachii. J. Vert. Paleont. 32, 255-266. doi: 10.1080/02724634.2012.644646 Upper Ordovician chondrichthyan-like scales from North America. Palaeontology 58, 691-704. doi: 10.1111/pala.12167 origins of the clade. PeerJ 4, e1850. doi:10.7717/peerj.1850 (2016b). Elegestolepis and its kin, the earliest monodontode chondrichthyans. J. Vert. Paleont. 37, e1245664. doi: 10.1080/02724634.2017.1245664

Anquetin, J., André, C. (2020). The last surviving Thalassochelydia-A new turtle cranium from the PCI Paleo. doi: 10.31233/osf.io/7pa5c 
Aranciaga Rolando, A. M., Agnolin, F. L., Corsolini, J. (2019). A new pipoid frog (Anura, Pipimorpha) from the Paleogene of Patagonia. Paleobiogeographical implications. C. R. Palevol 18, 725-734. doi: 10.1016/j.crpv.2019.04.003

1869 Arribas, I., Buscalioni, A. D., Royo Torres, R., Espílez, E., Mampel, L., Alcalá, L. (2019). A new 1870 goniopholidid crocodyliform, Hulkepholis rori sp. nov. from the Camarillas Formation (early 1871 Barremian) in Galve, Spain). PeerJ 7, e7911. doi: 10.7717/peerj.7911

1872 Ascarrunz, E., Rage, J.-C., Legreneur, P., Laurin, M. (2016). Triadobatrachus massinoti, the earliest 1873 known lissamphibian (Vertebrata: Tetrapoda) re-examined by $\mu \mathrm{CT}$ scan, and the evolution of trunk length in batrachians. Contr. Zool. 85, 201-234. doi: 10.1163/18759866-08502004

Asher, R. J., Meng, J., Wible, J. R., McKenna, M. C., Rougier, G. W., Dashzeveg, D., Novacek, M. J. (2005). Stem Lagomorpha and the antiquity of Glires. Science 307, 1091-1094. doi: 10.1126/science.1107808

Asher, R. J., Smith, M. R., Rankin, A., Emry, R. J. (2019). Congruence, fossils and the evolutionary tree of rodents and lagomorphs. R. Soc. Open Sci. 6: 190387. doi: 10.1098/rsos.190387 Ax, P. (1987). The phylogenetic system: the systematization of organisms on the basis of their phylogenesis. New York: John Wiley \& Sons.

1882 Báez, A. M. (2013). Anurans from the Early Cretaceous Lagerstätte of Las Hoyas, Spain: New evidence on the Mesozoic diversification of crown-clade Anura. Cret. Res. 41: 90-106. doi: 10.1016/j.cretres.2012.11.002

1885 Báez, A. M., Gómez, R. O. (2016). Revision of the skeletal morphology of Eodiscoglossus santonjae, an Early Cretaceous frog from northeastern Spain, with comments on its phylogenetic placement. Foss. Imprint 72, 67-77. doi: 10.14446/FI.2016.67

1888 Báez, A. M., Gómez, R. O. (2019). Redescription of the overlooked basal frog Wealdenbatrachus reveals increased diversity among Early Cretaceous anurans. Cret. Res. 99, 14-29. doi:

1890 10.1016/j.cretres.2019.02.006

Bailleul, A. M., O’Connor, J. K., Zhang, S., Li, Z., Wang, Q., Lamanna, M. C., et al. (2019). An Commun. 10, 1275. doi: 10.1038/s41467-019-09259-x stratigraphic age uncertainty leads to erroneous estimates of species divergence times under the fossilized birth-death process. Proc. R. Soc. B 286, 0685. doi: 10.1098/rspb.2019.0685 evidence to date the tree of life. Mol. Biol. Evol. 24, 889-891.

1902 Benton, M. J., Donoghue, P. C. J., Asher, R. J., Friedman, M., Near, T. J., Vinther, J. (2015).

1903 Constraints on the timescale of animal evolutionary history. Palaeont. Electron. 18.1.1FC. doi: $1904 \quad 10.26879 / 424$

1905 Berv, J. S., Field, D. J. (2017, printed 2018). Genomic signature of an avian Lilliput effect across the 1906 K-Pg extinction. Syst. Biol. 67, 1-13. doi: 10.1093/sysbio/syx064 

eutherian and the placental-marsupial dichotomy. Nature 558, 390-395. doi: 10.1038/s41586-0180210-3

1910 Bi, S., Wible, J. R., Zheng, X., Wang, X. (2019). The Early Cretaceous eutherian Ambolestes and its 1911 implications for the eutherian-metatherian dichotomy [abstract, Society of Vertebrate Paleontology, $79^{\text {th }}$ annual meeting]. J. Vert. Paleont., Program and Abstracts 2019, 64. Entire abstract book available at http://vertpaleo.org/Annual-Meeting/Annual-Meeting-Home/SVP-Program-book-v5_wcovers.aspx

1915 Blackburn, D. C., Paluh, D. J., Krone, I., Roberts, E. M., Stanley, E. L., Stevens, N. J. (2019). The 1916 earliest fossil of the African clawed frog (genus Xenopus) from sub-Saharan Africa. J. Herpetol. 53, 1917 125-130. doi: 10.1670/18-139

1918 Boisvert, C. A., Johnston, P., Trinajstic, K., Johanson, Z. (2019). “Chondrichthyan Evolution, Diversity, and Senses", in Heads, Jaws, and Muscles. Anatomical, Functional, and Developmental Diversity in Chordate Evolution, eds. J. Ziermann, R. Diaz Jr., R. Diogo (Cham: Springer), 65-91. doi: 10.1007/978-3-319-93560-7_4 crocodylian from southern Argentina sheds light on the early history of caimanines. Proc. R. Soc. B 285: 20180843. doi: 10.1098/rspb.2018.0843

1925 Borsuk-Białynicka, M. (1996). The Late Cretaceous lizard Pleurodontagama and the origin of tooth permanency in Lepidosauria. Acta Palaeont. Pol. 41, 231-252. Available at https://www.app.pan.pl/article/item/app41-231.html

1928 Botella, H., Blom, H., Dorka, M., Ahlberg, P. E., Janvier, P. (2007). Jaws and teeth of the earliest bony fishes. Nature 448, 583-586. doi: 10.1038/nature05989

1930 Burbrink, F. T., Grazziotin, F. G., Pyron, R. A., Cundall, D., Donnellan, S., Irish, F., et al. (2020). 1931 Interrogating genomic-scale data for Squamata (lizards, snakes, and amphisbaenians) shows no support for key traditional morphological relationships. Syst. Biol. 69, 502-520. doi:

1934 Burrow, C. J., Young, G. C. (1999). An articulated teleostome fish from the Late Silurian (Ludlow) of Victoria, Australia. Rec. West. Austral. Mus. suppl. 57, 1-14. Available at

1936 http://www.academia.edu/download/4084574/burrow_young1999.pdf

1937 Burrow, C. J., Hovestadt, D. C., Hovestadt-Euler, M., Turner, S., Young, G. C. (2008). New 1938 information on the Devonian shark Mcmurdodus, based on material from western Queensland, Australia. Acta Geol. Pol. 58, 155-163. Available at

1940 https://geojournals.pgi.gov.pl/agp/article/view/10016/8546

1941 Butler, R. J., Brusatte, S. L., Reich, M., Nesbitt, S. J., Schoch, R. R., Hornung, J. J. (2011). The sail1942 backed reptile Ctenosauriscus from the latest Early Triassic of Germany and the timing and 1943 biogeography of the early archosaur radiation. PLOS ONE 6, e25693. doi:

1944 10.1371/journal.pone.0025693

1945 Cadena, E. (2015). A global phylogeny of Pelomedusoides turtles with new material of Neochelys 1946 franzeni Schleich, 1993 (Testudines, Podocnemididae) from the middle Eocene, Messel Pit, of 1947 Germany. PeerJ 3, e1221. doi: 10.7717/peerj.1221 
1948 Caldwell, M. W., Nydam, R. L., Palci, A., Apesteguía, S. (2015). The oldest known snakes from the Middle Jurassic-Lower [sic] Cretaceous provide insights on snake evolution. Nat. Commun. 6, 5996. doi: 10.1038/ncomms6996

1951 Campbell Mekarski, M., Pierce, S. E., Caldwell, M. W. (2019). Spatiotemporal distributions of non1952 ophidian ophidiomorphs, with implications for their origin, radiation, and extinction. Front. Earth 1953 Sci. 7, 245. DOI 10.3389/feart.2019.00245

1954 Cannatella, D. (2015). Xenopus in space and time: fossils, node calibrations, tip-dating, and 1955 paleobiogeography. Cytogenet. Genome Res. 145, 283-301. doi: 10.1159/000438910

1956 Cantino, P. D., de Queiroz, K. (2020). International Code of Phylogenetic Nomenclature

1957 (PhyloCode). Version 6. Boca Raton, London, New York: CRC Press. Openly accessible at 1958 https://phylonames.org/code/

1959 Carneiro, L. M. (2017, printed 2018). A new species of Varalphadon (Mammalia, Metatheria, 1960 Sparassodonta) from the upper Cenomanian of southern Utah, North America: Phylogenetic and 1961 biogeographic insights. Cret. Res. 84, 88-96. doi: 10.1016/j.cretres.2017.11.004

1962 Carneiro, L. M., Oliveira, É. V. (2017). The Eocene South American metatherian Zeusdelphys 1963 complicatus is not a protodidelphid but a hatcheriform: Paleobiogeographic implications. Acta 1964 Palaeont. Pol. 62, 497-507. doi: 10.4202/app.00351.2017

1965 Carpenter, D. K., Falcon-Lang, H. J., Benton, M. J., Grey, M. (2015). Early Pennsylvanian 1966 (Langsettian) fish assemblages from the Joggins Formation, Canada, and their implications for 1967 palaeoecology and palaeogeography. Palaeontology 58, 661-690. doi: 10.1111/pala.12164

1968 Carroll, R. L. (1964). The earliest reptiles. Zool. J. Linn. Soc. 45, 61-83. doi: 10.1111/j.10961969 3642.1964.tb00488.x

1970 Carroll, R. L., Chorn, J. (1995). Vertebral development in the oldest microsaur and the problem of 1971 "lepospondyl” relationships. J. Vert. Paleont. 15, 37-56. doi: 10.1080/02724634.1995.10011206

1972 Carroll, R. L., Bybee, P., Tidwell, W. D. (1991). The oldest microsaur (Amphibia). J. Paleont. 65, 1973 314-322. doi: 10.1017/s0022336000020552

1974 Celik, M. A., Phillips, M. J. (2020). Conflict resolution for Mesozoic mammals: reconciling

1975 phylogenetic incongruence among anatomical regions. Front. Genet. 11, 0651. doi:

1976 10.3389/fgene.2020.00651

1977 Cellinese, N., Dell, C. (2020) RegNum - The international clade names repository [website]. 1978 https://www.phyloregnum.org/

1979 Chen, D., Blom, H., Sanchez, S., Tafforeau, P., Ahlberg, P. E. (2016). The stem osteichthyan 1980 Andreolepis and the origin of tooth replacement. Nature 539, 237-241. doi: 10.1038/nature 19812

1981 Chester, S. G. B., Bloch, J. I., Boyer, D. M., Clemens, W. A. (2015). Oldest known euarchontan 1982 tarsals and affinities of Paleocene Purgatorius to Primates. PNAS 112, 1487-1492. doi:

1983 10.1073/pnas.1421707112

1984 Chinzorig, T., Kobayashi, Y., Tsogtbaatar, K., Currie, P.J., Watabe, M., Barsbold, R. (2017). First 1985 Ornithomimid (Theropoda, Ornithomimosauria) from the Upper Cretaceous Djadokhta Formation of 1986 Tögrögiin Shiree, Mongolia. Sci. Rep. 7, 5835. doi: 10.1038/s41598-017-05272-6

1987 Choo, B., Zhu, M., Qu, Q., Yu, X., Jia, L., Zhao, W. (2017). A new osteichthyan from the late 1988 Silurian of Yunnan, China. PLOS ONE 12, e0170929. doi: 10.1371/journal.pone.0170929 
Clack, J. A. (2011). A new microsaur from the Early Carboniferous (Viséan) of East Kirkton,

1992 Clack, J. A., Bennett, C. E., Carpenter, D. K., Davies, S. J., Fraser, N. C., Kearsey, T. I., et al. (2016). 1993 Phylogenetic and environmental context of a Tournaisian tetrapod fauna. Nat. Ecol. Evol. 1, 0002.

1994 DOI 10.1038/s41559-016-0002

1995 Clack, J. A., Ruta, M., Milner, A. R., Marshall, J. E. A., Smithson, T. R., Smithson, K. Z. (2019).

1996 Acherontiscus caledoniae: the earliest heterodont and durophagous tetrapod. R. Soc. Open Sci. 6, 182087. doi: 10.1098/rsos.182087

1998 Clarke, J. A., Tambussi, C. P., Noriega, J. I., Erickson, G. M., Ketcham, R. A. (2005). Definitive fossil evidence for the extant avian radiation in the Cretaceous. Nature 433, 305-308. doi: 10.1038 /nature 03150

2001

Clement, A. M., King, B., Giles, S., Choo, B., Ahlberg, P. E., Young, G. C., Long, J. A. (2018).

2002 Neurocranial anatomy of an enigmatic Early Devonian fish sheds light on early osteichthyan

2003 evolution. eLife 7, e34349. doi: 10.7554/eLife.34349

2004

2005

Cohen, J. E. (2017) Radiation of tribosphenic mammals during the early Late Cretaceous (Turonian)

2006

of North America [doctoral thesis]. Norman: The University of Oklahoma. Available at https://hdl.handle.net/11244/52435 (abstract only until December 2020).

Cohen, J. E., Cifelli, R. L. (2015). The first eutherian mammals from the early Late Cretaceous of North America [abstract, Society of Vertebrate Paleontology, $75^{\text {th }}$ annual meeting]. J. Vert. Paleont., Program and Abstracts 2015, 108. Entire abstract book available at http://vertpaleo.org/PDFS/SVP2015-Program-and-Abstract-Book-9-22-2015.aspx

2011 Cohen, K. M., Harper, D. A. T., Gibbard, P. L., Fan, J.-X. (2020). International Chronostratigraphic

2013 http://www.stratigraphy.org/ICSchart/ChronostratChart2020-03.jpg or .pdf

2014 Conrad, J. L. (2015). A new Eocene casquehead lizard (Reptilia, Corytophanidae) from North

2015 America. PLOS ONE 10, e0127900. doi: 10.1371/journal.pone.0127900

2016 Conrad, J. L. (2017, printed 2018). A new lizard (Squamata) was the last meal of Compsognathus

2017 (Theropoda: Dinosauria) and is a holotype in a holotype. Zool. J. Linn. Soc. 183, 584-634. doi:

2018 10.1093/zoolinnean/zlx055

2019 Conrad, J. L., Norell, M. A. (2007). A complete Late Cretaceous iguanian (Squamata, Reptilia) from 0082(2007)3584[1:ACLCIS]2.0.CO;2

2022 Cossette, A. P., Brochu, C. A. (2018). A new specimen of the alligatoroid Bottosaurus harlani and the early history of character evolution in alligatorids. J. Vert. Paleont. 38, e1486321. doi:

2024 10.1080/02726434.2018.1486321 
2032 Clyde, W. C., Ramezani, J., Johnson, K. R., Bowring, S. A., Jones, M. M. (2016). Direct high-

2033

2034 precision $\mathrm{U}-\mathrm{Pb}$ geochronology of the end-Cretaceous extinction and calibration of Paleocene astronomical timescales. Earth Planet. Sci. Lett. 452, 272-280. doi: 10.1016/j.eps1.2016.07.041

2035 Danto, M., Witzmann, F., Kamenz, S. K., Fröbisch, N. B. (2019). How informative is vertebral 2036 development for the origin of lissamphibians? J. Zool. 307, 292-305. doi: 10.1111/jzo.12648

2037

2038

2039

Dashzeveg, D., Dingus, L., Loope, D. B., Swisher, C. C. III, Dulam, T., Sweeney, M. R. (2005). New stratigraphic subdivision, depositional environment, and age estimate for the Upper Cretaceous Djadokhta Formation, southern Ulan Nur Basin, Mongolia. Am. Mus. Novit. 3498, 1-31. doi:

2040 10.1206/0003-0082(2005)498[0001:NSSDEA]2.0.CO;2

2042 Davies, T. M., Bell, M. A., Goswami, A., Halliday, T. J. D. (2017). Completeness of the eutherian mammal fossil record and implications for reconstructing mammal evolution through the Cretaceous/Paleogene mass extinction. Paleobiology 43, 521-536. doi: 10.1017/pab.2017.20 fossils illuminate the past diversity of tropical lizards. Sci. Adv. 2, e1501080. doi:

$2046 \quad 10.1126 /$ sciadv. 1501080 687-691. doi: 10.1126/science.abb6005

2050 DeMar, D. G. Jr., Conrad, J. L., Head, J. J., Varricchio, D. J., Wilson, G. P. (2017). A new Late Cretaceous iguanomorph from North America and the origin of New World Pleurodonta (Squamata, Iguania). Proc. R. Soc. B 284, 20161902. doi: 10.1098/rspb.2016.1902 survival of an ancient lineage of anseriform birds into the Neogene of Australia: the youngest record of Presbyornithidae. R. Soc. Open Sci. 3, 150635. doi: 10.1098/rsos.150635 A. (2008). The geology of Ukhaa Tolgod (Djadokhta Formation, Upper Cretaceous, Nemegt Basin, Mongolia). Am. Mus. Novit. 3616, 1-40. doi: 10.1206/442.1

2059 Eldridge, M. D. B., Beck, R. M. D., Croft, D. A., Travouillon, K. J., Fox, B. J. (2019). An emerging consensus in the evolution, phylogeny, and systematics of marsupials and their fossil relatives

2061 (Metatheria). J. Mammal. 100, 802-837. doi: 10.1093/jmammal/gyz018 avian genus Presbyornis. Acta Palaeont. Pol. 59, 821-825. doi: 10.4202/app.00027.2013 http://www.palaeontologia.pan.pl/PP65/PP65_179-202.pdf Poland. Palaeont. Pol. 65, 79-105. Available at http://www.palaeontologia.pan.pl/PP65/PP65 079106.pdf of India. J. Vert. Paleont. 22, 299-312. doi: 10.1671/0272-4634(2002)022[0299:FLFTJK]2.0.CO;2 
Evans, S. E., Manabe, M., Noro, M., Isaji, S., Yamaguchi, M. (2006). A long-bodied lizard from the Lower Cretaceous of Japan. Palaeontology 49, 1143-1165. doi: 10.1111/j.1475-4983.2006.00598.x

(Protostegidae) and marine adaptation during the early evolution of chelonioids. PeerJ 7, e6811. doi:

$2079 \quad 10.7717 /$ peerj.6811

2080 Ezcurra, M. D., Scheyer, T. M., Butler, R. J. (2014). The origin and early evolution of Sauria:

2081

2082

reassessing the Permian saurian fossil record and the timing of the crocodile-lizard divergence. PLOS ONE 9, e89165. doi: 10.1371/journal.pone.0089165

2083 Field, D. J., Benito, J., Chen, A., Jagt, J. W. M., Ksepka, D. T. (2020). Late Cretaceous neornithine 2084 from Europe illuminates the origins of crown birds. Nature 579, 397-401. doi: 10.1038/s41586-020$2085 \quad 2096-0$

2086 Ford, D. P., Benson, R. B. J. (2018, printed 2019). A redescription of Orovenator mayorum (Sauropsida, Diapsida) using high-resolution $\mu \mathrm{CT}$, and the consequences for early amniote

2088

2089 phylogeny. Pap. Palaeont. 5, 197-239. doi: 10.1002/spp2.1236

2090

Ford, D. P., Benson, R. B. J. (2019, printed 2020). The phylogeny of early amniotes and the affinities of Parareptilia and Varanopidae. Nat. Ecol. Evol. 4, 57-65. doi: 10.1038/s41559-019-1047-3

Fostowicz-Frelik, Ł., Kielan-Jaworowska, Z. (2002). Lower incisor in zalambdalestid mammals (Eutheria) and its phylogenetic implications. Acta Palaeont. Pol. 47, 177-180. Available at http://www.app.pan.pl/article/pdf/41/item/app47-177.html

2094 Fox, R. C. (2016). The status of Schowalteria clemensi, the Late Cretaceous taeniodont (Mammalia). J. Vert. Paleont. 36, e1211666. doi: 10.1080/02724634.2016.1211666

2096

2097

2098

Fox, R. C., Scott, C. S. (2011). A new, early Puercan (earliest Paleocene) species of Purgatorius (Plesiadapiformes, Primates) from Saskatchewan, Canada. J. Paleont. 85, 537-548. doi: 10.1666/10059.1

2099 Fraguas, Á., Comas-Rengifo, M. J., Goy, A., Gómez, J. J. (2018). Upper Sinemurian - Pliensbachian section for the connection between the Boreal and Tethyan Realms. Newsl. Strat. 51, 227-244. doi: $10.1127 / \operatorname{nos} / 2017 / 0401$

Frey, L., Coates, M., Ginter, M., Hairapetian, V., Rücklin, M., Jerjen, I., Klug, C. (2019). The early elasmobranch Phoebodus: phylogenetic relationships, ecomorphology and a new time-scale for shark evolution. Proc. R. Soc. B 286: 20191336. doi: 10.1098/rspb.2019.1336 10.1111/pala.12150

de la Fuente, M. S., Iturralde-Vinent, M. (2001). A new pleurodiran turtle from the Jagua Formation 3360(2001)075<0860:ANPTFT>2.0.CO;2 issue: $10.18435 /$ vamp29365

Gaffney, E. S., Jenkins, F. A. Jr. (2010). The cranial morphology of Kayentachelys, an Early Jurassic cryptodire, and the early history of turtles. Acta Zool. 91, 335-368. doi: 10.1111/j.14636395.2009.00439.x 
2118 Gaffney, E. S., Tong, H., Meylan, P. A. (2006). Evolution of the side-necked turtles: the families

2119 Bothremydidae, Euraxemydidae, and Araripemydidae. Bull. Am. Mus. Nat. Hist. 300, 1-698. doi:

2120 10.1206/0003-0090(2006)300[1:EOTSTT]2.0.CO;2

2121 Gaffney, E. S., Rich, T. H., Vickers-Rich, P., Constantine, A., Vacca, R., Kool, L. (2007).

2122 Chubutemys, a new eucryptodiran turtle from the Early Cretaceous of Argentina, and the

2123 relationships of the Meiolaniidae. Am. Mus. Novit. 3599, 1-35. doi: 10.1206/0003-

2124 0082(2007)3599[1:CANETF]2.0.CO;2

2125 Galli, K. G., Buchwaldt, R., Lucas, S. G., Tanner, L. (2018). New chemical abrasion thermal

2126

2127 ionization mass spectrometry dates from the Brushy Basin Member, Morrison Formation, western Colorado: implications for dinosaur evolution. The J. Geol. 126, 473-486. doi: 10.1086/699208

2128

2129

Gao, K., Norell, M. A. (2000). Taxonomic composition and systematics of Late Cretaceous lizard assemblages from Ukhaa Tolgod and adjacent localities, Mongolian Gobi desert. Bull. Am. Mus. Nat. Hist. 249, 1-118. doi: 10.1206/0003-0090(2000)249<0001:TCASOL>2.0.CO;2

2131 Gao, K.-Q., Shubin, N. H. (2003). Earliest known crown-group salamanders. Nature 422, 424-428.

2132 doi: 10.1038/nature01491

2133 Gao, K.-Q., Shubin, N. H. (2012). Late Jurassic salamandroid from western Liaoning, China. PNAS 2134 109, 5767-5772. doi: 10.1073/pnas.1009828109

2135 Garberoglio, F. F., Apesteguía, S., Simões, T. R., Palci, A., Gómez, R. O., Nydam, R. L. et al.

2136 (2019). New skulls and skeletons of the Cretaceous legged snake Najash, and the evolution of the

2137 modern snake body plan. Sci. Adv. 5, eaax5833. doi: 10.1126/sciadv.aax5883

2138 Gardner, J. D., Rage, J.-C. (2016). The fossil record of lissamphibians from Africa, Madagascar, and

2139 the Arabian Plate. Palaeobiodiv. Palaeoenv. 96, 169-220. doi: 10.1007/s12549-015-0221-0

2140 Gentry, A. D., Ebersole, J. A., Kiernan, C. R. (2019). Asmodochelys parhami, a new fossil marine turtle from the Campanian Demopolis Chalk and the stratigraphic congruence of competing marine turtle phylogenies. R. Soc. Open Sci. 6, 191950. doi: 10.1098/rsos.191950

Giles, S., Xu, G.-H., Near, T. J., Friedman, M. (2017). Early members of 'living fossil' lineage imply later origin of modern ray-finned fishes. Nature 549, 265-268. doi: 10.1038/nature23654 10.1080/02724634.2014.918041

Gómez, R. O. (2016). A new pipid frog from the Upper Cretaceous of Patagonia and early evolution of crown-group Pipidae. Cret. Res. 62, 52-64. doi: 10.1016/j.cretres.2016.02.006 the Jurassic turtle Neusticemys neuquina and phylogenetic relationships of the only thalassochelydian known from the eastern Pacific. J. Paleont. 94, 145-164. doi: 10.1017/jpa.2019.74

2153 Goodrich, E. S. (1916). On the classification of the Reptilia. Proc. R. Soc. Lond. B 89, 261-276. doi:

2154 10.1098/rspb.1916.0012

2155 Goswami, A., Prasad, G. V. R., Upchurch, P., Boyer, D. M., Seiffert, E. R., Verma, O., et al. (2011)

2156 
2158

2159

2160

2161

2162

2163

2164

2165

2166

2167

2168

2169

2170

2171

2172

2173

2174

2175

2176

2177

2178

2179

2180

2181

2182

2183

2184

2185

2186

2187

2188

2189

2190

2191

2192

2193

2194

2195

2196

2197

2198

2199

Goswami, S., Gierlowski-Kordesch, E., Ghosh, P. (2016, printed 2018). Sedimentology of the Early

Jurassic limestone beds of the Kota Formation: record of carbonate wetlands in a continental rift basin of India. J. Paleolimnol. 59, 21-38. doi: 10.1007/s10933-016-9918-y

Graur, D., Martin, W. (2004). Reading the entrails of chickens: molecular timescales of evolution and the illusion of precision. Trends Genet. 20, 80-86. doi: 10.1016/j.tig.2003.12.003

Groh, S. S., Upchurch, P., Barrett, P. M., Day, J. J. (2019, printed 2020). The phylogenetic relationships of neosuchian crocodiles and their implications for the convergent evolution of the longirostrine condition. Zool. J. Linn. Soc. 188, 473-506. doi: 10.1093/zoolinnean/zlz1 17

Guindon, S. (2020). Rates and rocks: strengths and weaknesses of molecular dating methods. Front. Genet. 11, 526. doi: 10.3389/fgene.2020.00526

Haddoumi, H., Allain, R., Meslouh, S., Metais, G., Monbaron, M., Pons, D. et al. (2015, printed 2016). Guelb el Ahmar (Bathonian, Anoual Syncline, eastern Morocco): First continental flora and fauna including mammals from the Middle Jurassic of Africa. Gondw. Res. 29, 290-319. doi: 10.1016/j.gr.2014.12.004

Halliday, T. J. D., Brandalise de Andrade, M., Benton, M. J., Efimov, M. B. (2013). A re-evaluation of goniopholidid crocodylomorph material from Central Asia: biogeographic and phylogenetic implications. Acta Palaeont. Pol. 60, 291-312. doi: 10.4202/app.2013.0018

Halliday, T. J. D., Upchurch, P., Goswami, A. (2015, printed 2017). Resolving the relationships of Paleocene placental mammals. Biol. Rev. 92, 521-550. doi: 10.1111/brv.12242

Halliday, T. J. D., Upchurch, P., Goswami, A. (2016) Eutherians experienced elevated evolutionary rates in the immediate aftermath of the Cretaceous-Palaeogene mass extinction. Proc. R. Soc. B 283, 20153026. doi: 10.1098/rspb.2015.3026

Halliday, T. J. D., dos Reis, M., Tamuri, A. U., Ferguson-Gow, H., Yang, Z., Goswami, A. (2019). Rapid morphological evolution in placental mammals post-dates the origin of the crown group. Proc. R. Soc. B 286: 20182418. doi: 10.1098/rspb.2018.2418

Haridy, Y., MacDougall, M. J., Reisz, R. R. (2017, printed 2018). The lower jaw of the Early Permian parareptile Delorhynchus, first evidence of multiple denticulate coronoids in a reptile. Zool. J. Linn. Soc. 184, 791-803. doi: 10.1093/zoolinnean/zlx085

Harjunmaa, E., Seidel, K., Häkkinen, T., Renvoisé, E., Corfe, I. J., Kallonen, A., et al. (2014). Replaying evolutionary transitions from the dental fossil record. Nature 512, 44-48. doi: 10.1038/nature13613

Hasegawa, H., Tada, R., Ichinnorov, N., Minjin, C. (2008, printed 2009). Lithostratigraphy and depositional environments of the Upper Cretaceous Djadokhta Formation, Ulan Nuur basin, southern Mongolia, and its paleoclimatic implication. J. As. Earth Sci. 35, 13-26. doi:

10.1016/j.jseaes.2008.11.010

Head, J. J. (2015). Fossil calibration dates for molecular phylogenetic analysis of snakes 1: Serpentes, Alethinophidia, Boidae, Pythonidae. Palaeont. Electron. 18, 6FC. doi: 10.26879/487

Henrici, A. C. (1998). A new pipoid anuran from the Late Jurassic Morrison Formation at Dinosaur National Monument, Utah. J. Vert. Paleont. 18, 321-332. doi: 10.1080/02724634.1998.10011060

Hermanson, G., Iori, F. V., Evers, S. W., Langer, M. C., Ferreira, G. S. (2020). A small podocnemidoid (Pleurodira, Pelomedusoides) from the Late Cretaceous of Brazil, and the innervation and carotid circulation of side-necked turtles. Pap. Palaeont. 6: 329-347. doi: 10.1002/spp2.1300

This is a provisional file, not the final typeset article 
2200

2201

2202

2203

2204

2205

2206

2207

2208

2209

2210

2211

2212

2213

2214

2215

2216

2217

2218

2219

2220

2221

2222

2223

2224

2225

2226

2227

2228

2229

2230

2231

2232

2233

2234

2235

2236

2237

2238

2239

2240

2241 von Heyden, L. (1870). Entomologische Reise nach dem südlichen Spanien, der Sierra Guadarrama und Sierra Morena, Portugal und den Cantabrischen Gebirgen [...]. Berlin: Entomologischer Verein. Available at https://books.google.com/books?id=FXBTAAAAcAAJ

Hicks, J. F., Fastovsky, D., Nichols, D. J., Watabe, M. (2001). Magnetostratigraphic correlation of Late Cretaceous dinosaur-bearing localities in the Nemegt and Ulan [sic] Nuur basins, Gobi desert, Mongolia [abstract 135-0, Geological Society of America Annual Meeting]. Available at https://gsa.confex.com/gsa/2001AM/finalprogram/abstract_28817.htm

Hime, P. M., Lemmon, A. R., Moriarty Lemmon, E. C., Prendini, E., Brown, J. M., Thomson, R. C., et al. (2020). Phylogenomics reveals ancient gene tree discordance in the amphibian tree of life. Syst. Biol. online early. doi: 10.1093/sysbio/syaa034

Hu, X., Li, L., Dai, H., Wang, P., Buffetaut, É., Wei, G. et al. (2020). Turtle remains from the Middle Jurassic Xintiangou Formation of Yunyang, Sichuan Basin, China | Restes de tortues de la Formation Xintiangou (Jurassique moyen) de Yunyang, bassin du Sichuan, Chine. Ann. Paléont. 106, 102440. doi: 10.1016/j.annpal.2020.102440

Hutchinson, M. N., Skinner, A., Lee, M. S. Y. (2012). Tikiguania and the antiquity of squamate reptiles (lizards and snakes). Biol. Lett. 8, 665-669. doi: 10.1098/rsbl.2011.1216

Huttenlocker, A. K., Grossnickle, D. M., Kirkland, J. I., Schultz, J. A., Luo, Z.-X. (2018). Latesurviving stem mammal links the lowermost Cretaceous of North America and Gondwana. Nature 558, 108-112. doi: 10.1038/s41586-018-0126-y

[ICZN] International Commission on Zoological Nomenclature (1999). International Code of Zoological Nomenclature. $4^{\text {th }}$ ed. London: International Trust for Zoological Nomenclature. Openly accessible, including the updates from 2012, at https://www.iczn.org/the-code/the-international-codeof-zoological-nomenclature/the-code-online/

Irisarri, I., Baurain, D., Brinkmann, H., Delsuc, F., Sire, J.-Y., Kupfer, A., et al. (2017). Phylotranscriptomic consolidation of the jawed vertebrate timetree. Nat. Ecol. Evol. 1, 1370-1378. doi: $10.1038 / \mathrm{s} 41559-017-0240-5$

Ivanov, A. (2005). Early Permian chondrichthyans of the Middle and South Urals. Rev. Bras. Paleont. 8, 127-138. Available at http://www.sbpbrasil.org/revista/edicoes/8_2/8(2)ivanov.pdf

Jia, J., Gao, K.-Q. (2016). A new basal salamandroid (Amphibia, Urodela) from the Late Jurassic of Qinglong, Hebei Province, China. PLOS ONE 11, e0153834. doi: 10.1371/journal.pone.0153834

Jia, J., Gao, K.-Q. (2019). A new stem hynobiid salamander (Urodela, Cryptobranchoidea) from the Upper Jurassic (Oxfordian) of Liaoning Province, China. J. Vert. Paleont. 39, e1588285. doi:

$10.1080 / 02724634.2019 .1588285$

Jiang, J.-Q., Cai, C.-Y., Huang, D.-Y. (2015, printed 2016). Progonocimicids (Hemiptera, Coleorrhyncha) from the Middle Jurassic Haifanggou Formation, western Liaoning, northeast China support stratigraphic correlation with the Daohugou beds. Alcheringa 40, 53-61. doi:

10.1080/03115518.2015.1086053

Jones, M. E. H., Anderson, C. L., Hipsley, C. A., Müller, J., Evans, S. E., Schoch, R. R. (2013) Integration of molecules and new fossils supports a Triassic origin for Lepidosauria (lizards, snakes, and tuatara). BMC Evol. Biol. 13, 208. doi: 10.1186/1471-2148-13-208

Kangas, A. T., Evans, A. R., Thesleff, I., Jernvall, J. (2004). Nonindependence of mammalian dental characters. Nature 432, 211-214. doi: 10.1038/nature02927 
Kearney, M., Clark, J.M. (2003). Problems due to missing data in phylogenetic analyses including fossils: a critical review. J. Vert. Paleont. 23, 263-274. doi: 10.1671/02724634(2003)023[0263:PDTMDI]2.0.CO;2

2245 King, B. (2019). Which morphological characters are influential in a Bayesian phylogenetic analysis? 2246 Examples from the earliest osteichthyans. Biol. Lett. 15, 20190288. doi: 10.1098/rsbl.2019.0288

Kissel, R. (2010). Morphology, Phylogeny and Evolution of Diadectidae (Cotylosauria: http://hdl.handle.net/1807/24357

2250 Klembara, J., Hain, M., Ruta, M., Berman, D. S, Pierce, S. E., Henrici, A. C. (2019, printed 2020). Inner ear morphology of diadectomorphs and seymouriamorphs (Tetrapoda) uncovered by highresolution X-ray microcomputed tomography, and the origin of the amniote crown group. Palaeontology 63, 131-154. doi: 10.1111/pala.12448 891-917. doi: 10.1080/14772019.2014.963179

Krause, D. W. (1978). Paleocene primates from western Canada. Can. J. Earth Sci. 15, 1250-1271. doi: $10.1139 / \mathrm{e} 78-133$

2259 Ksepka, D. T., Parham, J. F., Allman, J. F., Benton, M. J., Carrano, M. T., Cranston, K. A. et al.

2260 (2015). The Fossil Calibration Database - a new resource for divergence dating. Syst. Biol. 64, 8532261 859. doi:10.1093/sysbio/syv025.

2262 Kurochkin, E. N., Dyke, G. J., Karhu, A. A. (2002). A new presbyornithid bird (Aves, Anseriformes) 2263 from the Late Cretaceous of southern Mongolia. Am. Mus. Novit. 3386, 1-11. doi: 10.1206/00032264 0082(2002)386<0001:ANPBAA>2.0.CO;2

2265 Langer, M. C., de Oliveira Martins, N., Manzig, P. C., de Souza Ferreira, G., de Almeida Marsola, J. 2266 C., Fortes, E., et al. (2019). A new desert-dwelling dinosaur (Theropoda, Noasaurinae) from the 2267 Cretaceous of south Brazil. Sci. Rep. 9, 9379. doi: 10.1038/s41598-019-45306-9

Lartillot, N. (2015). PhyloBayes [software]. Version 4.1c. Available at http://www.atgcmontpellier.fr/phylobayes/

2270 Laurin, M., Piñeiro, G. (2018). Response: Commentary: A reassessment of the taxonomic position of mesosaurs, and a surprising phylogeny of early amniotes. Front. Earth Sci. 6, 220. doi:

$227210.3389 /$ feart.2018.00220

Laurin, M., Lapauze, O., Marjanović, D. (2019). What do ossification sequences tell us about the origin of extant amphibians? bioR $\chi i v, 352609$ version 4, peer-reviewed by PCI Paleo. doi: $10.1101 / 352609 \mathrm{v} 4$

2276 Lawver, D. R., Debee, A. M., Clarke, J. A., Rougier, G. W. (2011). A new enantiornithine bird from the Upper Cretaceous La Colonia Formation of Patagonia, Argentina. Ann. Carnegie Mus. 80, 35-42. doi: 10.2992/007.080.0104

2282 Lefebvre, B., Gutiérrez-Marco, J.C., Lehnert, O., Martin, E. L. O., Nowak, H., Akodad, M., et al. 2283 (2017, printed 2018). Age calibration of the Lower Ordovician Fezouata Lagerstätte, Morocco.

2284 Lethaia 51, 296-311. doi: 10.1111/let.12240 
2285

2286

2287

2288

2289

2290

2291

2292

2293

2294

2295

2296

2297

2298

2299

2300

2301

2302

2303

2304

2305

2306

2307

2308

2309

2310

2311

2312

2313

2314

2315

2316

2317

2318

2319

2320

2321

2322

2323

2324

2325

Li, P.-P., Gao, K.-Q., Hou, L.-H., Xu, X. (2007). A gliding lizard from the Early Cretaceous of China. PNAS 104, 5507-5509. doi: 10.1073/pnas.0609552104

Liang, C., Liu, Y., Hu, Z., Li, X., Li, W., Zheng, C. et al. (2019, printed 2020). Provenance study from petrography and geochronology of Middle Jurassic Haifanggou Formation in Xingcheng Basin, western Liaoning Province. Geol. J. 55, 2420-2446. doi: 10.1002/gj.3509

Liu, Y.-H., Gai, Z.-K., Zhu, M. (2017, printed 2018). New findings of galeaspids (Agnatha) from the Lower Devonian of Qujing, Yunnan, China. Vert. PalAsiat. 56, 1-15.

Lombard, R. E., Bolt, J. R. (1999). A microsaur from the Mississippian of Illinois and a standard format for morphological characters. J. Paleont. 73, 908-923. doi: 10.1017/s0022336000040749

López-Arbarello, A., Sferco, E. (2018). Neopterygian phylogeny: the merger assay. R. Soc. Open Sci. 5, 172337. doi: 10.1098/rsos.172337

López-Torres, S., Fostowicz-Frelik, Ł. (2018). A new Eocene anagalid (Mammalia:

Euarchontoglires) from Mongolia and its implications for the group's phylogeny and dispersal. Sci. Rep. 8, 13955. doi: 10.1038/s41598-018-32086-x

Lu, J., Zhu, M., Long, J. A., Zhao, W., Senden, T. J., Jia, L., Qiao, T. (2012) The earliest known stem-tetrapod[omorph] from the Lower Devonian of China. Nat. Commun. 3, 1160. doi: $10.1038 /$ ncomms 2170

Lu, J., Giles, S., Friedman, M., Zhu, M. (2017). A new stem sarcopterygian illuminates patterns of character evolution in early bony fishes. Nat. Commun. 8, 1932. doi: 10.1038/s41467-017-01801-z

Luo, Z.-X., Yuan, C.-X., Meng, Q.-J, Ji, Q. (2011). A Jurassic eutherian mammal and divergence of marsupials and placentals. Nature 476, 442-445. doi: 10.1038/nature10291

MacDougall, M. J., Winge, A., Ponstein, J., Jansen, M., Reisz, R. R., Fröbisch, J. (2019). New information on the early [sic] Permian lanthanosuchoid Feeserpeton oklahomensis [sic] based on computed tomography. PeerJ 7, e7753. doi: 10.7717/peerj.7753

Maddin, H. C., Mann, A., Hebert, B. (2019, printed 2020). Varanopid from the Carboniferous of Nova Scotia reveals evidence of parental care in amniotes. Nat. Ecol. Evol. 4, 50-56. doi: 10.1038/s41559-019-1030-z

Maidment, S. C. R., Muxworthy, A. (2019). A chronostratigraphic framework for the Upper Jurassic Morrison Formation, western U.S.A. J. Sedim. Res. 89, 1017-1038. doi: 10.2110/jsr.2019.54

Mann, A., Paterson, R. S. (2019, printed 2020). Cranial osteology and systematics of the enigmatic early 'sail-backed' synapsid Echinerpeton intermedium Reisz, 1972, and a review of the earliest 'pelycosaurs'. J. Syst. Palaeont. 18, 529-539. doi: 10.1080/14772019.2019.1648323

Mann, A., McDaniel, E. J., McColville, E. R., Maddin, H. C. (2019). Carbonodraco lundi gen et sp. nov., the oldest parareptile, from Linton, Ohio, and new insights into the early radiation of reptiles. $R$. Soc. Open Sci. 6, 191191. doi: 10.1098/rsos.191191

Mann, A., Gee, B. M., Pardo, J. D., Marjanović, D., Adams, G. R., Calthorpe, A. S. et al. (2020). Reassessment of historic 'microsaurs' from Joggins, Nova Scotia, reveals hidden diversity in the earliest amniote ecosystem. Palaeontology online early. doi: 10.1002/spp2.1316

Manz, C. L., Chester, S. G. B., Bloch, J. I., Silcox, M. T., Sargis, E. J. (2015). New partial skeletons of Palaeocene Nyctitheriidae and evaluation of proposed euarchontan affinities. Biol. Lett. 11, 20140911. doi: 10.1098/rsbl.2014.0911 
2326

2327

2328

2329

2330

2331

2332

2333

2334

2335

2336

2337

2338

2339

2340

2341

2342

2343

2344

2345

2346

2347

2348

2349

2350

2351

2352

2353

2354

2355

2356

2357

2358

2359

2360

2361

2362

2363

2364

2365

Mao, F., Hu, Y., Li, C., Wang, Y., Hill Chase, M., Smith, A. K., Meng, J. (2019). Integrated hearing and chewing modules decoupled in a Cretaceous stem therian mammal. Science 367, 305-308. doi: $10.1126 /$ science.aay9220

Marjanović, D. (2019) Recalibrating the transcriptomic timetree of jawed vertebrates [first preprint of this paper]. bioR $\chi i v$ 2019.12.19.882829v1. doi: 10.1101/2019.12.19.882829v1

Marjanović, D., Laurin, M. (2007). Fossils, molecules, divergence times, and the origin of lissamphibians. Syst. Biol. 56, 369-388. doi: 10.1080/10635150701397635

Marjanović, D., Laurin, M. (2013a). The origin(s) of extant amphibians: a review with emphasis on the "lepospondyl hypothesis". Geodiversitas 35, 207-272. doi: 10.5252/g2013n1a8

Marjanović, D., Laurin, M. (2013b, printed 2014). An updated paleontological timetree of lissamphibians, with comments on the anatomy of Jurassic crown-group salamanders (Urodela). Hist. Biol. 26, 535-550. doi: 10.1080/08912963.2013.797972

Marjanović, D., Laurin, M. (2019). Phylogeny of Paleozoic limbed vertebrates reassessed through revision and expansion of the largest published relevant data matrix. PeerJ 6, e5565. doi: 10.7717/peerj.5565

Marjanović, D., Witzmann, F. (2015). An extremely peramorphic newt (Urodela: Salamandridae: Pleurodelini) from the latest Oligocene of Germany, and a new phylogenetic analysis of extant and extinct salamandrids. PLOS ONE 10, e0137068. doi: 10.1371/journal.pone.0137068

Maron, M., Muttoni, G., Rigo, M., Gianolla, P., Kent, D. V. (2018, printed 2019). New magnetobiostratigraphic results from the Ladinian of the Dolomites and implications for the Triassic geomagnetic polarity timescale. Palaeogeogr. Palaeoclimat. Palaeoecol. 517, 52-73. doi: 10.1016/j.palaeo.2018.11.024

Marshall, C. R. (2019). Using the fossil record to evaluate timetree timescales. Front. Genet. 10, 1049. doi: $10.3389 /$ fgene. 2019.01049

Martill, D. M., Tischlinger, H., Longrich, N. R. (2015). A four-legged snake from the Early Cretaceous of Gondwana. Science 349, 416-419. doi: 10.1126/science.aaa9208

Mateus, O., Puértolas-Pascual, E., Callapez, M. (2018, printed 2019). A new eusuchian crocodylomorph from the Cenomanian (Late Cretaceous) of Portugal reveals novel implications on the origin of Crocodylia. Zool. J. Linn. Soc. 186, 501-528. doi: 10.1093/zoolinnean/zly064

Matschiner, M. (2019). Selective sampling of species and fossils influences age estimates under the fossilized birth-death model. Front. Genet. 10, 1064. doi: 10.3389/fgene.2019.01064

Matsumoto, R., Evans, S. E. (2018). The first record of albanerpetontid amphibians (Amphibia: Albanerpetontidae) from East Asia. PLOS ONE 13, e0189767. doi: 10.1371/journal.pone.0189767

Matsui, M., Tominaga, A., Liu, W.-z., Tanaka-Ueno, T. (2008). Reduced genetic variation in the Japanese giant salamander, Andrias japonicus (Amphibia: Caudata). Mol. Phyl. Evol. 49, 318-326. doi: 10.1016/j.ympev.2008.07.020

Mayr, G., De Pietri, V. L., Scofield, R. P., Worthy, T. H. (2018). On the taxonomic composition and phylogenetic affinities of the recently proposed clade Vegaviidae Agnolín et al., $2017 \square$ neornithine birds from the Upper Cretaceous of the Southern Hemisphere. Cret. Res. 86, 178-185. doi:

10.1016/j.cretres.2018.02.013

This is a provisional file, not the final typeset article 
2366

2367

2368

2369

2370

2371

2372

2373

2374

2375

2376

2377

2378

2379

2380

2381

2382

2383

2384

2385

2386

2387

2388

2389

2390

2391

2392

2393

2394

2395

2396

2397

2398

2399

2400

2401

2402

2403

2404

2405

2406

2407

McLachlan, S. M. S., Kaiser, G. W., Longrich, N. R. (2017) Maaqwi cascadensis: A large, marine diving bird (Avialae: Ornithurae) from the Upper Cretaceous of British Columbia, Canada. PLOS ONE 12, e0189473. doi: 10.1371/journal.pone.0189473

Meng, J. (2014). Mesozoic mammals of China: implications for phylogeny and early evolution of mammals. Natl. Sci. Rev. 1, 521-542. doi: 10.1093/nsr/nwu070

Milanese, F. N., Olivero, E. B., Raffi, M. E., Franceschinis, P. R., Gallo, L. C., Skinner, S. M., et al. (2018, printed 2019). Mid Campanian-Lower Maastrichtian magnetostratigraphy of the James Ross Basin, Antarctica: Chronostratigraphical implications. Basin Res. 31, 562-583. doi: $10.1111 /$ bre. 12334

Milner, A. C. (2019). A morphological revision of Keraterpeton, the earliest horned nectridean from the Pennsylvanian of England and Ireland. Earth Env. Sci. Trans. R. Soc. Edinb. 109, 237-253. doi: $10.1017 /$ S1755691018000579

Milner, A. R., Sequeira, S. E. K. (1994, for 1993). The temnospondyl amphibians from the Viséan of East Kirkton, West Lothian, Scotland. Trans. R. Soc. Edinb. Earth Sci. 84, 331-361. doi: $10.1017 / \mathrm{s} 0263593300006155$

Missiaen, P., Escarguel, G., Hartenberger, J.-L., Smith, T. (2012). A large new collection of Palaeostylops from the Paleocene of the Flaming Cliffs area (Ulan-Nur Basin, Gobi Desert, Mongolia), and an evaluation of the phylogenetic affinities of Arctostylopidae (Mammalia, Gliriformes). Geobios 45, 311-322. doi: 10.1016/j.geobios.2011.10.004

Modesto, S. P., Scott, D. M., MacDougall, M. J., Sues, H.-D., Evans, D. C., Reisz, R. R. (2015). The oldest parareptile and the early diversification of reptiles. Proc. R. Soc. B 282, 20141912. doi: 10.1098/rspb.2014.1912

Mongiardino Koch, N., Gauthier, J. A. (2018). Noise and biases in genomic data may underlie radically different hypotheses for the position of Iguania within Squamata. PLOS ONE 13, e0202729. doi: 10.1371/journal.pone.0202729

Mongiardino Koch, N., Parry, L. A. (2020). Death is on our side: paleontological data drastically modify phylogenetic hypotheses. Syst. Biol. 69, 1052-1067. doi: 10.1093/sysbio/syaa023

Morris, J. L., Puttick, M. N., Clark, J. W., Edwards, D., Kenrick, P., Pressel, S., et al. (2018). The timescale of early land plant evolution. PNAS 115, E2274-E2283. doi: 10.1073/pnas.1719588115

Müller, J., Reisz, R. R. (2006). The phylogeny of early eureptiles: comparing parsimony and Bayesian approaches in the investigation of a basal fossil clade. Syst. Biol. 55, 503-511. doi: 10.1080/10635150600755396

Müller, J., Reisz, R. R. (2007). Four well-constrained calibration points from the vertebrate fossil record for molecular clock estimates. BioEssays 27, 1069-1075. doi: 10.1002/bies.20286

Murphy, W. J., Eizirik, E., O’Brien, S.J., Madsen, O., Scally, M., Douady, C. J., et al. (2001). Resolution of the early placental mammal radiation using Bayesian phylogenetics. Science 294, 2348-2351. doi: 10.1126/science. 1067179

Napoli, J. G., Williamson, T. E., Shelley, S. L., Brusatte, S. L. (2017, printed 2018). A digital endocranial cast of the early Paleocene (Puercan) 'archaic' mammal Onychodectes tisonensis (Eutheria: Taeniodonta). J. Mammal. Evol. 25, 179-195. doi: 10.1007/s10914-017-9381-1

Naylor, B. G. (1981). Cryptobranchid salamanders from the Paleocene and Miocene of Saskatchewan. Copeia 1981, 76. doi: 10.2307/1444042 
2408

2409

2410

2411

2412

2413

2414

2415

2416

2417

2418

2419

2420

2421

2422

2423

2424

2425

2426

2427

2428

2429

2430

2431

2432

2433

2434

2435

2436

2437

2438

2439

2440

2441

2442

2443

2444

2445

2446

2447

2448

2449

Ni, X., Li, Q., Li, L., Beard, K.C. (2016). Oligocene primates from China reveal divergence between African and Asian primate evolution. Science 352, 673-677. doi: 10.1126/science.aaf2107

Noonan, B. P., Chippindale, P. T. (2006) Vicariant origin of Malagasy reptiles supports Late Cretaceous Antarctic land bridge. The Am. Nat. 168, 730-741. doi: 10.2307/4122245

Novacek, M., Rougier, G., Wible, J., McKenna, M. C., Dashzeveg, D., Horovitz, I. (1997). Epipubic bones in eutherian mammals from the Late Cretaceous of Mongolia. Nature 389, 483-486. doi: $10.1038 / 39020$

O’Connor, P. M., Krause, D. W., Stevens, N. J, Groenke, J. R., MacPhee, R. D. E., Kalthoff, D. C., Roberts, E. M. (2019). A new mammal from the Turonian-Campanian (Upper Cretaceous) Galula Formation, southwestern Tanzania. Acta Palaeont. Pol. 64, 65-84. doi: 10.4202/app.00568.2018

O’Connor, P. M., Turner, A. H., Groenke, J. R., Felice, R. N., Rogers, R. R., Krause, D. W., Rahantarisoa, L. J. (2020). Late Cretaceous bird from Madagascar reveals unique development of beaks. Nature online early. doi: 10.1038/s41586-020-2945-x

O’Leary, M. A., Bloch, J. I., Flynn, J. J., Gaudin, T. J., Giallombardo, A., Giannini, N. P. et al. (2013). The placental mammal ancestor and the post-K-Pg radiation of placentals. Science 339, 662667. doi: $10.1126 /$ science. 1229237

Olsen, P. E. (1988). "Paleontology and paleoecology of the Newark Supergroup (early Mesozoic, eastern North America)", in Triassic-Jurassic Rifting: Continental Breakup and the Origin of the Atlantic Ocean and Passive Margins, Part A. Developments in Geotectonics 22, ed. W. Manspeizer (Amsterdam, Oxford, New York, Tokyo: Elsevier), 185-230.

Olsen, P. E. (2010). Fossil Great Lakes of the Newark Supergroup - 30 Years Later [field trip guide]. NYSGA Field Trip 4. Available at http://citeseerx.ist.psu.edu/viewdoc/download?doi=10.1.1.407.418\&rep=rep1\&type=pdf

Palci, A., Hutchinson, M. N., Caldwell, M. W., Smith, K. T., Lee, M. S. Y. (2019, printed 2020). The homologies and evolutionary reduction of the pelvis and hindlimbs in snakes, with the first report of ossified pelvic vestiges in an anomalepidid (Liotyphlops beui). Zool. J. Linn. Soc. 188, 630-652. doi: 10.1093/zoolinnean/zlz098

Panciroli, E., Benson, R. B. J., Walsh, S., Butler, R. J., Andrade Castro, T., Jones, M. E. H., Evans, S. E. (2020). Diverse vertebrate assemblage of the Kilmaluag Formation (Bathonian, Middle Jurassic) of Skye, Scotland. Earth Env. Sci. Trans. R. Soc. Edinb. online early. doi:

10.1017/S1755691020000055

Pardo, J. D., Szostakiwskyj, M., Ahlberg, P. E., Anderson, J. S. (2017). Hidden morphological diversity among early tetrapods. Nature 546, 642-645. doi: 10.1038/nature22966

Pardo, J. D., Holmes, R., Anderson, J. S. (2018, printed 2019). An enigmatic braincase from Five Points, Ohio (Westphalian D) further supports a stem tetrapod position for aïstopods. Earth Env. Sci. Trans. R. Soc. Edinb. 109, 255-264. doi: 10.1017/S1755691018000567

Pardo, J. D., Lennie, K., Anderson J. S. (2020) Can we reliably calibrate deep nodes in the retrapod tree? Case studies in deep tetrapod divergences. Front. Genet. 11, 506749. doi: 10.3389/fgene.2020.506749

Parham, J. F., Donoghue, P. C. J., Bell, C. J., Calway, T. D., Head, J. J., Holroyd, P. A. et al. (2011, printed 2012). Best practices for justifying fossil calibrations. Syst. Biol. 61, 346-359. doi:

10.1093/sysbio/syr107

This is a provisional file, not the final typeset article 
Paton, R. L., Smithson, T. R., Clack, J. A. (1999). An amniote-like skeleton from the Early

2452 Pearson, M. R. (2016). Phylogeny and systematic history of early salamanders [doctoral thesis]. University College London. Available at https://discovery.ucl.ac.uk/id/eprint/1507772/

Penkrot, T. A., Zack, S. P. (2016). Tarsals of Sespedectinae (?Lipotyphla) from the middle Eocene of southern California, and the affinities of Eocene 'erinaceomorphs'. J. Vert. Paleont. 36, e1212059. doi: 10.1080/02724634.2016.1212059

Pérez-García, A. (2019). The African Aptian Francemys gadoufaouaensis gen. et sp. nov.: New data on the early diversification of Pelomedusoides (Testudines, Pleurodira) in northern Gondwana. Cret. Res. 102, 112-126. doi: 10.1016/j.cretres.2019.06.003

Phillips, M. J., Bennett, T. H., Lee, M. S. Y. (2009). Molecules, morphology, and ecology indicate a recent, amphibious ancestry for echidnas. PNAS 106, 17089-17094. doi: 10.1073/pnas.0904649106 Phillips, M. J., Fruciano, C. (2018). The soft explosive model of placental mammal evolution. BMC

Powell, C. L. E., Waskin, S., Battistuzzi, F. U. (2020). Quantifying the error of secondary vs. distant primary calibrations in a simulated environment. Front. Genet. 11, 252. doi:

2466 10.3389/fgene.2020.00252 of India. Palaeont. Electron. 10, 7A. https://palaeo-electronica.org/2007 2/00117/index.html mammal from India. Science 318, 937. doi: 10.1126/science. 1149267 Jurassic Kota Formation of India [abstract, Society of Vertebrate Paleontology, $74^{\text {th }}$ annual meeting]. J. Vert. Paleont., Program and Abstracts 2014, 208. Entire abstract book available at http://vertpaleo.org/CMSPages/GetFile.aspx?nodeguid=b51eb899-273b-4edb-ae8a-ae067050a3a8

Prevosti, F. J., Chemisquy, M. A. (2009, printed 2010). The impact of missing data on real morphological phylogenies: influence of the number and distribution of missing entries. Cladistics 26, 326-339. doi: 10.1111/j.1096-0031.2009.00289.x saurian from Connecticut and the early evolution of the diapsid feeding apparatus. Nat. Commun. 9, 1213. doi: 10.1038/s41467-018-03508-1 phylogeny of Periptychidae and "archaic" Paleocene mammals under different optimality criteria [abstract, Society of Vertebrate Paleontology, $79^{\text {th }}$ annual meeting]. J. Vert. Paleont., Program and Abstracts 2019, 174. Entire abstract book available at http://vertpaleo.org/Annual-Meeting/AnnualMeeting-Home/SVP-Program-book-v5_w-covers.aspx PhyloCode. Boca Raton, London, New York: CRC Press. Morocco - A preliminary study, with description of a new genus of pipid frog. Palaeontogr. A 285, 1-22. doi: 10.1127/pala/285/2008/1 
Reeder, T. W., Townsend, T. M., Mulcahy, D. G., Noonan, B. P., Wood, P. L. Jr., Sites, J. W. Jr., Wiens, J. J. (2015). Integrated analyses resolve conflicts over squamate reptile phylogeny and reveal unexpected placements for fossil taxa. PLOS ONE 10, e0118199. doi: 10.1371/journal.pone.0118199

Reinhard, S., Voitel, S., Kupfer, A. (2013). External fertilisation and paternal care in the paedomorphic salamander Siren intermedia Barnes, 1826 (Urodela: Sirenidae). Zool. Anz. 253, 1-15. doi: 10.1016/j.jcz.2013.06.002

Reisz, R. R., Modesto, S. P. (1996). Archerpeton anthracos from the Joggins Formation of Nova

Renesto, S., Bernardi, M. (2013, printed 2014). Redescription and phylogenetic relationships of

2500 Megachirella wachtleri Renesto et Posenato, 2003 (Reptilia, Diapsida). Paläont. Z. 88, 197-210. doi:

2501 10.1007/s12542-013-0194-0

Reynoso, V.-H. (2005). Possible evidence of a venom apparatus in a Middle Jurassic sphenodontian

2503 from the Huizachal red beds of Tamaulipas, México. J. Vert. Paleont. 25, 646-654. doi:

2504 10.1671/0272-4634(2005)025[0646:PEOAVA]2.0.CO;2

2506 Clack, J. A. (2018). Diverse and durophagous: Early Carboniferous chondrichthyans from the Scottish Borders. Earth Env. Sci. Trans. R. Soc. Edinb. 108, 67-87. doi: 10.1017/S1755691018000166

Romano, P. S. R., Gallo, V., Ramos, R. R. C., Antonioli, L. (2014a). Atolchelys lepida, a new sidenecked turtle from the Early Cretaceous of Brazil and the age of crown Pleurodira. Biol. Lett. 10, 20140290. doi: 10.1098/rsbl.2014.0290

2512

Romano, C., Koot, M. B., Kogan, I., Brayard, A., Minikh, A. V., Brinkmann, W., et al. (2014b, printed 2016). Permian-Triassic Osteichthyes (bony fishes): diversity dynamics and body size evolution. Biol. Rev. 91, 106-147. doi: 10.1111/brv.12161

2515 Romo de Vivar, P. R., Martinelli, A. G., Fonseca, P. H. M., Bento Soares, M. (2020): To be or not to 2516 be: the hidden side of Cargninia enigmatica and other puzzling remains of Lepidosauromorpha from 2517 the Upper Triassic of Brazil, J. Vert. Paleont. online early. doi: 10.1080/02724634.2020.1828438

2518 Ronchi, A., Santi, G., Marchetti, L., Bernardi, M., Gianolla, P. (2018). First report on swimming trace fossils of fish from the Upper Permian and Lower Triassic of the Dolomites (Italy). Ann. Soc.

2520 Geol. Pol. 88, 111-125. doi: 10.14241/asgp.2018.013

2521

2522

2523

Rong, Y.-F. (2018). Restudy of Regalerpeton weichangensis [sic] (Amphibia: Urodela) from the Lower Cretaceous of Hebei, China. Vert. PalAsiat. 56, 121-136. doi: 10.19615/j.cnki.10003118.170627

2524 Rougier, G. W., Chornogubsky, L., Casadio, S., Páez Arango, N., Giallombardo, A. (2008, printed 2525 2009). Mammals from the Allen Formation, Late Cretaceous, Argentina. Cret. Res. 30, 223-238. doi: 2526 10.1016/j.cretres.2008.07.006 Cretaceous frog Beelzebufo from Madagascar and the placement of fossil constraints based on temporal and phylogenetic evidence. J. Evol. Biol. 24, 274-285. doi: 10.1111/j.1420-

2530 9101.2010.02164.x

2531 Ruta, M., Clack, J. A., Smithson, T. R. (2020) A review of the stem amniote Eldeceeon rolfei from 
2534

2535

2536

2537

2538

2539

2540

2541

2542

2543

2544

2545

2546

2547

2548

2549

2550

2551

2552

2553

2554

2555

2556

2557

2558

2559

2560

2561

2562

2563

2564

2565

2566

2567

2568

2569

2570

2571

2572

2573

Salazar, C., Stinnesbeck, W., Quinzio-Sinn, L.A. (2010). Ammonites from the Maastrichtian (Upper Cretaceous) Quiriquina Formation in central Chile. N. Jb. Geol. Paläont. Abh. 257, 181-236. doi: 10.1127/0077-7749/2010/0072

Sansom, I. J., Andreev, P. S. (2018, printed 2019). "The Ordovician enigma. Fish, first appearances and phylogenetic controversies", in Evolution and Development of Fishes, ed. Z. Johanson, C. Underwood, M. Richter (Cambridge, New York, Port Melbourne, New Delhi, Singapore: Cambridge University Press), 59-70. doi: 10.1017/9781316832172.004

Sansom, R. S., Wills, M. A. (2013). Fossilization causes organisms to appear erroneously primitive by distorting evolutionary trees. Sci. Rep. 3, 2545. doi: 10.1038/srep02545

Sansom, I. J., Davies, N. S., Coates, M. I., Nicoll, R. S., Ritchie, A. (2012). Chondrichthyan-like scales from the Middle Ordovician of Australia. Palaeontology 55, 243-247. doi: 10.1111/j.14754983.2012.01127.x

Sansom, R. S., Choate, P. G., Keating, J. N., Randle, E. (2018). Parsimony, not Bayesian analysis, recovers more stratigraphically congruent phylogenetic trees. Biol. Lett. 14, 20180263. doi: 10.1098/rsbl.2018.0263

Scarpetta, S. G. (2019). The first known fossil Uma: ecological evolution and the origins of North American fringe-toed lizards. BMC Evol. Biol. 19, 178. doi: 10.1186/s12862-019-1501-5

Scarpetta, S. G. (2020) Effects of phylogenetic uncertainty on fossil identification illustrated by a new and enigmatic Eocene iguanian. Sci. Rep. 10, 15734. doi: 10.1038/s41598-020-72509-2

Schoch, R. R., Milner, A. R. (2014). Temnospondyli I. Part 3A2 of Handbook of Paleoherpetology, ed. H.-D. Sues. Munich: Dr. Friedrich Pfeil.

Schoch, R. R., Sues, H.-D. (2017, printed 2018). Osteology of the Middle Triassic stem-turtle Pappochelys rosinae and the early evolution of the turtle skeleton. J. Syst. Palaeont. 16, 927-965. doi: 10.1080/14772019.2017.1354936

Schoch, R. R., Werneburg, R., Voigt, S. (2020). A Triassic stem-salamander from Kyrgyzstan and the origin of salamanders. PNAS 117, 11584-11588. doi: 10.1073/pnas.2001424117

Scott, C. S., Fox, R. C., Redman, C. M. (2016). A new species of the basal plesiadapiform Purgatorius (Mammalia, Primates) from the early Paleocene Ravenscrag Formation, Cypress Hills, southwest Saskatchewan, Canada: further taxonomic and dietary diversity in the earliest primates. Can. J. Earth Sci. 53, 343-354. doi: 10.1139/cjes-2015-0238

Shao, S., Li, L., Yang, Y., Zhou, C. (2018). Hyperphalangy in a new sinemydid turtle from the Early Cretaceous Jehol Biota. PeerJ 6, e5371. doi: 10.7717/peerj.5371

Silcox, M. T., Bloch, J. I., Boyer, D. M., Chester, S. G. B., López-Torres, S. (2017). The evolutionary radiation of plesiadapiforms. Evol. Anthropol. 26, 74-94. doi: 10.1002/evan.21526

Simões, T. R., Wilner, E., Caldwell, M. W., Weinschütz, L. C., Kellner, A. W. A. (2015). A stem acrodontan lizard in the Cretaceous of Brazil revises early lizard evolution in Gondwana. Nat. Commun. 6, 8149. doi: 10.1038/ncomms9149

Simões, T. R., Caldwell, M. W., Weinschütz, L. C., Wilner, E., Kellner, A. W. A. (2017). Mesozoic lizards from Brazil and their role in early squamate evolution in South America. J. Herpetol. 51, 307-315. doi: 10.1670/16-007 
2574

2575

2576

2577

2578

2579

2580

2581

2582

2583

2584

2585

2586

2587

2588

2589

2590

2591

2592

2593

2594

2595

2596

2597

2598

2599

2600

2601

2602

2603

2604

2605

2606

2607

2608

2609

2610

2611

2612

2613

2614

2615

2616

Simões, T. R., Caldwell, M. W., Tałanda, M., Bernardi, M., Palci, A., Vernygora, O., et al. (2018). The origin of squamates revealed by a Middle Triassic lizard from the Italian Alps. Nature 557, 706709. doi: 10.1038/s41586-018-0093-3

Simões, T. R., Vernygora, O., Caldwell, M. W., Pierce, S. E. (2020). Megaevolutionary dynamics and the timing of evolutionary innovation in reptiles. Nat. Commun. 11, 3322. doi: 10.1038/s41467020-17190-9

Skutschas, P. P. (2013). Mesozoic salamanders and albanerpetontids of Middle Asia, Kazakhstan, and Siberia. Palaeobiodiv. Palaeoenv. 93, 441-457. doi: 10.1007/s12549-013-0126-8

Skutschas, P. P. (2014). Kiyatriton leshchinskiyi Averianov et Voronkevich, 2001, a crown-group salamander from the Lower Cretaceous of Western Siberia, Russia. Cret. Res. 51, 88-94. doi: 10.1016/j.cretres.2014.05.014

Skutschas, P. P. (2015, printed 2016). A new crown-group salamander from the Middle Jurassic of Western Siberia, Russia. Palaeobio. Palaeoenv. 96, 41-48. doi: 10.1007/s12549-015-0216-x

Smith, K. T. (2009). A new lizard assemblage from the earliest Eocene (zone Wa0) of the Bighorn Basin, Wyoming, USA: Biogeography during the warmest interval of the Cenozoic. J. Syst. Palaeont. 7, 299-358. doi: 10.1017/S1477201909002752

Smithson, T. R., Carroll, R. L., Panchen, A. L., Andrews, S. M. (1994, for 1993). Westlothiana lizziae from the Viséan of East Kirkton, West Lothian, Scotland, and the amniote stem. Trans. $R$. Soc. Edinb. Earth Sci. 84, 383-412. doi: 10.1017/s0263593300006192

Smithson, T. R., Wood, S. P., Marshall, J. E. A., Clack, J. A. (2012). Earliest Carboniferous tetrapod and arthropod faunas from Scotland populate Romer's Gap. PNAS 109, 4532-4537. doi: 10.1073/pnas.1117332109

Sobral, G., Simões, T. R., Schoch, R. R. (2020). A tiny new Middle Triassic stem-lepidosauromorph from Germany: implications for the early evolution of lepidosauromorphs and the Vellberg fauna. Sci. Rep. 10, 2273. doi: 10.1038/s41598-020-58883-x

Solé, F., Smith, T., de Bast, E., Codrea, V., Gheerbrant, E. (2016). New carnivoraforms from the latest Paleocene of Europe and their bearing on the origin and radiation of Carnivoraformes (Carnivoramorpha, Mammalia). J. Vert. Paleont. 36, e1082480. doi: $10.1080 / 02724634.2016 .1082480$

Sookias, R. B. (2019, printed 2020). Exploring the effects of character construction and choice, outgroups and analytical method on phylogenetic inference from discrete characters in extant crocodilians [sic]. Zool. J. Linn. Soc. 189, 670-699. doi: 10.1093/zoolinnean/zlz015

de Souza Carvalho, I., Agnolin, F., Aranciaga Rolando, M. A., Novas, F. E., Xavier-Neto, J., de Freitas, F. I., Ferreira Gomes de Andrade, J. A. (2019). A new genus of pipimorph frog (Anura) from the Early Cretaceous Crato Formation (Aptian) and the evolution of South American tongueless frogs. J. S. Am. Earth Sci. 92, 222-233. doi: 10.1016/j.jsames.2019.03.005

Spaulding, M., Flynn, J. J. (2012). Phylogeny of the Carnivoramorpha: the impact of postcranial characters. J. Syst. Palaeont. 10, 653-677. doi: 10.1080/14772019.2011.630681

Springer, M. S., Foley, N. M., Brady, P. L., Gatesy, J., Murphy, W. J. (2019). Evolutionary models for the diversification of placental mammals across the KPg boundary. Front. Genet. 10, 1241. doi: 10.3389/fgene.2019.01241

Sterli, J., de la Fuente, M. S., Rougier, G. W. (2019, for 2018). New remains of Condorchelys antiqua (Testudinata) from the Early-Middle Jurassic of Patagonia: anatomy, phylogeny, and

This is a provisional file, not the final typeset article 
2617 paedomorphosis in the early evolution of turtles. J. Vert. Paleont. 38, e1480112. doi:

$2618 \quad 10.1080 / 02724634.2018 .1480112$

2619 Sterli, J., Martínez, R. N., Cerda, I. A., Apaldetti, C. (2020). Appearances can be deceptive: bizarre shell microanatomy and histology in a new Triassic turtle (Testudinata) from Argentina at the dawn of turtles. Pap. Palaeont. online early. doi: 10.1002/spp2.1334

2622 Stocker, M. R., Nesbitt, S. J., Kligman, B. T., Paluh, D. J., Marsh, A. D., Blackburn, D. C., Parker, W. G. (2019). The earliest equatorial record of frogs from the Late Triassic of Arizona. Biol. Lett. 15: 20180922. doi: 10.1098/rsbl.2018.0922

2625 Stumpf, S., Kriwet, J. (2019). A new Pliensbachian elasmobranch (Vertebrata, Chondrichthyes) assemblage from Europe, and its contribution to the understanding of late Early Jurassic elasmobranch diversity and distributional patterns. Paläont. Z. 93, 637-658. doi: 10.1007/s12542019-00451-4

Sullivan, R. M. (1982). Fossil lizards from Swain Quarry "Fort Union Formation," middle Paleocene (Torrejonian), Carbon County, Wyoming. J. Paleont. 56, 996-1010. Available at

2631 https://www.jstor.org/stable/1304719

2632

2633

2634

2635

2636

2637

2638

2639

2640

2641

2642

2643

2644

2645

2646

2647

2648

2649

2650

2651

2652

2653

2654

2655

2656

2657

2658
Sun, Z.-y., Tintori, A., Lombardo, C., Jiang, D.-y. (2016). New miniature neopterygians from the Middle Triassic of Yunnan Province, South China. N. Jb. Geol. Paläont. Abh. 282, 135-156. doi: 10.1127/njgpa/2016/0610

Sweetman, S. C., Smith, G., Martill, D. M. (2017). Highly derived eutherian mammals from the earliest Cretaceous of southern Britain. Acta Palaeont. Pol. 62, 657-665. doi:

10.4202/app.00408.2017

Tambussi, C. P., Degrange, F. J., de Mendoza, R. S., Sferco, E., Santillana, S. (2019). A stem anseriform from the early Palaeocene of Antarctica provides new key evidence in the early evolution of waterfowl. Zool. J. Linn. Soc. 186, 673-700. doi: 10.1093/zoolinnean/zly085

Tanner, L. H., Lucas, S. G. (2015). The Triassic-Jurassic strata of the Newark Basin, USA: A complete and accurate astronomically-tuned timescale? Stratigraphy 12, 47-65. Available at http://www.micropress.org/microaccess/stratigraphy/issue-316/article-1933

The PLOS ONE Staff (2014). Correction: The origin and early evolution of Sauria: reassessing the Permian saurian fossil record and the timing of the crocodile-lizard divergence. PLOS ONE 9, e97828. doi: 10.1371/journal.pone.0097828

Tomiya, S. (2011). A new basal caniform (Mammalia: Carnivora) from the middle Eocene of North America and remarks on the phylogeny of early carnivorans. PLOS ONE 6, e24146. doi:

10.1371/journal.pone.0024146

Tomiya, S., Tseng, Z. J. (2016) Whence the beardogs? Reappraisal of the Middle to Late [sic] Eocene 'Miacis' from Texas, USA, and the origin of Amphicyonidae (Mammalia, Carnivora). $R$. Soc. Open Sci. 3, 160518. doi: 10.1098/rsos.160518

Tong, H., Danilov, I., Ye, Y., Ouyang, H., Peng, G. (2011, printed 2012). Middle Jurassic turtles from the Sichuan Basin, China: a review. Geol. Mag. 149, 675-695. doi: 10.1017/S0016756811000859

Tong, H., Li, L., Ouyang, H. (2013, printed 2014). A revision of Sinaspideretes wimani Young \& Chow, 1953 (Testudines: Cryptodira: Trionychoidae) from the Jurassic of the Sichuan Basin, China. Geol. Mag. 151, 600-610. doi: 10.1017/S0016756813000575 
Trujillo, K.C., Carrano, M.T., Chamberlain, K.R. (2015). A U-Pb zircon age for Reed's Quarry 9,

2660

Upper Jurassic Morrison Formation, Albany County, WY [abstract, Society of Vertebrate

2662

Paleontology, $75^{\text {th }}$ annual meeting]. J. Vert. Paleont., Program and Abstracts 2015, 226. Entire

2663

abstract book available at http://vertpaleo.org/PDFS/SVP-2015-Program-and-Abstract-Book-9-22-

2015.aspx

2664

2665

van Tuinen, M., Hedges, S. B. (2004). The effects of external and internal fossil calibrations on the

2666

avian evolutionary timescale. J. Paleont. 78, 45-50. doi: 10.1666/0022-

2667

3360(2004)078<0045:TEOEAI > 2.0.CO;2

2668

Tykoski, R. S., Rowe, T. B., Ketcham, R. A., Colbert, M. W. (2002). Calsoyasuchus valliceps, a new

2669

crocodyliform from the Early Jurassic Kayenta Formation of Arizona. J. Vert. Paleont. 22, 593-611.

doi: 10.1671/0272-4634(2002)022[0593:CVANCF]2.0.CO;2

2670

Vasilyan, D., Böhme, M. (2012). Pronounced peramorphosis in lissamphibians-Aviturus exsecratus

2672 (Urodela, Cryptobranchidae) from the Paleocene-Eocene Thermal Maximum of Mongolia. PLOS ONE 7, e40665. doi: 10.1371/journal.pone.0040665

2674

Vasilyan, D., Böhme, M., Chkhikvadze, V. M., Semenov, Yu. A., Joyce, W. G. (2013). A new giant

2675 salamander (Urodela, Pancryptobrancha) from the Miocene of Eastern Europe (Grytsiv, Ukraine). $J$. Vert. Paleont. 33, 301-318. doi: 10.1080/02724634.2013.722151

Vijayakumar, S. P., Pyron, R. A., Dinesh, K. P., Torsekar, V. R., Srikanthan, A. N., Swamy, P.,

Nyctibatrachidae: Astrobatrachinae subfam. nov.) endemic to the Western Ghats of Peninsular India. PeerJ 7, e6457. doi: 10.7717/peerj.6457

Waddell, P. J., Kishino, H., Ota, R. (2001). A phylogenetic foundation for comparative mammalian genomics. Genome Informatics 12, 141-154. doi: 10.11234/gi1990.12.141

2682 Waggoner, B., Collins, A. G. (2004) Reductio ad absurdum: testing the evolutionary relationships of 2683 Ediacaran and Paleozoic problematic fossils using molecular divergence dates. J. Paleont. 78, 51-61. doi: 10.1666/0022-3360(2004)078<0051:RAATTE >2.0.CO;2

Wang, Y., Evans, S. E. (2006). A new short-bodied salamander from the Upper Jurassic/Lower Cretaceous of China. Acta Palaeont. Pol. 51, 127-130.

2687 Wang, Y., Dong, L., Evans, S. E. (2015, printed 2016). Polydactyly and other limb abnormalities in 2688 the Jurassic salamander Chunerpeton from China. Palaeobiol. Palaeoenv. 96, 49-59. doi:

2689 10.1007/s12549-015-0219-7

Wang, Y.-M., O’Connor, J. K., Li, D.-Q., You, H.-L. (2013). Previously unrecognized ornithuromorph bird diversity in the Early Cretaceous Changma Basin, Gansu Province, northwestern China. PLOS ONE 8, e77693. doi: 10.1371/journal.pone.0077693 http://www.ivpp.cas.cn/cbw/gjzdwxb/xbwzXz/201604/P020160429371137449751.pdf sauropods in Sichuan, China: A reappraisal of basal sauropod evolution. GSA Bull. 130, 1493-1500. doi: 10.1130/B31910.1 
2701

2702

2703

2704

2705

2706

2707

2708

2709

2710

2711

2712

2713

2714

2715

2716

2717

2718

2719

2720

2721

2722

2723

2724

2725

2726

2727

2728

2729

2730

2731

2732

2733

2734

2735

2736

2737

2738

2739

2740

2741

2742
Wesley, G. D., Flynn, J. J. (2003). A revision of Tapocyon (Carnivoramorpha), including analysis of the first cranial specimens and identification of a new species. J. Paleont. 77, 769-783. doi: $10.1017 / \mathrm{S} 0022336000044486$

Whelan, N. V., Halanych, K. M. (2016, printed 2017). Who let the CAT out of the bag? Accurately dealing with substitutional heterogeneity in phylogenomic analyses. Syst. Biol. 66, 232-255. doi: 10.1093/sysbio/syw084

Wible, J. R., Rougier, G. W., Novacek, M. J., Asher, R. J. (2009). The eutherian mammal Maelestes gobiensis from the Late Cretaceous of Mongolia and the phylogeny of Cretaceous Eutheria. Bull. Am. Mus. Nat. Hist. 327, 1-123. doi: 10.1206/623.1

Wiens, J. J. (2003a). Incomplete taxa, incomplete characters, and phylogenetic accuracy: is there a missing data problem? J. Vert. Paleont. 23, 297-310. doi: 10.1671/02724634(2003)023[0297:ITICAP]2.0.CO;2

Wiens, J. J. (2003b). Missing data, incomplete taxa, and phylogenetic accuracy. Syst. Biol. 52, 528538. doi: $10.1080 / 10635150390218330$

Wiens, J. J. (2005a). Can incomplete taxa rescue phylogenetic analyses from long-branch attraction? Syst. Biol. 54, 731-742. doi: 10.1080/10635150500234583

Wiens, J. J. (2005b, printed 2006). Missing data and the design of phylogenetic analyses. J. Biomed. Informatics 39, 34-42. doi: 10.1016/j.jbi.2005.04.001

Wiens, J. J., Bonett, R. M., Chippindale, P. T. (2005). Ontogeny discombobulates phylogeny: paedomorphosis and higher-level salamander relationships. Syst. Biol. 54, 91-110. doi: 10.1080/10635150590906037

Williamson, T. E., Flynn, A., Peppe, D. J., Heizler, M. T., Leslie, C. E., Secord, R., et al. (2019). A revised, high-resolution age model for the Paleocene of the San Juan Basin, New Mexico, U.S.A[,] and implications for faunal and floral dynamics during the dawn of the age of mammals [abstract, Society of Vertebrate Paleontology, $79^{\mathrm{th}}$ annual meeting]. J. Vert. Paleont., Program and Abstracts 2019, 219-220. Entire abstract book available at http://vertpaleo.org/Annual-Meeting/AnnualMeeting-Home/SVP-Program-book-v5_w-covers.aspx

Wilson, G. P., Ekdale, E. G., Hoganson, J. W., Calede, J. J., Vander Linden, A. (2016). A large carnivorous mammal from the Late Cretaceous and the North American origin of marsupials. Nat. Commun. 7, 13734. doi: 10.1038/ncomms13734

Wolfe, J. M., Daley, A. C., Legg, D. A., Edgecombe, G. D. (2016). Fossil calibrations for the arthropod Tree of Life. Earth-Sci. Rev. 160, 43-110. doi: 10.1016/j.earscirev.2016.06.008

Woodburne, M. O., Goin, F. J., Raigemborn, M. S., Heizler, M., Gelfo, J. N., Oliveira, E. V. (2014). Revised timing of the South American early Paleogene land mammal ages. J. S. Am. Earth Sci. 54, 109-119. doi: 10.1016/j.jsames.2014.05.003

Woodhead, J., Reisz, R. [R.], Fox, D., Drysdale, R., Hellstrom, J., Maas, R., et al. (2010). Speleothem climate records from deep time? Exploring the potential with an example from the Permian. Geology 38, 455-458. doi: 10.1130/G30354.1

Xing, L.-D., Lockley, M. G., Wei, C., Gierliński, G. D., Li, J.-J., Persons, W. S. IV, et al. (2013).

Two theropod track assemblages from the Jurassic of Chongqing, China, and the Jurassic stratigraphy of Sichuan Basin. Vert. PalAsiat. 51, 107-130. Available at http://www.ivpp.cas.cn/cbw/gizdwxb/xbwzxz/201305/P020130507384125932092.pdf 
2743

2744

2745

2746

2747

2748

2749

2750

2751

2752

2753

2754

2755

2756

2757

2758

2759

2760

2761

2762

2763

2764

2765

2766

2767

2768

2769

2770

2771

2772

2773

2774

2775

2776

2777

2778

2779

2780

2781

2782

2783

$\mathrm{Xu}$, G.-H. (2019). Osteology and phylogeny of Robustichthys luopingensis, the largest holostean fish in the Middle Triassic. PeerJ 7, e7184. doi: 10.7717/peerj.7184

Yuan, C.-X., Ji, Q., Meng, Q.-J., Tabrum, A. R., Luo, Z.-X. (2013). Earliest evolution of multituberculate mammals revealed by a new Jurassic fossil. Science 341, 779-783. doi: 10.1126/science. 1237970

Zack, S. P. (2009). The phylogeny of eutherian mammals: a new analysis emphasizing dental and postcranial morphology of Paleogene taxa [doctoral thesis]. Baltimore: Johns Hopkins University. UMI number 3399111.

Žigaitè-Moro, Ž., Karatajūtè-Talimaa, V., Joachimski, M. M., Jeffries, T. (2018). Silurian vertebrates from northern Mongolia: diversity, ecology and environment [abstract, $5^{\text {th }}$ International

Palaeontological Congress]. Entire abstract book available at https://ipc5.sciencesconf.org/data/IPC5_Abstract_Book.pdf

Zhang, Y., Wang, Y., Zhan, R., Fan, J., Zhou, Z., Fang, X. (2014). Ordovician and Silurian

Stratigraphy and Palaeontology of Yunnan, Southwest China. A guide to the field excursion across the South China, Indochina and Sibumasu [blocks]. Beijing: Science Press. Cited pages available at https://www.researchgate.net/profile/Wenjin_Zhao/publication/272093484_The_Chongjiawan_Camb rian-Silurian boundary section/links/54dafabc0cf2ba88a68eaa18.pdf

Zhou, C.-F., Bhullar, Bh.-A. S., Neander, A. I., Martin, T., Luo, Z.-X. (2019). New Jurassic mammaliaform sheds light on early evolution of mammal-like hyoid bones. Science 365, 276-279. doi: 10.1126/science.aau9345

Zhu, M., Fan, J. (1995). Youngolepis from the Xishancun Formation (Early Lochkovian) of Qujing, China. Geobios 28 (supp. 2), 293-299. doi: 10.1016/S0016-6995(95)80130-8

\section{$1 \quad$ Figure legend}

Figure 1: Timetree resulting from application of the calibrations described here. The $95 \%$ confidence intervals of each node are drawn vertically narrower where the tree is particularly crowded. The calibrations are shown as red arrows horizontally in line with the nodes they apply to; note that the arrow that is almost aligned with the branch of Lalagobatrachia and the one that is almost aligned with the terminal branch for Silurana are the maximum and minimum ages of node 178 (Pipidae), the one on the branch for Siren applies to node 161 (Caudata), the one on Iguana to node 131 (Iguania), and the one on Pelodiscus to node 117 (Testudines). The abbreviated genus names are spelled out as clade names on their common branches; where only one species per genus is sampled, see Irisarri et al. (2017) for full species names. To the extent possible, clade names with minimum-clade (nodebased) definitions are placed close to those nodes, while names with maximum-clade (branch-based) definitions are shown close to the origin of that branch (i.e. the preceding node if sampled).

Period/epoch symbols from oldest to youngest: Cambrian (cut off at $500 \mathrm{Ma}$ ), Ordovician, Silurian, Devonian, Carboniferous, Permian, Triassic, Jurassic, Early Cretaceous, Late Cretaceous, Paleogene, Neogene including Quaternary (which comprises the last 2.58 Ma and is not shown separately). Timescale (including colors) from the International Chronostratigraphic Chart, version 2020/03 (Cohen et al., 2020). Node numbers, also used in the text and the Tables, from Irisarri et al. (2017).

The figure will change somewhat once the ongoing new analysis with the updated calibrations is finished, and perhaps the legend will as well. I have therefore not included it in this preprint.

This is a provisional file, not the final typeset article 


\section{Recalibrating the gnathostome timetree}

Table 1: The first four columns of Irisarri et al. (2017: supplementary table 8), here expanded to five, followed by the ages used here for the same calibrations and the differences $(\Delta)$. Boldface is a rough indicator of my confidence. Hard bounds are marked with an asterisk. Dates in parentheses were not specified in the analysis; the node was constrained in practice by the given constraint on a preceding (for maximum ages) or following node (for minimum ages) elsewhere in this table - see Fig. 1 for which nodes precede each other. The two dates in quotation marks were specified by Irisarri et al. (2017), but had no effect because they were in practice constrained by the dates specified for other nodes. Dashes in the second and third column separate the two branches stemming from the node in question. See the text for discussion of each node and references.

\begin{tabular}{|c|c|c|c|c|c|c|c|c|}
\hline $\begin{array}{l}\text { Node number } \\
\text { in Irisarri et al. } \\
\text { (2017: supp. } \\
\text { table } 8 \text {, supp. } \\
\text { fig. 19) }\end{array}$ & Description of cladogenesis & $\begin{array}{l}\text { The sampled terminal } \\
\text { taxa that stem from } \\
\text { this node are: }\end{array}$ & $\begin{array}{l}\text { Minimum } \\
\text { age in } \\
\text { Irisarri et } \\
\text { al. (2017) }\end{array}$ & $\begin{array}{l}\text { Maximum } \\
\text { age in } \\
\text { Irisarri et } \\
\text { al. (2017) }\end{array}$ & $\begin{array}{l}\text { Minimum } \\
\text { age used } \\
\text { here }\end{array}$ & $\begin{array}{l}\text { Maximum } \\
\text { age used } \\
\text { here }\end{array}$ & $\begin{array}{l}\Delta \\
\text { minimum } \\
\text { ages }\end{array}$ & $\begin{array}{l}\Delta \\
\text { maximum } \\
\text { ages }\end{array}$ \\
\hline 100 & $\begin{array}{l}\text { Root node }=\text { Gnathostomata: total } \\
\text { group including Chondrichthyes - } \\
\text { Pan-Osteichthyes }\end{array}$ & entire sample & 421.75 & 462.5 & $465^{*}$ & 475 & +43.25 & +12.5 \\
\hline 102 & $\begin{array}{l}\text { Osteichthyes: Pan-Actinopterygii - } \\
\text { Sarcopterygii }\end{array}$ & $\begin{array}{l}\text { entire sample except } \\
\text { Chondrichthyes }\end{array}$ & 416 & 439 & $(420 *)$ & $(475)$ & +4 & +36 \\
\hline 104 & Dipnomorpha - Tetrapodomorpha & Dipnoi - Tetrapoda & 408 & 419 & $420 *$ & $(475)$ & +12 & +56 \\
\hline 105 & Tetrapoda: Amphibia - Pan-Amniota & $\begin{array}{l}\text { Lissamphibia - } \\
\text { Amniota }\end{array}$ & 330.4 & 350.1 & $\begin{array}{l}\text { 335* (or } \\
350 *)\end{array}$ & 365 & $\begin{array}{l}+4.6 \text { (or } \\
+19.6)\end{array}$ & +14.9 \\
\hline 106 & $\begin{array}{l}\text { Amniota: Pan-Mammalia - } \\
\text { Sauropsida }\end{array}$ & Mammalia - Reptilia & 288 & 338 & 318* & $(365)$ & +30 & +27 \\
\hline 107 & $\begin{array}{l}\text { Reptilia: Pan-Lepidosauria - total } \\
\text { group of Archelosauria }\end{array}$ & $\begin{array}{l}\text { Lepidosauria - } \\
\text { Testudines, }\end{array}$ & 252 & 257 & $\left(263^{*}\right)$ & $(365)$ & +11 & +108 \\
\hline
\end{tabular}


Recalibrating the gnathostome timetree

\begin{tabular}{|c|c|c|c|c|c|c|c|c|}
\hline & & Crocodylia, Aves & & & & & & \\
\hline 108 & $\begin{array}{l}\text { Archelosauria: Pan-Testudines - } \\
\text { Pan-Archosauria }\end{array}$ & $\begin{array}{l}\text { Testudines - } \\
\text { Crocodylia, Aves }\end{array}$ & (243) & $(257)$ & $263 *$ & $(365)$ & +20 & +108 \\
\hline 109 & $\begin{array}{l}\text { Archosauria: Crocodylotarsi - } \\
\text { Avemetatarsalia }\end{array}$ & Crocodylia - Aves & 243 & 251 & $248 *$ & 252 & +5 & +1 \\
\hline 111 & $\begin{array}{l}\text { Alligatoridae: Alligatorinae - } \\
\text { Caimaninae }\end{array}$ & Alligator-Caiman & 66 & 75 & $65 *$ & $200 *$ & -1 & +125 \\
\hline 113 & Neognathae: Galloanserae - Neoaves & $\begin{array}{l}\text { Anas, Gallus, } \\
\text { Meleagris - } \\
\text { Taeniopygia }\end{array}$ & 66 & 86.5 & 71 & 115 & +5 & +28.5 \\
\hline 117 & $\begin{array}{l}\text { Testudines: Pan-Pleurodira - Pan- } \\
\text { Cryptodira }\end{array}$ & $\begin{array}{l}\text { Phrynos, Pelusios - } \\
\text { all other sampled } \\
\text { turtles }\end{array}$ & 210 & $(257)$ & $158 *$ & 185 & -52 & -72 \\
\hline 124 & $\begin{array}{l}\text { Pleurodira: Pan-Chelidae - Pan- } \\
\text { Pelomedusoides }\end{array}$ & Phrynops - Pelusios & 25 & $(257)$ & $125 *$ & $(185)$ & +100 & -122 \\
\hline 125 & $\begin{array}{l}\text { Lepidosauria: Rhynchocephalia - } \\
\text { Pan-Squamata }\end{array}$ & $\begin{array}{l}\text { Sphenodon- } \\
\text { Squamata }\end{array}$ & 238 & $(257)$ & $244 *$ & 290 & +6 & +33 \\
\hline 129 & $\begin{array}{l}\text { Toxicofera: Pan-Serpentes - } \\
\text { Anguimorpha + Pan-Iguania }\end{array}$ & $\begin{array}{l}\text { snakes - their sister- } \\
\text { group }\end{array}$ & $\begin{array}{l}\text { "148" } \\
(165)\end{array}$ & $(257)$ & $130 *$ & $(290)$ & $\begin{array}{l}“-18 ” \\
(-35)\end{array}$ & +33 \\
\hline 131 & $\begin{array}{l}\text { Iguania: Pan-Acrodonta - Pan- } \\
\text { Iguanidae }\end{array}$ & $\begin{array}{l}\text { Pogona, Chamaeleo - } \\
\text { Iguana, Basiliscus, }\end{array}$ & 165 & 230 & $72 *$ & $(290)$ & -93 & +60 \\
\hline
\end{tabular}

This is a provisional file, not the final typeset article 
Recalibrating the gnathostome timetree

\begin{tabular}{|c|c|c|c|c|c|c|c|c|}
\hline & & Sceloporus, Anolis & & & & & & \\
\hline 132 & $\begin{array}{l}\text { Iguanidae: Iguaninae }+ \\
\text { Corytophanidae }- \text { Phrynosomatidae } \\
\text { + Dactyloidae }\end{array}$ & $\begin{array}{l}\text { Iguana, Basiliscus - } \\
\text { Sceloporus, Anolis }\end{array}$ & 125 & 180 & $53 *$ & $(290)$ & -72 & +110 \\
\hline 150 & $\begin{array}{l}\text { Mammalia (Pan-Monotremata - } \\
\text { Theriimorpha) }\end{array}$ & $\begin{array}{l}\text { Ornithorhynchus - } \\
\text { Theria }\end{array}$ & 162.5 & 191.4 & $179 *$ & $233 *$ & +16.5 & +41.6 \\
\hline 151 & Theria: Metatheria - Eutheria & $\begin{array}{l}\text { Marsupialia - } \\
\text { Placentalia }\end{array}$ & 124.6 & 138.4 & $126 *$ & 160 & +1.4 & +21.6 \\
\hline 152 & $\begin{array}{l}\text { Placentalia: Atlantogenata - } \\
\text { Boreo(eu)theria }\end{array}$ & $\begin{array}{l}\text { Loxodonta, Dasypus- } \\
\text { Felis, Canis, Homo, } \\
\text { Mus }\end{array}$ & 95.3 & 113 & $\left(66^{*}\right)$ & $72 *$ & -29.3 & -41 \\
\hline 153 & $\begin{array}{l}\text { Boreo(eu)theria: Laurasiatheria - } \\
\text { Euarchontoglires/Supraprimates }\end{array}$ & $\begin{array}{l}\text { Felis, Canis - Homo, } \\
\text { Mus }\end{array}$ & $(61.5)$ & $(113)$ & $66 *$ & $(72 *)$ & +4.5 & -41 \\
\hline 154 & $\begin{array}{l}\text { Carnivora: Pan-Feliformia - Pan- } \\
\text { Caniformia }\end{array}$ & Felis-Canis & 42.8 & 63.8 & $38 *$ & $56 *$ & -4.8 & -7.8 \\
\hline 155 & $\begin{array}{l}\text { Euarchontoglires/Supraprimates: } \\
\text { Gliriformes - Primatomorpha }\end{array}$ & Mus - Homo & 61.5 & 100.5 & $65 *$ & $(72 *)$ & +3.5 & -28.5 \\
\hline 157 & $\begin{array}{l}\text { Marsupialia: Didelphimorphia - } \\
\text { Paucituberculata + Australidelphia }\end{array}$ & $\begin{array}{l}\text { Monodelphis- } \\
\text { Macropus, } \\
\text { Sarcophilus }\end{array}$ & 61.5 & 71.2 & $55^{*}$ & $68 *$ & -6.5 & -3.2 \\
\hline 160 & Batrachia: Urodela - Salientia & Caudata - Anura & 249 & $(350.1)$ & $249 *$ & 290 & 0 & -60.1 \\
\hline
\end{tabular}


Recalibrating the gnathostome timetree

\begin{tabular}{|c|c|c|c|c|c|c|c|c|}
\hline 169 & $\begin{array}{l}\text { crown group of Cryptobranchoidea: } \\
\text { Hynobiidae - Pancryptobrancha }\end{array}$ & Hynobius - Andrias & 145.5 & $(350.1)$ & $101 *$ & (290) & -44.5 & -60.1 \\
\hline 170 & $\begin{array}{l}\text { Lalagobatrachia/Bombinanura: total } \\
\text { group of Bombinatoroidea/Costata - } \\
\text { total group of Pipanura }\end{array}$ & $\begin{array}{l}\text { Bombina, } \\
\text { Discoglossus - all } \\
\text { other sampled frogs }\end{array}$ & 161.2 & $(350.1)$ & $\left(153^{*}\right)$ & (290) & -8.2 & -60.1 \\
\hline 171 & $\begin{array}{l}\text { Pipanura: total group of } \\
\text { Pipoidea/Xenoanura - total group of } \\
\text { Acosmanura }\end{array}$ & $\begin{array}{l}\text { Pipa, Hymenochirus, } \\
\text { Silurana - their sister- } \\
\text { group }\end{array}$ & 145.5 & $(350.1)$ & $153 *$ & (290) & +7.5 & -60.1 \\
\hline 178 & $\begin{array}{l}\text { Pipidae: Pipinomorpha - } \\
\text { Xenopodinomorpha }\end{array}$ & $\begin{array}{l}\text { Pipa - Silurana, } \\
\text { Hymenochirus }\end{array}$ & 86 & $(350.1)$ & $84 *$ & $199 *$ & -2 & -151.1 \\
\hline 187 & $\begin{array}{l}\text { crown group of Chondrichthyes } \\
\text { (Holocephali - Elasmobranchii) }\end{array}$ & $\begin{array}{l}\text { Callorhinchus - } \\
\text { Elasmobranchii }\end{array}$ & 410 & $\begin{array}{l}“ 495 ” \\
(462.5)\end{array}$ & $385 *$ & (475) & -25 & $\begin{array}{l}“-20 " \\
(+12.5)\end{array}$ \\
\hline 188 & $\begin{array}{l}\text { crown group of Elasmobranchii } \\
\text { (Selachimorpha - Batomorpha) }\end{array}$ & sharks - rays & 190 & $(462.5)$ & $201 *$ & $395 *$ & +11 & -67.5 \\
\hline 192 & Batoidea (Rajiformes - rays) & $\begin{array}{l}\text { Neotrygon - Raja, } \\
\text { Leucoraja }\end{array}$ & 176 & $(462.5)$ & $184 *$ & $201 *$ & +8 & -261.5 \\
\hline 195 & $\begin{array}{l}\text { Neopterygii (Holosteomorpha - Pan- } \\
\text { Teleostei) }\end{array}$ & $\begin{array}{l}\text { Lepisosteus, Amia- } \\
\text { Takifugu, Danio }\end{array}$ & 345 & 392 & $249 *$ & 299 & -96 & -93 \\
\hline
\end{tabular}

This is a provisional file, not the final typeset article 


\section{Recalibrating the gnathostome timetree}

Table 2: The ages found by Irisarri et al. (2017: supplementary table 9: last three columns) when all calibrations were used, and the results obtained here with the updated calibrations. All are rounded to whole Ma. Irisarri et al. (2017) treated all bounds as soft; the hard and soft bounds used here are shown in Table 1.

This is a placeholder; the last three columns will change a little once the ongoing new analysis with the updated calibrations is finished.

\begin{tabular}{|c|c|c|c|c|c|c|}
\hline & $\begin{array}{l}\text { Irisarri et a } \\
(2017)\end{array}$ & & & $\begin{array}{l}\text { Present } \\
\text { results }\end{array}$ & & \\
\hline $\begin{array}{l}\text { Node } \\
\text { number }\end{array}$ & Mean age & $\begin{array}{l}\text { younger } \\
\text { bound of } \\
95 \% \text { CI }\end{array}$ & $\begin{array}{l}\text { older bound } \\
\text { of } 95 \% \text { CI }\end{array}$ & Mean age & $\begin{array}{l}\text { younger } \\
\text { bound of } \\
95 \% \text { CI }\end{array}$ & $\begin{array}{l}\text { older bound } \\
\text { of } 95 \% \mathrm{CI}\end{array}$ \\
\hline 100 & 460 & 452 & 465 & 472 & 466 & 475 \\
\hline 101 & 393 & 383 & 403 & 370 & 340 & 400 \\
\hline 102 & 437 & 431 & 440 & 454 & 440 & 466 \\
\hline 103 & 426 & 420 & 431 & 424 & 407 & 437 \\
\hline 104 & 412 & 408 & 418 & 410 & 394 & 424 \\
\hline 105 & 341 & 331 & 350 & 359 & 346 & 366 \\
\hline 106 & 289 & 283 & 296 & 312 & 300 & 322 \\
\hline 107 & 257 & 256 & 257 & 296 & 286 & 305 \\
\hline 108 & 254 & 253 & 256 & 286 & 277 & 294 \\
\hline 109 & 243 & 242 & 245 & 249 & 248 & 252 \\
\hline 110 & 120 & 90 & 162 & 160 & 131 & 182 \\
\hline 111 & 71 & 66 & 75 & 158 & 129 & 179 \\
\hline 112 & 137 & 111 & 173 & 166 & 148 & 184 \\
\hline 113 & 83 & 70 & 87 & 105 & 87 & 116 \\
\hline 114 & 63 & 47 & 73 & 89 & 71 & 104 \\
\hline 115 & 16 & 8 & 25 & 65 & 52 & 82 \\
\hline
\end{tabular}


bioRxiv preprint doi: https://doi.org/10.1101/2019.12.19.882829; this version posted November 30, 2020 . The copyright holder for this preprint (which was not certified by peer review) is the author/funder, who has granted bioRxiv a license to display the preprint in perpetuity. It is made available under aCC-BY-ND 4.0 International license.

Recalibrating the gnathostome timetree

\begin{tabular}{|c|c|c|c|c|c|c|}
\hline 116 & 92 & 66 & 130 & 162 & 144 & 181 \\
\hline 117 & 224 & 211 & 234 & 172 & 164 & 176 \\
\hline 118 & 206 & 184 & 221 & 159 & 143 & 168 \\
\hline 119 & 168 & 133 & 188 & 134 & 111 & 148 \\
\hline 120 & 155 & 117 & 176 & 132 & 108 & 146 \\
\hline 121 & 127 & 90 & 150 & 127 & 104 & 142 \\
\hline 122 & 95 & 63 & 124 & 109 & 85 & 127 \\
\hline 123 & 78 & 45 & 107 & 114 & 91 & 132 \\
\hline 124 & 192 & 167 & 211 & 164 & 151 & 172 \\
\hline 125 & 239 & 233 & 244 & 254 & 244 & 268 \\
\hline 126 & 199 & 190 & 208 & 169 & 153 & 182 \\
\hline 127 & 195 & 185 & 204 & 166 & 150 & 179 \\
\hline 128 & 187 & 177 & 196 & 161 & 144 & 173 \\
\hline 129 & 182 & 173 & 192 & 158 & 141 & 170 \\
\hline 130 & 181 & 172 & 190 & 157 & 140 & 168 \\
\hline 131 & 166 & 159 & 175 & 149 & 131 & 161 \\
\hline 132 & 137 & 124 & 151 & 134 & 115 & 146 \\
\hline 133 & 127 & 111 & 142 & 133 & 113 & 145 \\
\hline 134 & 130 & 115 & 145 & 108 & 86 & 125 \\
\hline 135 & 128 & 104 & 143 & 129 & 108 & 143 \\
\hline 136 & 94 & 72 & 119 & 122 & 103 & 140 \\
\hline 137 & 88 & 66 & 112 & 118 & 98 & 136 \\
\hline
\end{tabular}

This is a provisional file, not the final typeset article 
bioRxiv preprint doi: https://doi.org/10.1101/2019.12.19.882829; this version posted November 30, 2020. The copyright holder for this preprint (which was not certified by peer review) is the author/funder, who has granted bioRxiv a license to display the preprint in perpetuity. It is made available under aCC-BY-ND 4.0 International license.

Recalibrating the gnathostome timetree

\begin{tabular}{|c|c|c|c|c|c|c|}
\hline 138 & 64 & 40 & 91 & 98 & 76 & 121 \\
\hline 139 & 47 & 26 & 72 & 84 & 65 & 109 \\
\hline 140 & 11 & 4 & 25 & 69 & 53 & 93 \\
\hline 141 & 46 & 25 & 72 & 92 & 69 & 115 \\
\hline 142 & 27 & 13 & 49 & 62 & 42 & 82 \\
\hline 143 & 39 & 21 & 64 & 88 & 66 & 111 \\
\hline 144 & 22 & 11 & 42 & 85 & 63 & 108 \\
\hline 145 & 179 & 167 & 190 & 122 & 98 & 141 \\
\hline 146 & 156 & 136 & 172 & 132 & 110 & 148 \\
\hline 147 & 57 & 34 & 77 & 79 & 58 & 102 \\
\hline 148 & 44 & 24 & 65 & 79 & 57 & 101 \\
\hline 149 & 165 & 146 & 181 & 155 & 136 & 168 \\
\hline 150 & 165 & 161 & 172 & 230 & 217 & 237 \\
\hline 151 & 138 & 136 & 140 & 137 & 126 & 156 \\
\hline 152 & 94 & 91 & 96 & 67 & 61 & 72 \\
\hline 153 & 89 & 85 & 92 & 64 & 58 & 68 \\
\hline 154 & 61 & 53 & 65 & 54 & 48 & 57 \\
\hline 155 & 79 & 71 & 84 & 59 & 53 & 64 \\
\hline 156 & 91 & 87 & 94 & 60 & 52 & 67 \\
\hline 157 & 68 & 62 & 72 & 66 & 61 & 69 \\
\hline 158 & 50 & 38 & 60 & 60 & 53 & 67 \\
\hline 159 & 315 & 300 & 328 & 321 & 297 & 334 \\
\hline
\end{tabular}


bioRxiv preprint doi: https://doi.org/10.1101/2019.12.19.882829; this version posted November 30,2020 . The copyright holder for this preprint (which was not certified by peer review) is the author/funder, who has granted bioRxiv a license to display the preprint in perpetuity. It is made available under aCC-BY-ND 4.0 International license.

Recalibrating the gnathostome timetree

\begin{tabular}{|c|c|c|c|c|c|c|}
\hline 160 & 307 & 290 & 323 & 286 & 274 & 292 \\
\hline 161 & 202 & 173 & 237 & 166 & 152 & 185 \\
\hline 162 & 192 & 163 & 226 & 161 & 146 & 180 \\
\hline 163 & 177 & 146 & 210 & 139 & 127 & 157 \\
\hline 164 & 168 & 137 & 199 & 135 & 122 & 153 \\
\hline 165 & 117 & 86 & 143 & 102 & 90 & 115 \\
\hline 166 & 92 & 62 & 117 & 59 & 49 & 68 \\
\hline 167 & 77 & 49 & 101 & 58 & 49 & 67 \\
\hline 168 & 53 & 30 & 74 & 43 & 34 & 54 \\
\hline 169 & 162 & 134 & 196 & 136 & 119 & 157 \\
\hline 170 & 201 & 170 & 232 & 167 & 151 & 185 \\
\hline 171 & 192 & 161 & 224 & 164 & 149 & 183 \\
\hline 172 & 186 & 154 & 218 & 159 & 141 & 179 \\
\hline 173 & 155 & 123 & 186 & 136 & 118 & 164 \\
\hline 174 & 105 & 71 & 140 & 96 & 79 & 135 \\
\hline 175 & 94 & 62 & 127 & 68 & 54 & 99 \\
\hline 176 & 70 & 33 & 110 & 70 & 56 & 113 \\
\hline 177 & 54 & 22 & 89 & 66 & 53 & 107 \\
\hline 178 & 156 & 119 & 189 & 120 & 98 & 142 \\
\hline 179 & 144 & 106 & 177 & 115 & 92 & 137 \\
\hline 180 & 160 & 125 & 194 & 122 & 100 & 141 \\
\hline 181 & 213 & 162 & 255 & 177 & 148 & 241 \\
\hline
\end{tabular}

This is a provisional file, not the final typeset article 
bioRxiv preprint doi: https://doi.org/10.1101/2019.12.19.882829; this version posted November 30, 2020 . The copyright holder for this preprint (which was not certified by peer review) is the author/funder, who has granted bioRxiv a license to display the preprint in perpetuity. It is made available under aCC-BY-ND 4.0 International license.

\section{Recalibrating the gnathostome timetree}

\begin{tabular}{|c|c|c|c|c|c|c|}
\hline 182 & 155 & 105 & 195 & 147 & 117 & 212 \\
\hline 183 & 36 & 12 & 65 & 67 & 47 & 107 \\
\hline 184 & 223 & 165 & 279 & 334 & 295 & 363 \\
\hline 185 & 78 & 48 & 107 & 155 & 124 & 177 \\
\hline 186 & 6 & 2 & 15 & 47 & 26 & 65 \\
\hline 187 & 414 & 402 & 428 & 377 & 350 & 402 \\
\hline 188 & 293 & 256 & 332 & 294 & 282 & 314 \\
\hline 189 & 202 & 140 & 269 & 160 & 131 & 190 \\
\hline 190 & 156 & 92 & 223 & 134 & 104 & 167 \\
\hline 191 & 98 & 50 & 168 & 72 & 53 & 112 \\
\hline 192 & 207 & 172 & 262 & 194 & 184 & 201 \\
\hline 193 & 76 & 42 & 110 & 66 & 49 & 95 \\
\hline 194 & 380 & 370 & 390 & 361 & 331 & 390 \\
\hline 195 & 345 & 338 & 352 & 270 & 250 & 295 \\
\hline 196 & 330 & 319 & 340 & 249 & 222 & 278 \\
\hline 197 & 55 & 18 & 91 & 121 & 57 & 168 \\
\hline 198 & 277 & 244 & 297 & 166 & 126 & 209 \\
\hline
\end{tabular}

